Florida International University FIU Digital Commons

$11-12-2009$

\title{
Development of a hurricane-resistant roof-to-wall connection using high-performance fiber composites
}

Cetin Canbek

Florida International University

DOI: $10.25148 /$ etd.FI14052555

Follow this and additional works at: https://digitalcommons.fiu.edu/etd

Part of the Civil Engineering Commons

\section{Recommended Citation}

Canbek, Cetin, "Development of a hurricane-resistant roof-to-wall connection using high-performance fiber composites" (2009). FIU Electronic Theses and Dissertations. 1991.

https://digitalcommons.fiu.edu/etd/1991 
FLORIDA INTERNATIONAL UNIVERSITY

Miami, Florida

DEVELOPMENT OF A HURRICANE-RESISTANT ROOF-TO-WALL CONNECTION USING HIGH-PERFORMANCE FIBER COMPOSITES

A thesis submitted in partial fulfillment of the

requirements for the degree of

MASTER OF SCIENCE

in

CIVIL ENGINEERING

by

Cetin Canbek

2009 
To: Dean Amir Mirmiran

College of Engineering and Computing

This thesis, written by Cetin Canbek, and entitled Development of a Hurricane-Resistant Roof-to-Wall Connection using High-Performance Fiber Composites, having been approved in respect to style and intellectual content, is referred to you for judgment.

We have read this thesis and recommend that it be approved.

Arindam Gan Chowdhury

Nakin Suksawang

Amir Mirmiran, Major Professor

Date of Defense: November 12, 2008

The thesis of Cetin Canbek is approved.

Dean Amir Mirmiran
College of Engineering and Computing
Dean George Walker
University Graduate School

Florida International University, 2008 


\section{DEDICATION}

I dedicate this thesis to my parents and my sister Simge. 


\section{ACKNOWLEDGMENTS}

Firstly, I would like to express my gratitude to Dr. Mirmiran for his encouragement and guidance throughout my studies. Working under his supervision was truly a privilege and a source of inspiration for me.

I am grateful to my committee members Dr. Chowdhury and Dr. Suksawang for their sincere support.

I would like to thank Ivan Canino and Sheikh Saad Ahmed for their help in this study along with all students and personnel of Florida International University Structures and Construction Laboratory.

I would like to thank my parents and my grandmother, who took me to where I am today. Also I thank my dearest friends, Kerem, Engin and Merve for continuously reminding me that I am never alone. I know that these years that we live physically away will only strengthen out friendship. 


\title{
ABSTRACT OF THE THESIS \\ DEVELOPMENT OF A HURRICANE-RESISTANT ROOF-TO-WALL \\ CONNECTION USING HIGH-PERFORMANCE FIBER COMPOSITES
}

by

\author{
Cetin Canbek \\ Florida International University, 2009 \\ Miami, Florida \\ Professor Amir Mirmiran, Major Professor
}

Significant portion of losses in hurricanes occur due to a discontinuous load path and weak connections. The purpose of this study was to develop an innovative, efficient and non-intrusive roof-to-wall connection for wood-frame structures using highperformance fiber reinforced polymer (FRP) composite materials.

The development of new connections was carried out at the component level tests. Initially the bond strength between FRP and wood interface was investigated. Subsequently, a progressive FRP tie development test was conducted and several alternatives were tested and the most feasible one was chosen.

The new FRP tie was then tested in a full-scale wood-frame structure to assess the in-situ performance under simulated uplift forces. The results of full-scale tests were in close agreement with the results obtained at the component level. The FRP tie system offers an easy-to-apply, non-intrusive and rather stiff alternative to existing metal connectors for both new construction and existing structures. 


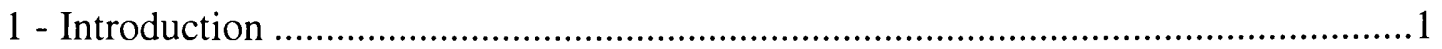

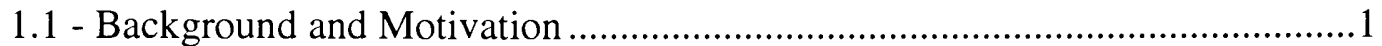

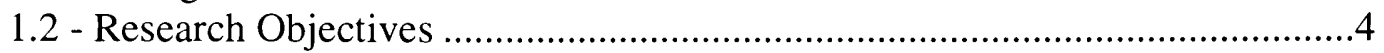

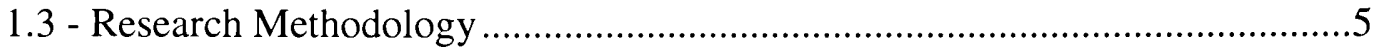

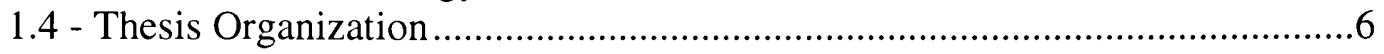

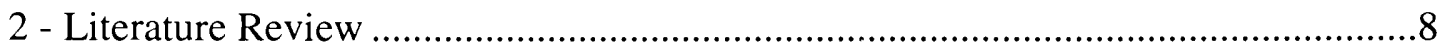

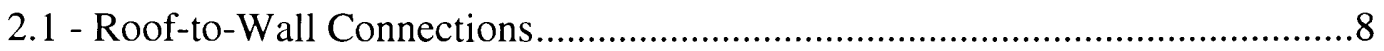

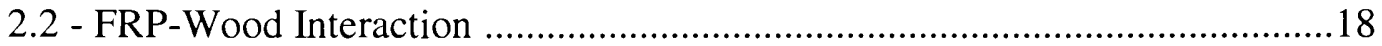

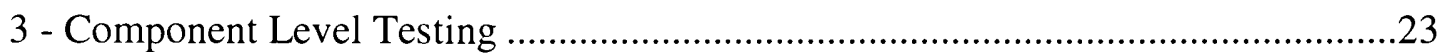

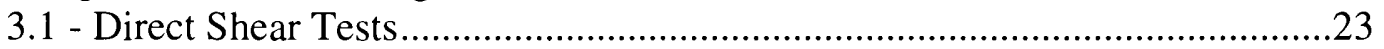

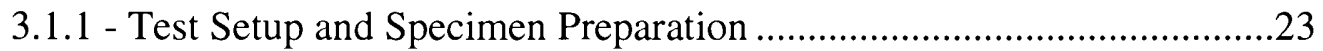

3.1.2 - Test Observations and Results.......................................................24

3.2 - FRP Tie Development Tests....................................................................28

3.2.1 - Test Setup and Specimen Preparation …….......................................28

3.2.2 - FRP Tie Development: Stage I .........................................................

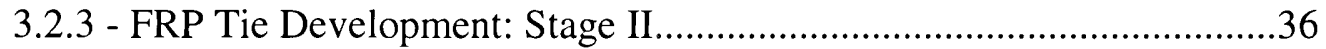

3.2.4 - FRP Tie Development: Stage III .......................................................42

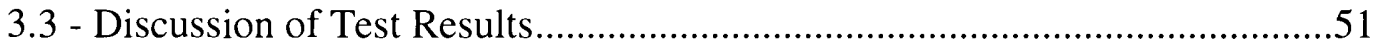

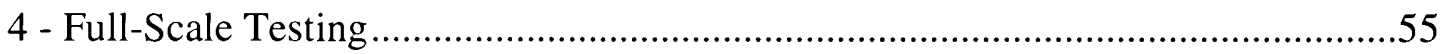

4.1 - Test Setup and Specimen Preparation .......................................................55

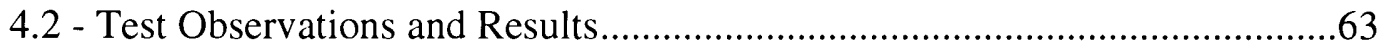

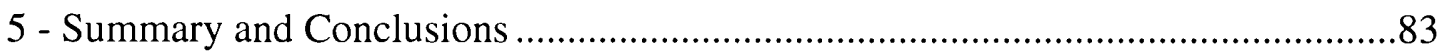

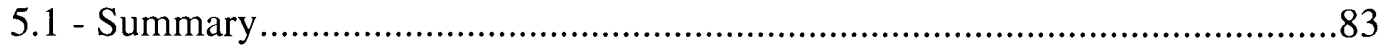

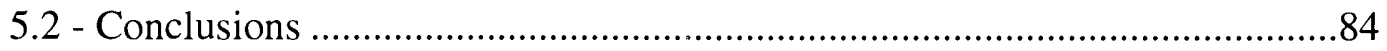

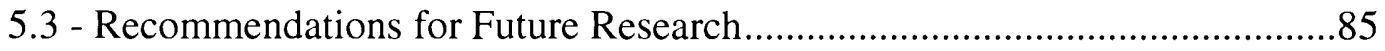

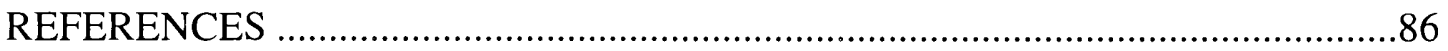




\section{LIST OF TABLES}

TABLE

PAGE

2.1 - Full-scale tests on wood-frame structures (Yancey et al. 1998)...........................

2.2 - Test results of roof-to-wall connections (Reed et al. 1997) …...........................15

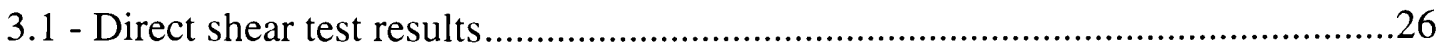

3.2 - Schematics and types of FRP connections tested in Stage II ..............................36

3.3 - Cost analysis for Configuration A with GFRP and CFRP .................................40

3.4 - Results of tests conducted at FRP tie development Stage II ..............................41

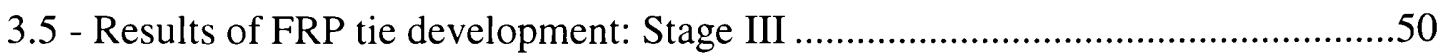

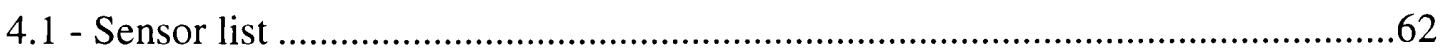




\section{LIST OF FIGURES}

FIGURE

PAGE

1.1 - A schematic representation of forces acting on the roof during a high wind event (FEMA 1992)

2.1 - (a) Hurricane clip tested by NIST, (b) Application of monotonic uplift load to the full-scale specimen (NISTIR 6938 by Riley and Sadek, 2003)

2.2 - Schematic representation of instrumentation (NISTIR 6938 by Riley and Sadek, 2003)

2.3 - Structural response of toe-nailed connections to monotonic uplift load

(Drawn after NISTIR 6938 by Riley and Sadek, 2003)

2.4 - Failed toe-nailed connection (NISTIR 6938 by Riley and Sadek, 2003) 12

2.5 - Structural response of hurricane clips to monotonic uplift load, (Drawn after NISTIR 6938 by Riley and Sadek, 2003)

2.6 - Failed hurricane clip connection (NISTIR 6938 by Riley and Sadek, 2003) .....13

2.7 - Roof-to-wall connection testing setup (Reed et al. 1997) .................................14

2.8 - Connections tested by Reed et al. (1997) (a) Hurricane clips, (b) Epoxy, and (c) Epoxy with wooden blocks 16

2.9 - (a) Specimen consisting of 7 rafters, (b) Load tree used (Reed et al. 1997) ......17

2.10 - (a) Modified ASTM D 2559 test, (b) Modified ASTM D 905 test (Davalos et al. 2000)

2.11 - The contoured double-cantilevered beam specimen (Davalos et al. 2000) ......20

3.1 - (a) Schematic representation of direct shear test setup, (b) Specimen placed

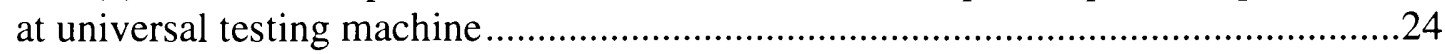

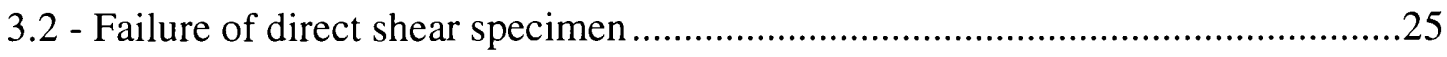

3.3 - Typical failure of direct shear specimen...........................................................26

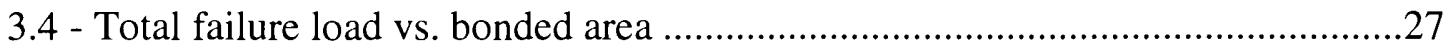

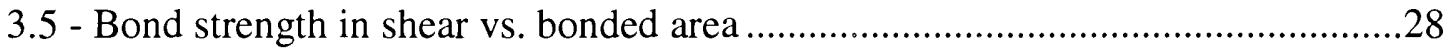




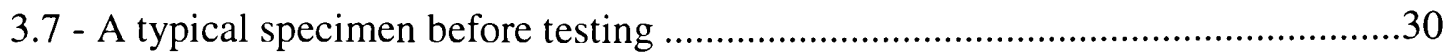

3.8 - Schematics and application of FRP tie Configuration I ....................................31

3.9 - Failure of FRP tie Configuration I.................................................................

3.10 - Schematics and application of FRP tie Configuration II .................................32

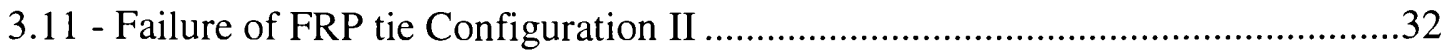

3.12 - Schematics and application of FRP tie Configuration III................................33

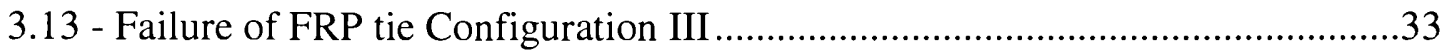

3.14 - Schematics and application of FRP tie Configuration IV .................................34

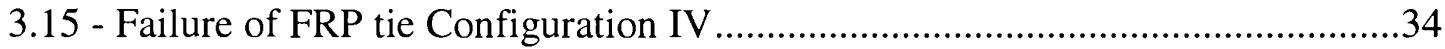

3.16 - Schematics and application of FRP tie Configuration V V.................................35

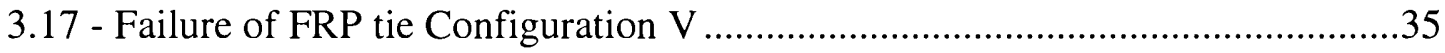

3.18 - Configuration A with GFRP (left) and CFRP (right) before testing ..................37

3.19 - Failure of Configuration A with GFRP (left) and CFRP (right) .......................37

3.20 - Configuration B with GFRP (left) and CFRP (right) before testing ..................38

3.21 - Two modes of failure observed in Configuration B .........................................38

3.22 - Configuration $\mathrm{C}$ with GFRP (left) and CFRP (right) before testing ..................39

3.23 - Failure of Configuration C with GFRP (left) and CFRP (right) ......................39

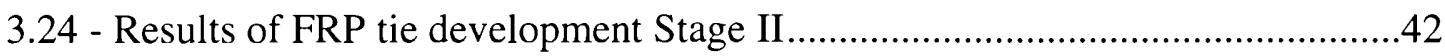

3.25 - (a)Top view of test specimen to accommodate longer ties, (b)Longer

FRP tie

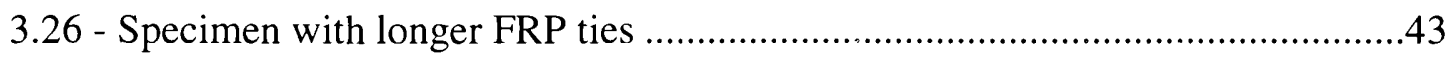

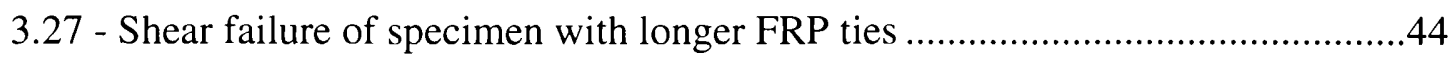


3.28 - Failure of specimen strengthened with straps

3.29 - One of the top plates after testing.

3.30 - Joist separating from top plates with FRP ties peeled off ................................46

3.31 - Failure of specimen with SYP wood ..........................................................47

3.32 - Top and side views of specimen tested for lateral loading ...............................47

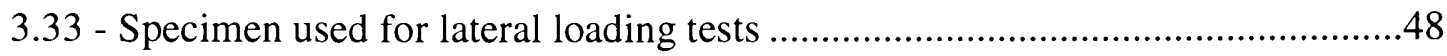

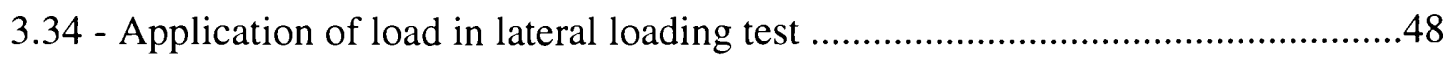

3.35 - Typical mode of failure under lateral loading ................................................49

3.36 - FRP-wood bond strength in shear versus bonded area ....................................52

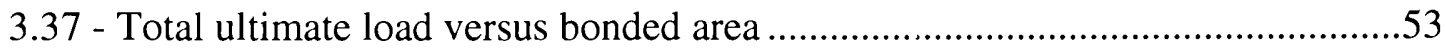

3.38 - Bond strength in peeling versus bonded area ..............................................54

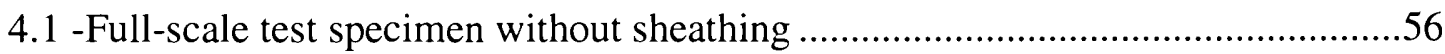

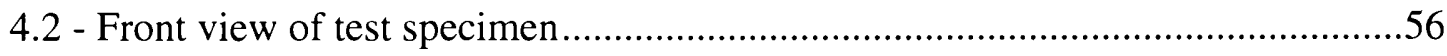

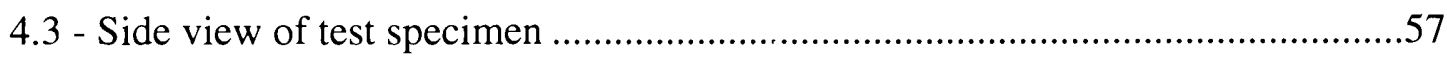

4.4 - (1) The strap holding the stud and the lower top plate together; and (2)

U-shaped metal plates holding the upper and lower top plates together 58

4.5 - Full-scale test specimen and the loading frame without sheathing and instrumentation 59

4.6 - Placement of load cell between the loading frame and steel plate .60

4.7 - Jack with the load distribution channel mounted on top ....................................60

4.8 - Schematic representation of sensor locations ................................................62

4.9- - Schematics of full-scale test specimen with sensors in place ...........................63

4.10 - Load applied from each jack ...........................................................................64

4.11 - Load applied to each quadrant of the roof ......................................................64 
4.12 - Total load applied on the specimen 665

4.13 - The loads applied at each cylinder at initial failure load .................................65

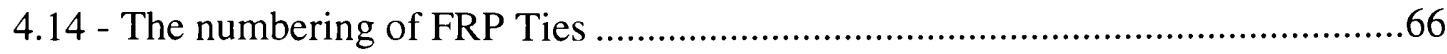

4.15 - Initiation of failure in FRP ties 13 and 14 at 20,716 lbs................................67

4.16 - Complete failure of FRP ties 13 and 14 at 23,659 lbs..................................68

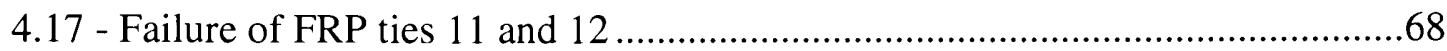

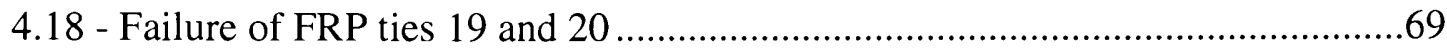

4.19 - Failure of FRP tie 7 and 8 and separation of wood fibers ..............................69

4.20 - The loads at pairs of FRP ties at initiation of failure .......................................70

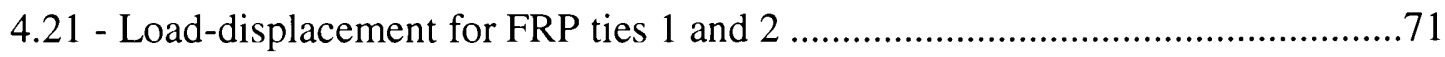

4.22 - Load-displacement for FRP ties 3 and 4 .................................................... 71

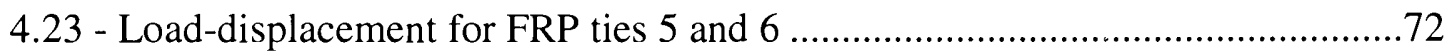

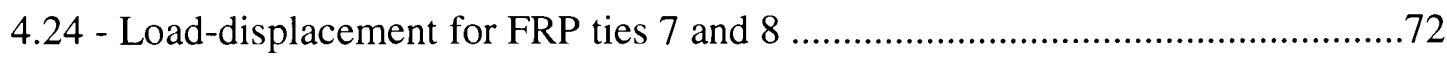

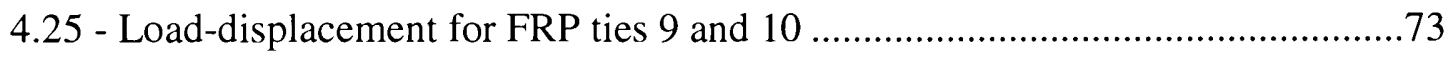

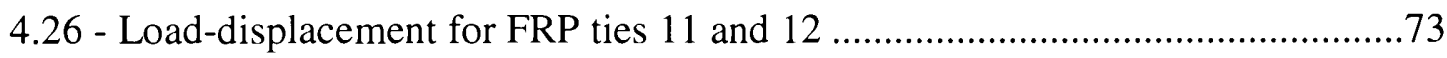

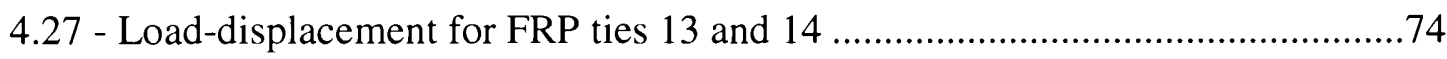

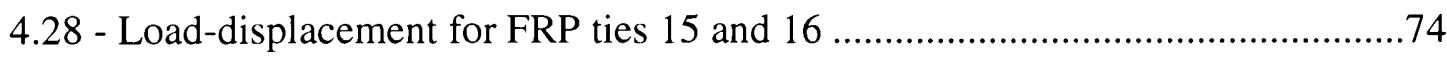

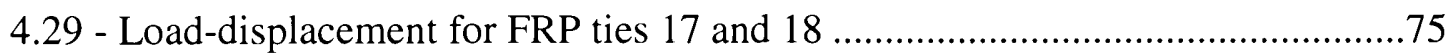

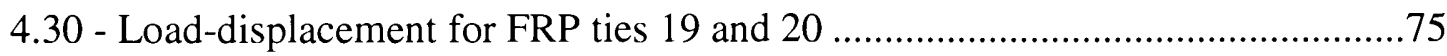

4.31 - Total load-displacements on the north side of the truss ....................................76

4.32 - Total load-displacements on the south side of the truss ...................................77

4.33 - Total load-displacements at the center of the bottom chord of the truss ..........77

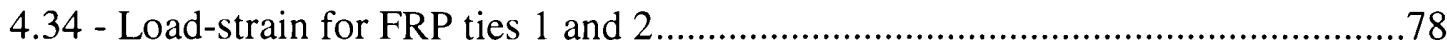




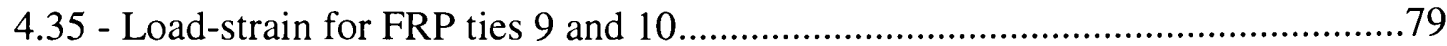

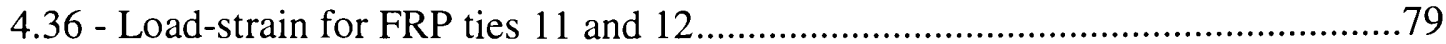

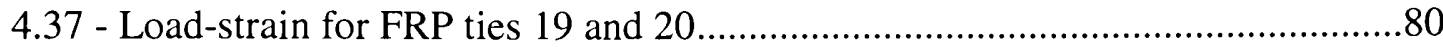

4.38 - Strain values of FRP ties located at the corners of the truss.............................80

4.39 - Total load-strain for FRP ties located at the corners ........................................ 81 


\section{1 - Introduction}

\section{1 - Background and Motivation}

Hurricanes are the most costly of any form of natural disaster in the United States. According to a study conducted by Stubbs and Perry (1996), wind and hail related damages account for $90 \%$ of the total losses due to natural disasters. In order to underline the significance of hurricane damages and to promote public awareness, Pielke et al. (2008) gathered information on economic losses due to hurricanes occurred between 1900 and 2005. Considering factors such as inflation, population, wealth and housing units; the estimated loss exceeded $\$ 1$ trillion (based on 2005 value), indicating the need for strategies to harden constructed facilities against hurricane.

As one of the costliest disasters in the U.S. history, Hurricane Andrew hit South Florida and Louisiana in 1992, and caused an insured loss of $\$ 15.5$ billion. Since then, hurricanes have continued to hit the coastal regions at an alarming rate. Hurricanes Katrina, Rita, Wilma, Charley, Ivan, Frances and Jeanne were recorded as seven out of the ten most detrimental hurricanes ever. These seven storms took place in a 14-month period between August 2004 and October 2005, and caused a total insured loss of $\$ 79.1$ billion, with Hurricane Katrina being at the top of the list at an estimated loss of $\$ 41$ billion (Insurance Information Institute, www.iii.org).

If the nature of the economic losses described above is investigated, it can be seen that a significant portion of the losses stems from the damages to residential buildings. Because of economic factors, these residential building are generally built by dimensional lumber. It is estimated that $90 \%$ of residential buildings in the U.S. are light-frame wood 
construction. These one or two story family dwellings have been the source of most commonly observed building damages caused by hurricanes in the last two decades (Ellingwood et al. 2004). When the modes of failure of damaged houses are studied, a lack of continuity in the load path starting from the roof to foundation is observed. Upon an on-site survey, Lindt et al. (2007) prepared a report on the performance of wood-frame structures after Hurricane Katrina. In their report, the different modes of failure were classified for the high velocity winds. They stated that most of the wood-frame residential structures on the Mississippi Gulf Coast are built following conventional techniques, as non-engineered buildings. Furthermore, they stated that lack of continuity in the vertical load path accounted for a significant number of observed failures. In one of the typical failures mentioned in the report, improper use of hurricane clips resulted in a roof collapse, as the uplift load induced by high-speed winds could not be transferred to the wall and down to the foundation.

After Hurricane Andrew, a report was prepared by the Federal Emergency Management Agency (FEMA 1992). The main purpose of the report was to identify the failure modes, improper construction practices and recommended changes in construction. The report stated that the most tragic failures of all site-built structures were observed in one or two story wood-frame houses. The main reason for these failures was stated as wind forces due to negative wind pressure accompanied with internal pressure from breach of envelope (see Figure 1.1). Absence or inappropriate use of connections that would transfer loads between different components of the structure was considered as one of the primary reasons for failure. 


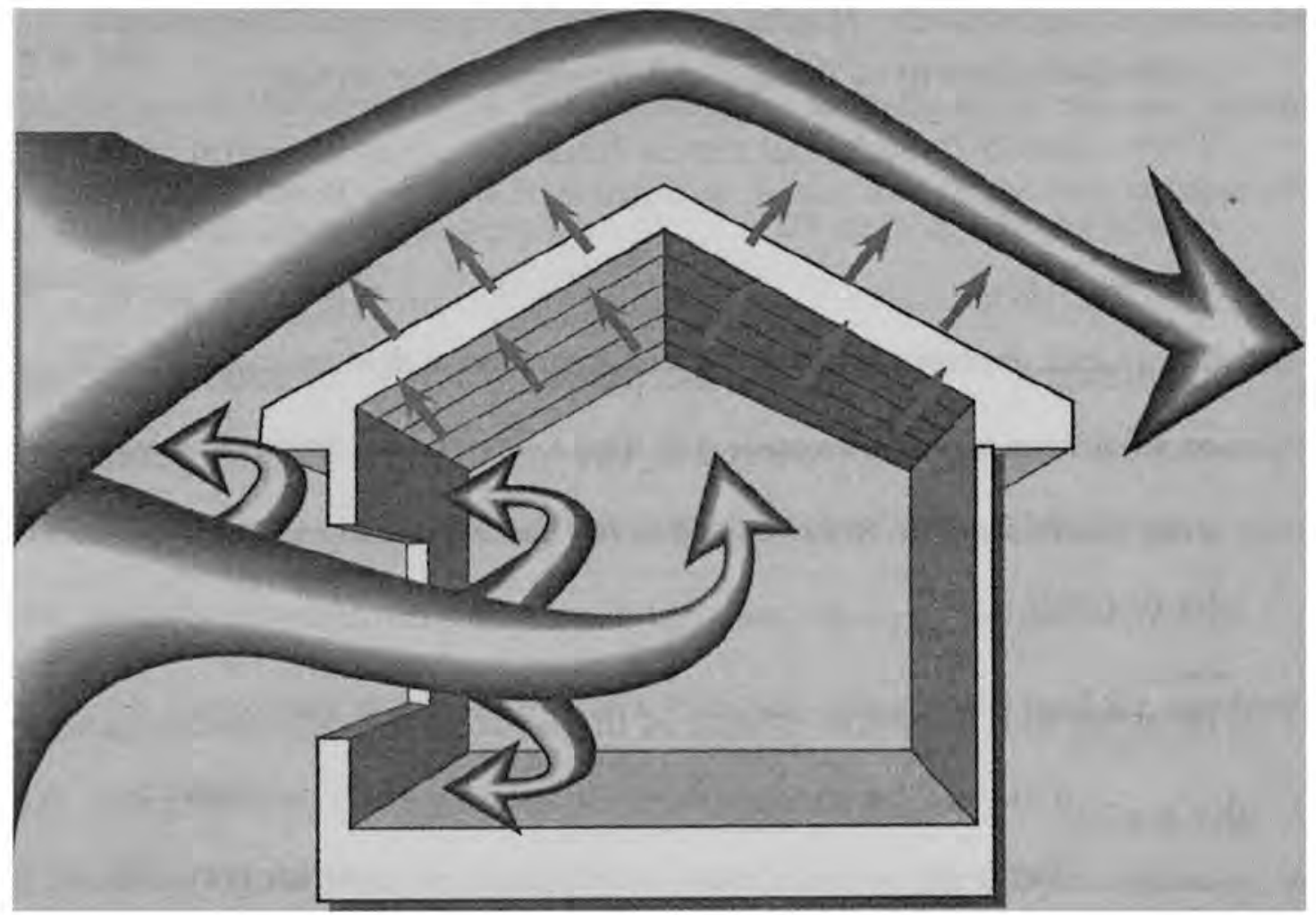

Figure 1.1 - A schematic representation of forces acting on the roof during a high

\section{wind event (FEMA 1992)}

Several post-hurricane damage assessment reports have identified the breach of building envelope as a contributing factor to structural failure. Several researchers indicate that roofs are not well, if at all, engineered in majority of the cases. Therefore, either a loss of sheathing or a failure in the roof-to-wall connection can cause intrusion of water and high-speed wind into the building. In most cases, economic losses on building contents reported in insurance claims are greater than the structural costs. Sparks et al. (1994) reported that the losses upon roof damage may account for $80 \%$ of the total insurance claim. Therefore, the roof-to-wall connection is critical to preserve the integrity of the building. 
A research on the performance of buildings after Hurricane Hugo was conducted by Manning and Nicholas (1991). They stressed on the integrity of the roof system to prevent the failure of shear walls, which may in turn lead to the total collapse of the building.

The literature on high wind events and wood-frame structures clearly indicates the necessity of a sound roof-to-wall connection system, which is capable of transferring wind induced forces in an efficient way. The drawbacks of conventional metal roof-towall connectors (sometimes referred to as hurricane clips) can be listed as follows:

- It forms weak points in wood due to closely spaced nails used for attaching the connector;

- It makes the structure susceptible to water intrusion due to holes created by wood penetrations;

- Humidity in coastal regions or other hard environmental conditions may weaken the connection and corrode the metal clips and the toe-nailed connection; and

- It may fail prematurely through nail pull-out at a much lower load than that specified by the manufacturer.

Therefore, an innovative connection, which can overcome the disadvantages of metal connections, is developed using advanced high-performance fiber composites.

\section{2 - Research Objectives}

The need for an innovative roof-to-wall connection becomes more obvious, when the significance of the roof-to-wall connection, its role in maintaining structural integrity, 
and the disadvantages of conventional metal connectors or toe-nailing type of connections are considered. The main objective of this study is to develop a non-intrusive and cost-effective fiber reinforced polymer (FRP) roof-to-wall connection. It is envisioned that the FRP connection will be effective in transferring wind loads, economically comparable to the commercially available metal connectors and easily applicable to existing structures in need of retrofit as well as to new construction. While the development and selection of the best FRP tie alternatives were conducted at the component level, performance assessment of the new connection type was carried out on a full-scale wood-frame construction by simulating the uplift forces of high winds.

\section{3 - Research Methodology}

An experimental approach was followed throughout this study. The development and testing of the FRP roof-to-wall connection, namely FRP tie, can be divided into two parts. First, the bond strength of FRP tie was assessed in a basic double-lap direct shear test, followed by three stages of progressive development of FRP tie connection. Following ASTM D 1761 standard, initially a set of FRP connections were developed to evaluate FRP-wood interface bond. Subsequently, the ones that yielded favorable results were improved using a variety of configurations. Finally, FRP tie selection was made with modifications to improve their strengths and to alter and control their modes of failure. Moreover, different types of wood were considered to assess the bond performance at the FRP-wood interface. 
The second part of the experimental work involved full-scale testing of the FRP tie that was developed in the first part. The test was performed to simulate the uplift forces from high winds. The full-scale testing was of great importance in terms of evaluating the real performance and applicability of the FRP connection.

\section{4 - Thesis Organization}

This thesis consists of five chapters, including this introductory chapter. Chapter 2 presents a review of literature on the roof-to-wall connections and FRP-wood bonding mechanisms, types of component level tests, connections tested and results and conclusions made from those tests. Also, full-scale wood-frame tests focusing on the roof-to-wall connections are discussed.

Chapter 3 describes the experiments for the development of FRP roof-to-wall connection. The double-lap direct shear test is explained along with the test set-up and results. Subsequently, the connection development stage is discussed in three stages; initial trial of feasible alternatives, enhancing the modified alternatives and assessing the impact of wood type on the bond interface with FRP. Test parameters included type of FRP materials, configuration and length of FRP tie, and type of wood.

Chapter 4 is devoted to the full-scale test on the performance of the novel FRP roof-to-wall connection. The full-scale test specimen, application of loads, instrumentation, test observations and results are explained in detail. 
Chapter 5 provides a summary of the research, and underlines its findings. The possible outcomes of the research in mitigating hurricane-related damages are also discussed. Finally, recommendations for future work are presented. 


\section{2 - Literature Review}

\section{1 - Roof-to-Wall Connections}

Yancey et al. (NISTIR 6224, 1998) conducted an extensive research on the performance of single-family wood-frame structures; and discussed the effects of hurricanes and earthquakes on wood-frame structures, experimental and analytical studies on full-scale specimens with shear walls and intercomponent connections. Underlining that the performance of wood-frame houses is usually assessed using component level studies and that very few full-scale experiments have been carried out, the report aimed to promote full-scale tests that will lead to a better and safer design. The previous fullscale wood-frame houses tested are summarized in Table 2.1. These tests were concentrated on the lateral stiffness of the structures and their response to racking during an earthquake or high-wind event. None was aimed at investigating the behavior of the structure when the predominant force is uplift. Main conclusions and recommendations of the report are summarized as follows:

- Full-scale testing of wood-frame houses is necessary to establish the performance characteristics and the data for analytical studies;

- The behavior of intercomponent connections, where majority of damages form during disasters, are not well understood; and

- Cost-effective design procedures and alternative construction materials are necessary to improve the resistance of structures to disasters. 
Table 2.1 - Full-scale tests on wood-frame structures (Yancey et al. 1998)

\begin{tabular}{|l|l|l|l|l|l|}
\hline Reference & $\begin{array}{l}\text { Testing } \\
\text { Location }\end{array}$ & $\begin{array}{l}\text { Shape of } \\
\text { House }\end{array}$ & $\begin{array}{l}\text { Plan } \\
\text { Dimensions } \\
\text { (ft.) }\end{array}$ & $\begin{array}{l}\text { Types of } \\
\text { Loading }\end{array}$ & $\begin{array}{l}\text { Loading to } \\
\text { Failure? }\end{array}$ \\
\hline $\begin{array}{l}\text { Yokel et al. } \\
(1973)\end{array}$ & Field & $\begin{array}{l}\text { Rectangular, } \\
\text { 2-story }\end{array}$ & $47 \times 26$ & Monotonic & No \\
\hline $\begin{array}{l}\text { Yancey et al. } \\
(1973)\end{array}$ & Laboratory & $\begin{array}{l}\text { Rectangular, } \\
1 \text {-story }\end{array}$ & $59 \times 12$ & $\begin{array}{l}\text { Monotonic } \\
\text { and Cyclic }\end{array}$ & No \\
\hline $\begin{array}{l}\text { Tuomi et al. } \\
(1974)\end{array}$ & Laboratory & $\begin{array}{l}\text { Rectangular } \\
1 \text {-story }\end{array}$ & $24 \times 16$ & $\begin{array}{l}\text { Monotonic } \\
\text { and Cyclic }\end{array}$ & No \\
\hline $\begin{array}{l}\text { Boughton et } \\
\text { al. (1982) }\end{array}$ & Field & $\begin{array}{l}\text { L-shaped, 1- } \\
\text { story }\end{array}$ & $60 \times 43 \times 22$ & Monotonic & Yes \\
\hline $\begin{array}{l}\text { Philips } \\
(1970)\end{array}$ & Laboratory & Rectangular & $32 \times 16$ & Cyclic & Yes \\
\hline
\end{tabular}

The National Institute of Standards and Technology (NIST) conducted a comprehensive study on the roof-to-wall connections using full-scale wood-frame structures (NISTIR 6938 by Riley and Sadek, 2003). The NIST reported that while woodframe buildings are satisfactory when only gravity loads are imposed, they perform poorly under earthquake and hurricane-induced loads. They stressed that there are not enough studies for assessing the in-place performance of roof-to-wall connections, which is a key factor in the overall building performance. The specimens tested consisted of two 4-ft-long by 8 -ft-1.25-in.-high shear walls that supported four roof trusses with 16 -ft spans. Two different types of roof-to-wall connections were tested, namely, toe-nailed connections and hurricane clips (Figure 2.1a). These connections were tested under monotonic uplift loading, monotonic lateral loading, combined uplift and lateral loading, and cyclic lateral loading. While applying the loads, one vertical actuator and one lateral actuator were used, as needed. The monotonic uplift load was distributed using a spreader steel beam connected to nominal $2 \times 8$ in. lumbers under the sheathing using steel rods 
(Figure $2.1 \mathrm{~b}$ ). The displacement rate used for the monotonic uplift load was $0.25 \mathrm{in} . / \mathrm{min}$. The instrumentation for the full-scale specimens consisted of 46 linear variable differential transformers (LVDTs) and 10 load cells located on rods which transfer the load from the actuator to the roof (Figure 2.2).

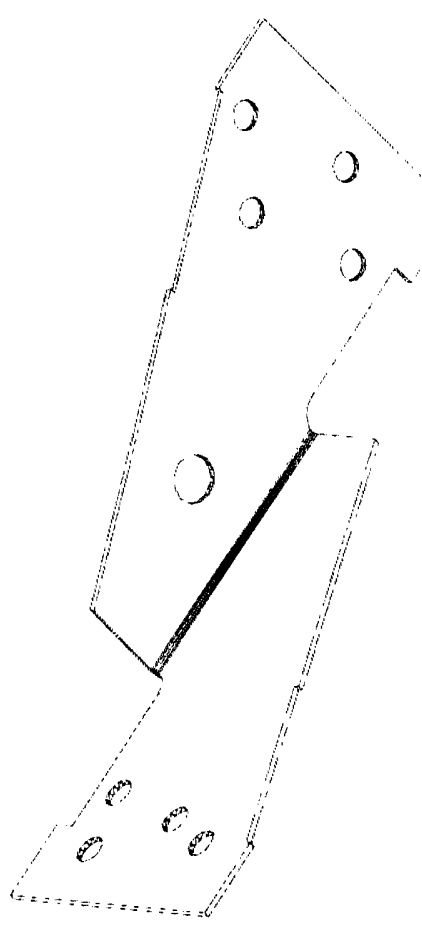

(a)

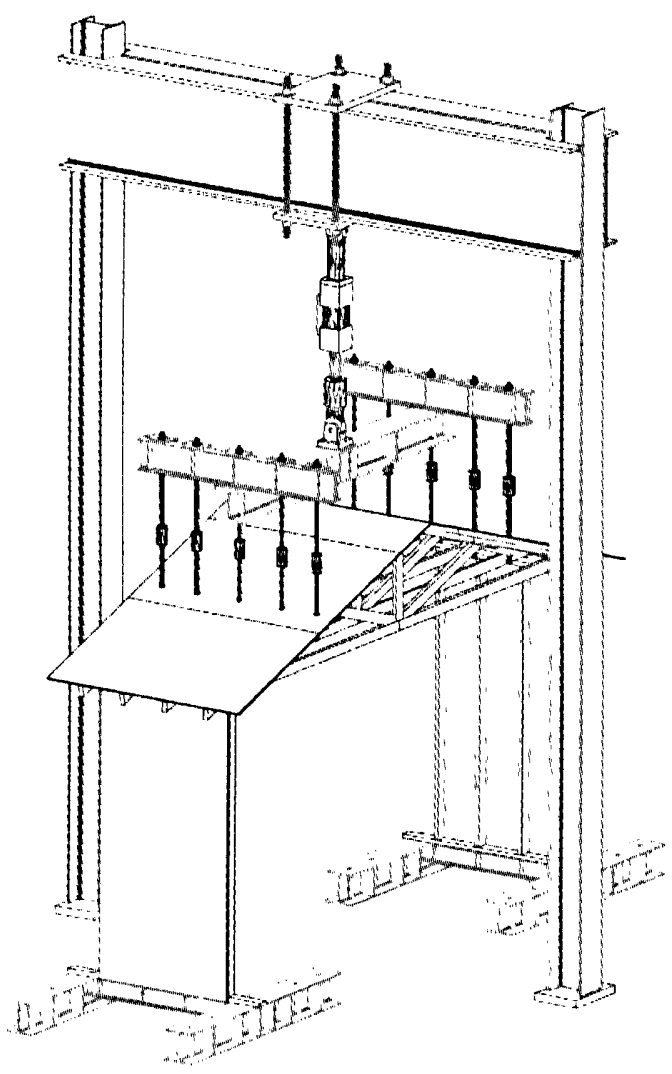

Figure 2.1 - (a) Hurricane clip tested by NIST, (b) Application of monotonic uplift load to the full-scale specimen (NISTIR 6938 by Riley and Sadek, 2003) 


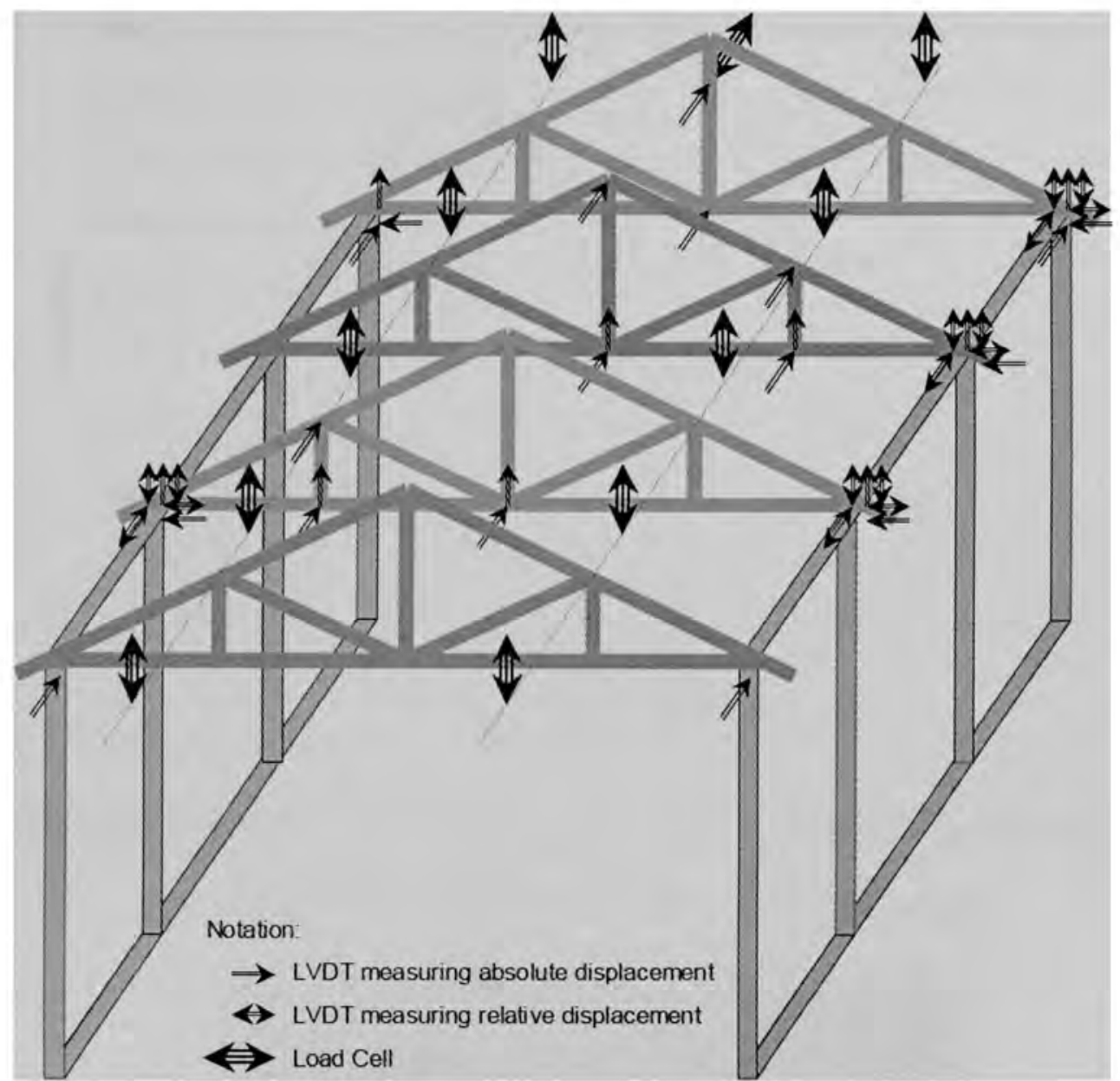

Figure 2.2 -Schematic representation of instrumentation (NISTIR 6938 by Riley and Sadek, 2003)

The toe-nailed connection, which consisted of three $16 \mathrm{~d}$ common nails driven at $45^{\circ}$ to the bottom chord through the top plate of the wall, failed at a load of $3,940 \mathrm{lbs}$ (Figure 2.3). The mode of failure was identified as withdrawal of nails from the top plate following separation of the bottom wood fibers of the truss bottom chord (Figure 2.4) 


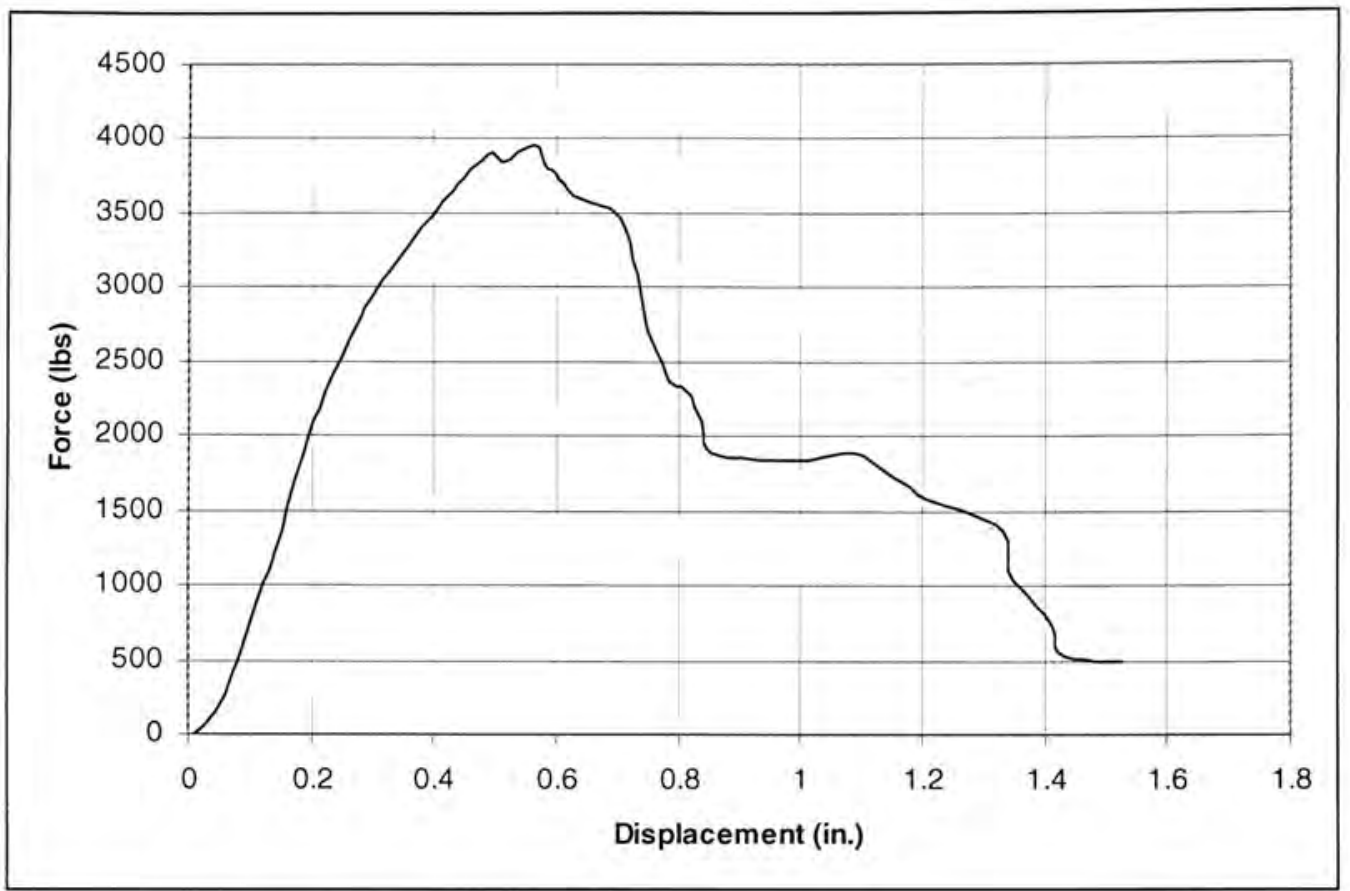

Figure 2.3 - Structural response of toe-nailed connections to monotonic uplift load (Drawn after NISTIR 6938 by Riley and Sadek, 2003)

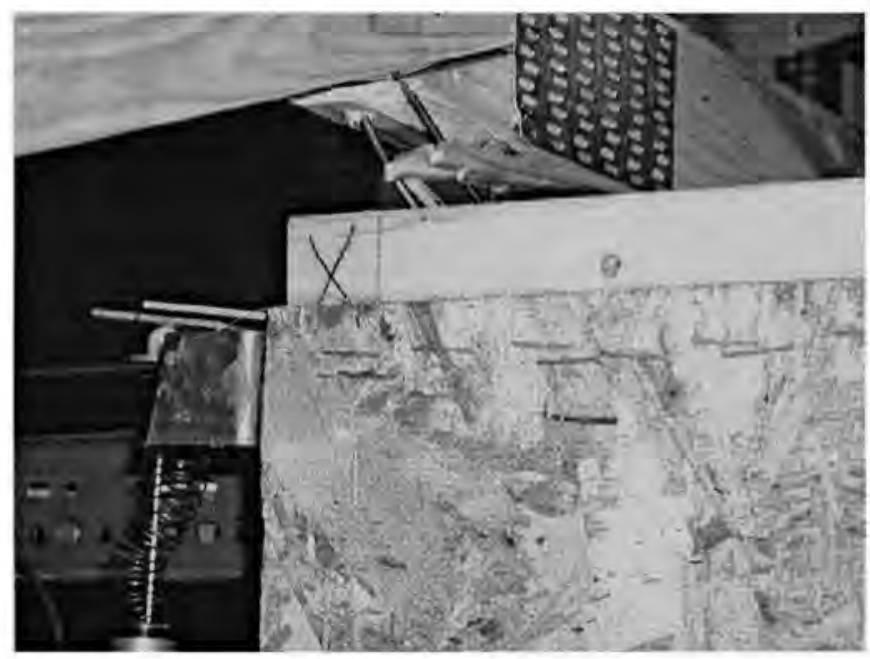

Figure 2.4 -Failed toe-nailed connection NISTIR 6938 by Riley and Sadek, 2003)

The specimen with hurricane clips reached a peak load of 6,070 lbs (Figure 2.5), and the connection failed as the roof truss separated from the lower top plate of the wall, with hurricane clips remaining attached to the upper top plate (Figure 2.6) 


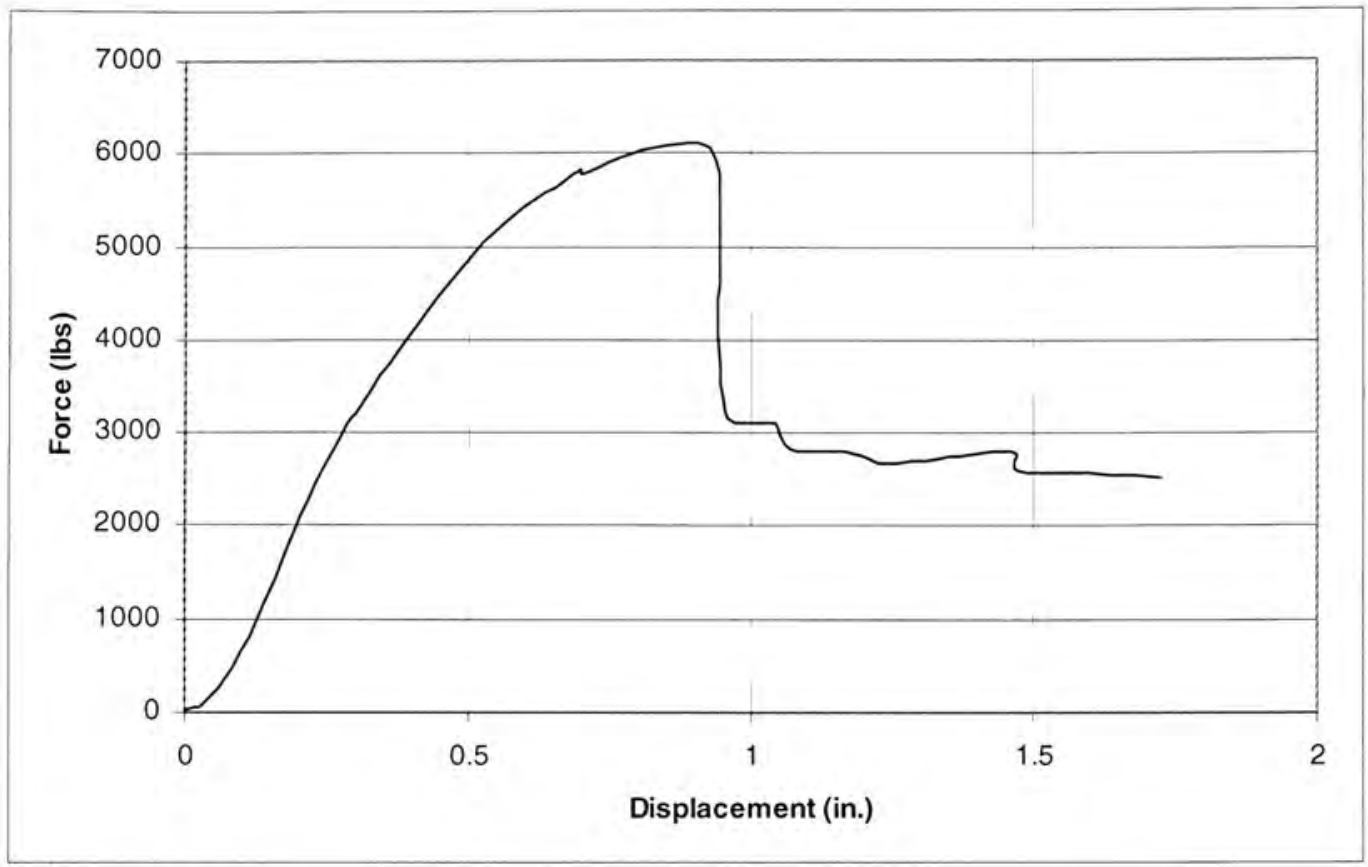

Figure 2.5 - Structural response of hurricane clips to monotonic uplift load, (Drawn after NISTIR 6938 by Riley and Sadek, 2003)

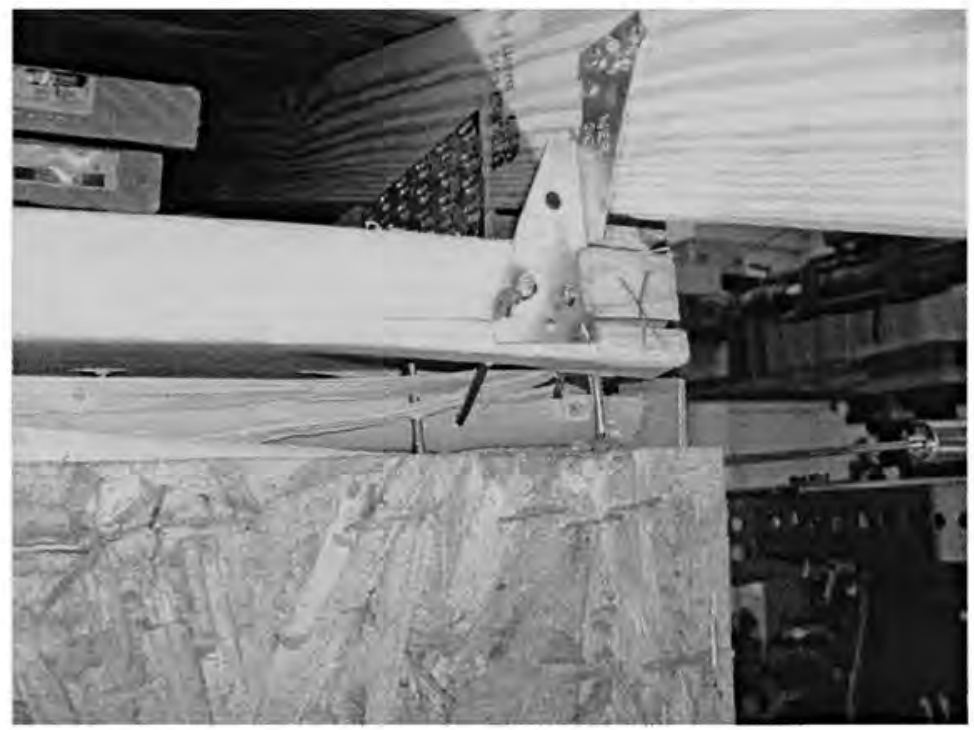

Figure 2.6 -Failed hurricane clip connection (NISTIR 6938 by Riley and Sadek, 2003) 
Overall, the hurricane clips performed much better than the toe-nailed connection in terms of both load capacity and deformations. Considering all four types of loading, a capacity increase of $40 \%$ was observed when hurricane clips were used instead of toenailed connections.

Reed et al. (1997) conducted a research focusing on the capacity of roof-to-wall connections in wood-frame structures. Identifying that the connection of rafter to top plate is vital in maintaining the integrity of the structure, they tested various commercially available metal straps and alternative connectors such as adhesives. The main goal of the study was to test the connection in a way that can reflect its in-situ response. Therefore, specimens consisting of 12 in. long Southern Yellow Pine (SYP) top plates were connected to the 14 in. long rafters. The rafters were either SYP or Spruce Pine Fir (SPF) with a grade of \#2 or better. The rafters were notched and connected to the top plates with a rafter slope of 3:12. The load was applied onto the rafter on both sides of the top plate using a hydraulic jack (Figure 2.7). An aluminum section, as long as a typical rafter, was used to prevent rotation of the $14 \mathrm{in.}$ long rafter piece. The tested connections included toe nails, small hurricane straps, large hurricane straps, epoxy, epoxy with large wood blocks and their combinations.

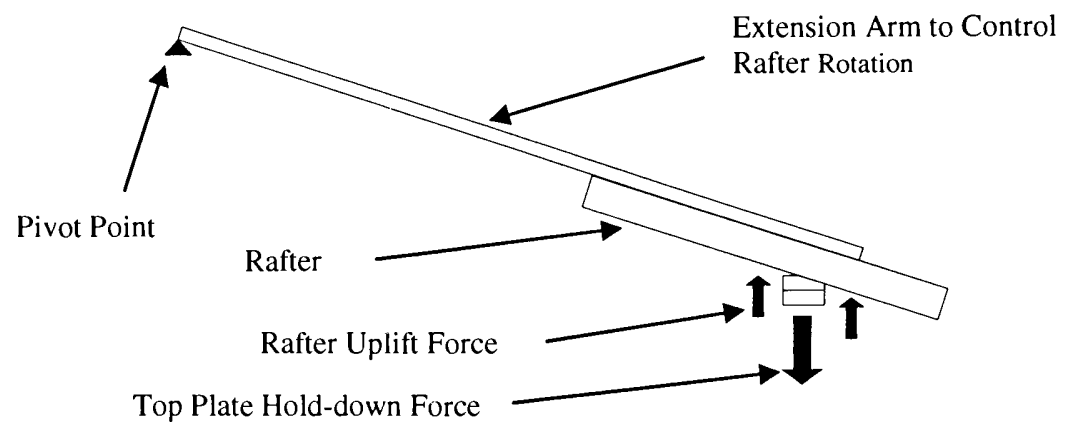

Figure 2.7 - Roof-to-wall connection testing setup (Reed et al. 1997) 
Table 2.2 lists some of the results obtained from the experiments of Reed et al. (1997). The values presented here will be used for comparison purposes in the following chapters.

Table 2.2 - Test results of roof-to-wall connections (Reed et al. 1997)

\begin{tabular}{|c|c|c|c|c|c|}
\hline $\begin{array}{l}\text { Test } \\
\text { Series }\end{array}$ & Description & $\begin{array}{l}\text { Number of } \\
\text { Specimens } \\
\text { Tested }\end{array}$ & $\begin{array}{l}\text { Average } \\
\text { ultimate } \\
\text { uplift load } \\
\text { (lbs) }\end{array}$ & $\begin{array}{l}\text { Coefficient } \\
\text { of variation }\end{array}$ & $\begin{array}{l}\text { Predominant } \\
\text { Failure Mode }\end{array}$ \\
\hline 1 & Toe nail ${ }^{\mathrm{a}}$ only & 16 & 430 & 0.23 & $\begin{array}{l}\text { Nail pullout of top } \\
\text { plate }\end{array}$ \\
\hline 3 & $\begin{array}{l}\text { Toe nail +small strap } \\
\text { located on outside of } \\
\text { wall }\end{array}$ & 16 & 1,900 & 0.11 & $\begin{array}{l}\text { Strap tear, nail pullout } \\
\text { of rafter }\end{array}$ \\
\hline 7 & $\begin{array}{l}\text { Toe nail + large strap } \\
\text { located on outside of } \\
\text { wall }\end{array}$ & 14 & 1,920 & 0.09 & Nail pullout \\
\hline 8 & $\begin{array}{l}\text { Toe nail + new large } \\
\text { strapd located on inside } \\
\text { of wall }\end{array}$ & 15 & 2,740 & 0.12 & Block shear in wood \\
\hline 9 & Epoxy $^{\mathrm{e}}$, no toe nails & 15 & 1,690 & 0.37 & $\begin{array}{l}\text { Rafter split, top-plate } \\
\text { fibers }\end{array}$ \\
\hline 11 & $\begin{array}{l}\text { Toe nail + epoxy on } \\
\text { small wood blocks } \\
\text { (one week set) }\end{array}$ & 15 & 1,470 & 0.16 & $\begin{array}{l}\text { Rafter split, top-plate } \\
\text { and rafter fibers, } \\
\text { wood block fibers, } \\
\text { epoxy failure }\end{array}$ \\
\hline 13 & $\begin{array}{l}\text { Toe nail + epoxy on } \\
\text { large wood blocks } \\
\text { (one week set) }\end{array}$ & 11 & 2,170 & 0.34 & $\begin{array}{l}\text { Top-plate and rafter } \\
\text { fiber tear, wood block } \\
\text { split }\end{array}$ \\
\hline 14 & $\begin{array}{l}\text { Acrylic adhesive }^{\text {h }} \text { (one } \\
\text { week set) toe nailed } \\
\text { when adhesive was wet }\end{array}$ & 14 & 1,480 & 0.19 & $\begin{array}{l}\text { Toe-nail pullout, top- } \\
\text { plate fiber tear }\end{array}$ \\
\hline 16 & $\begin{array}{l}\text { Toe nail + acrylic } \\
\text { adhesive on small } \\
\text { wood blocks (one } \\
\text { week set) }\end{array}$ & 16 & 1,170 & 0.21 & $\begin{array}{l}\text { Rafter split, top-plate } \\
\text { fiber tear }\end{array}$ \\
\hline 18 & $\begin{array}{l}\text { Toe nail }+1 / 2 \text { in. acrylic } \\
\text { adhesive bead }\end{array}$ & 5 & 920 & 0.31 & Wood fiber failure \\
\hline 19 & $\begin{array}{l}\text { Toe nail + foaming } \\
\text { polyurethane adhesive }\end{array}$ & 3 & 850 & 0.09 & Adhesive shear \\
\hline
\end{tabular}

\footnotetext{
${ }^{\mathrm{a}}$ Three $8 \mathrm{~d}$ nails between rafter and top plate

${ }^{\mathrm{b}}$ Small strap was an 18-gauge galvanized steel strap with five short $8 \mathrm{~d}$ nails into the rafter and five $8 \mathrm{~d}$ nails into the top plate. The strap had a $90^{\circ}$ bend and connected the top plate to the rafter. The nailing pattern prohibited nailing between the two top plates. (Figure 2.8a)

${ }^{c}$ Large strap was an 18-gauge galvanized steel strap with eight short $8 \mathrm{~d}$ nails into the top plate. The rafter was sandwiched between two small flanges bent from the metal plate

${ }^{d}$ The new large strap was an experimental 16-gauge galvanized steel strap with eight short $8 \mathrm{~d}$ nails into the rafter and eight short $8 \mathrm{~d}$ nails into the wall stud (SPF woof)

' Two-part, hand mixed epoxy paste applied as shown in Figure 2.8b
} 
${ }^{\mathrm{f}}$ Small blocks, approximately 1.5 in. $\times 3.5$ in. of either SPF or SYP wood installed as shown in Figure $2.8 \mathrm{c}$

${ }^{\mathrm{g}}$ Large blocks, approximately 3.5 in. $\times 3.5$ in. of pressure treated SYP wood installed as shown in Figure $2.8 \mathrm{c}$

${ }^{\mathrm{h}}$ Two part acrylic adhesive applied through diffuser nozzle, as shown in Fig $2.8 \mathrm{~b}$

i An acrylic adhesive bead was applied on either side of the rafter along the top plate

${ }^{\mathrm{j}}$ Foaming polyurethane adhesive product applied using air pressure gun to foam large fillets between rafter and top plate

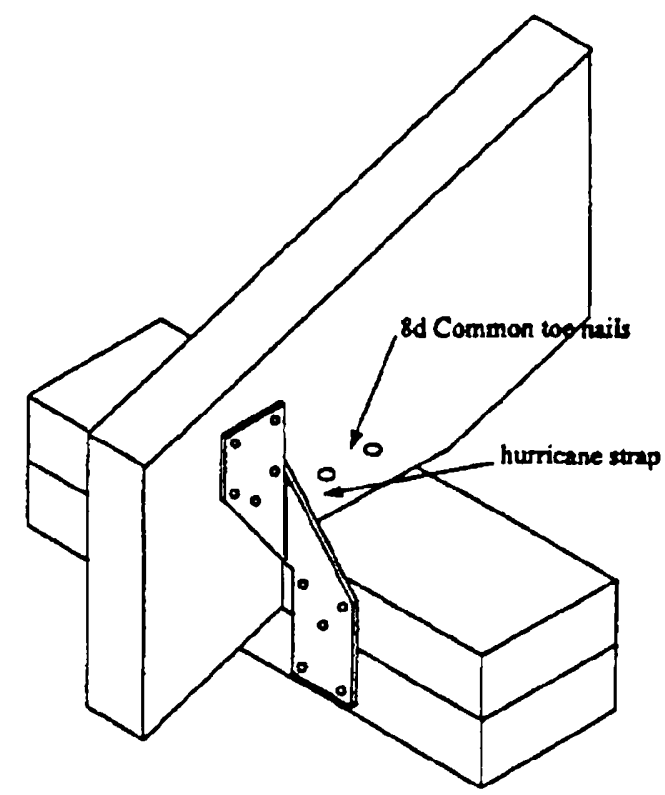

(a)

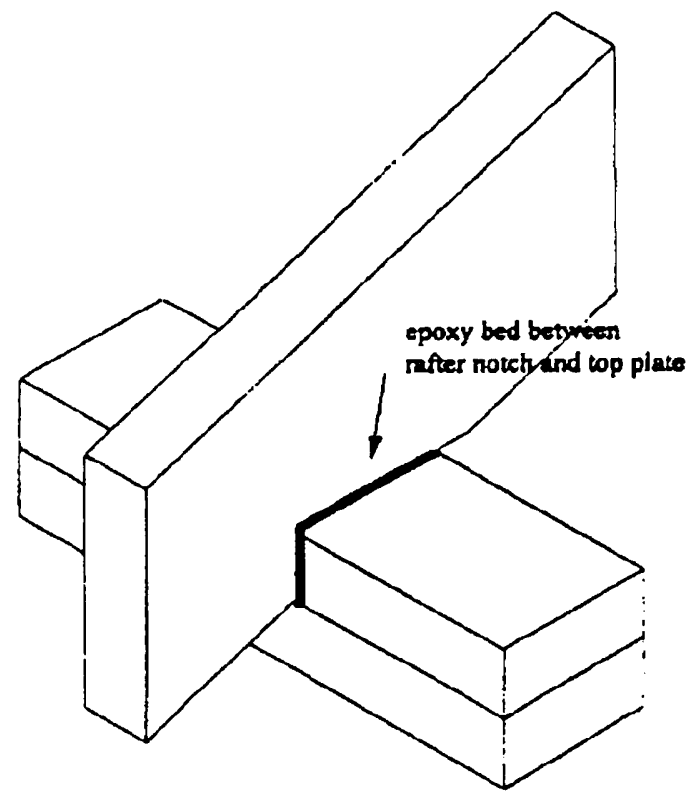

(b)

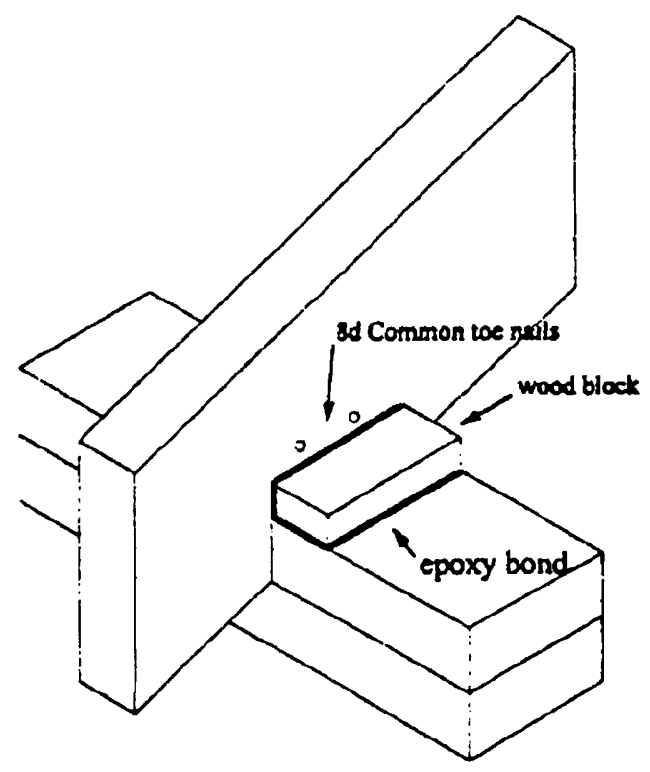

(c)

Figure 2.8 - Connections tested by Reed et al. (1997) (a) Hurricane clips, (b) Epoxy, and (c) Epoxy with wooden blocks 
Reed et al. (1997) also investigated the uplift capacity of some of the above connectors in a continuous system, where by the effect of sheathing and subfascia members were also evaluated. A system consisting of 7 rafters (Figure 2.9a) and a loading tree (Figure 2.9b) was constructed for the load testing.

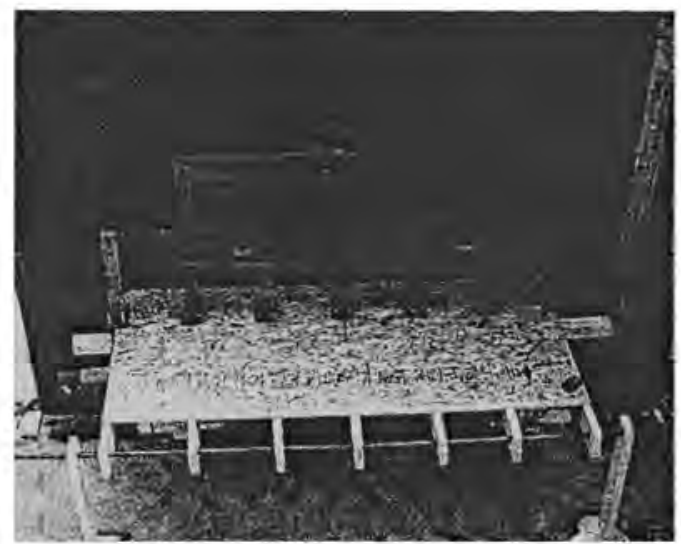

(a)

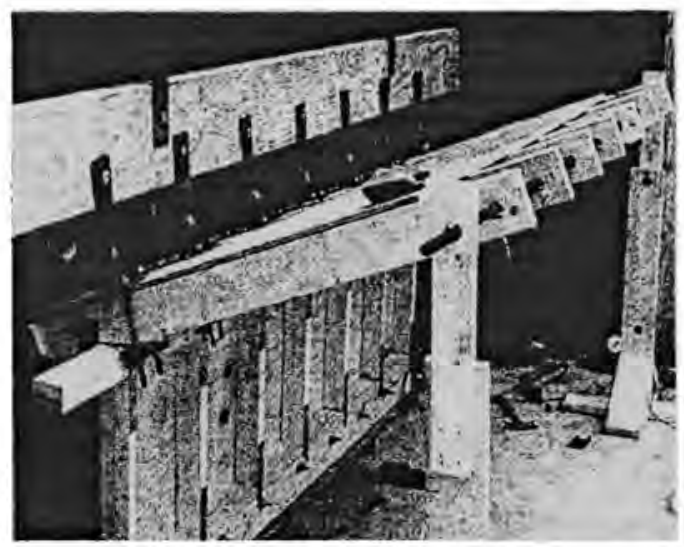

(b)

Figure 2.9 - (a) Specimen consisting of 7 rafters, (b) Load tree used (Reed et al. 1997)

Reed et al. (1997) reported that the load was well distributed and the capacity per rafter was increased in the toe-nailed connections. This load distribution mechanism was not significant for hurricane straps. Also, the 1/8 in. deflection, which is a criteria used for limiting the design load of straps by their manufacturers, seemed to occur at half of the ultimate load capacity of the metal connectors. The report underlined that the $1 / 8$ in. deflection may be too conservative for limiting the capacity of the connector. Furthermore, the report considered the factor of safety of 3 , used by manufacturers, as overly conservative. 


\section{2 - FRP-Wood Interaction}

Several studies have aimed at investigating the strengthening of wood members with fiber reinforced polymers (FRP), and the FRP-wood bonding mechanism. Lyons and Ahmed (2005) studied the parameters affecting the bond strength between wood and polymer composites. For this purpose, they used SYP wood treated with Chromated Copper Arsenate (CCA) treated SYP as wood and E-glass fabric as FRP applied with two different types of epoxies. Test parameters included wood surface (either wet or dry), surface roughness, type of epoxy, and addition of hydroxyl methanol resorcinol (HMR) as a bonding catalyst. The various specimens in the test matrix were subjected to different environmental exposures, including "as is" (control), "dried", "soaked" and "tidal" conditions. The bond strength was measured using a pull-off tester, which has an aluminum puck with a diameter of 2 in. It was reported that one type of epoxy performed better in the control environment, while the other worked better on wet surfaces in the soaked and tidal environments. The HMR did not make any significant contribution to the bond strength with one of the two epoxies, but it did improve the strength of the other epoxy in wet conditions. The highest bond strength of about 435 psi was achieved with dry wood surfaces and the control environment.

Davalos et al. (2000) conducted a two-part study on the FRP-wood bonded interfaces, focusing on shear strength and durability aspects, as well as the fracture behavior. Phenolic FRP-wood and epoxy FRP-wood interfaces were tested in the study. The effects of two coupling agents, HMR and resorcinol-formaldehyde (RF) on epoxy FRP-wood bond interface were investigated. For service performance tests, a modified 
ASTM D 2559 test procedure (Figure 2.10a) was followed, while for the shear strength test a modified ASTM D 905 test procedure (Figure 2.10b) was adopted. The HMR coupling agent was shown to improve the performance of epoxy FRP-wood bond subjected to cyclic wetting and drying. However, the RF agent did not provide satisfactory results. In the block shear tests, it was observed that the HMR coupling agent performed better than RF. The failure generally occurred on the wood surface when HMR was used, but the percentage of wood failure was lower with RF.

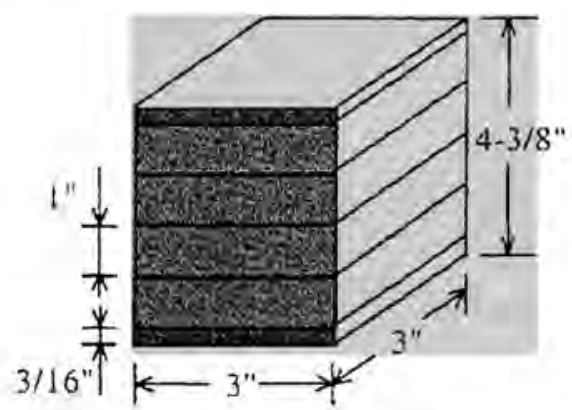

Epoxy FRP-wood Sample

(a)

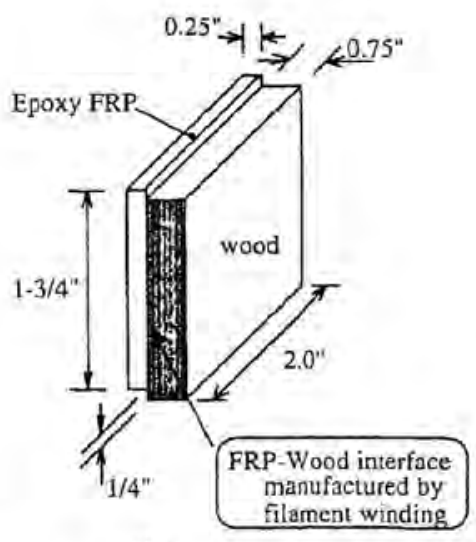

(b)

Figure 2.10 - (a) Modified ASTM D 2559 test, (b) Modified ASTM D 905 test (Davalos et al. 2000)

In the second part of their study, Davalos et al. (2000) investigated the Mode I fracture of FRP-wood bond interface using a contoured double-cantilevered beam specimen (Figure 2.11). The goal was to establish a fracture toughness data to predict whether delamination of FRP will occur in actual service conditions. It was again shown that HMR performed much better than RF as a coupling agent with higher strength and lower coefficient of variation values in dry conditions. Under wet conditions, the difference in specimens tested with HMR and RF became more apparent. 


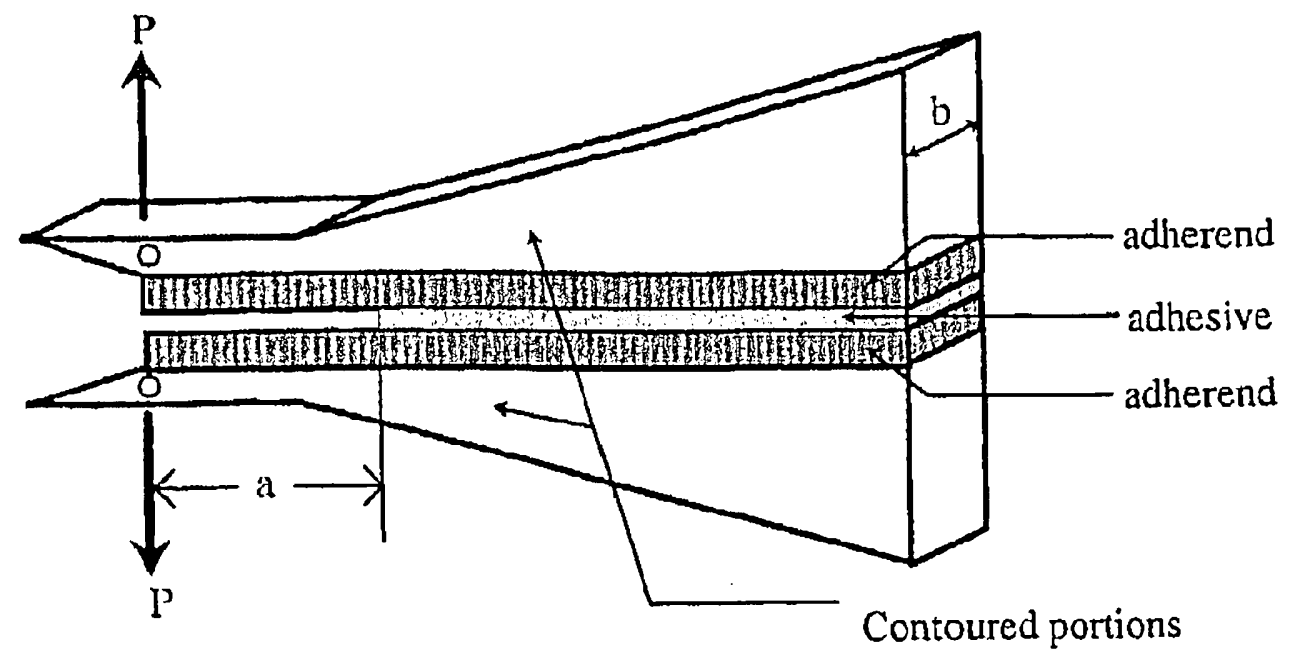

Figure 2.11 - The contoured double-cantilevered beam specimen (Davalos et al. 2000)

Jia and Davalos (2004) conducted a study to understand the effect of load ratio on Mode-I fatigue fracture of FRP-wood bonded interfaces. For this study, they used the contoured double cantilevered beam specimen show in Figure 2.11. The adherents used in this study were red maple wood and pultruded Phenolic FRP laminate. The FRP-wood interface was bonded using RF. After processing the results of the experiments, the following three equations were developed by modifying Paris Law:

$$
\begin{aligned}
& \frac{d a}{d N}=2 \times 10^{-17}\left(\frac{\Delta G}{(1-R)^{0.79}}\right)^{5.54} \\
& \frac{d a}{d N}=2 \times 10^{-15}\left(\Delta G^{0.87} G_{\text {min }}^{0.13}\right)^{5.34} \\
& \frac{d a}{d N}=9 \times 10^{-16}\left(\Delta G^{0.07} G_{\text {meun }}^{0.93}\right)^{5.59}
\end{aligned}
$$

where a is the crack length, $\mathrm{N}$ is the number of cycles, $\mathrm{G}$ is the energy release rate, as shown in Equation 2.4, $\mathrm{C}$ is the compliance, $\mathrm{b}$ is the thickness of the specimen, $\mathrm{P}$ is the 
applied load, and $\mathrm{R}$ is the load ratio $\left(\mathrm{P}_{\min } / \mathrm{P}_{\max }\right)$. Stating that any of these equations yields satisfactory results for determining the effect of load ratio on crack propagation, authors recommended Eq. (2.3) for use in engineering applications.

$$
G_{\text {min } \max }=\frac{P^{2}{ }_{\text {min.max }}}{2 b} \frac{d C}{d A}
$$

Tascioglu et al. (2003) studied the durability and shear strength of Eglass/Phenolic composite and treated wood bond interface. The goal of the study was to evaluate the effects of preservatives and pre- and post-treatment applications on FRPwood bond interface. After conducting the modified ASTM D 905 and ASTM D 2559 tests, the authors concluded that preservative treatments and pre- and post-treatment applications have significant negative effects on the FRP-wood bond strength. They underlined the need for further investigation of the effects of various treatment systems on FRP-wood interface.

Triantafillou (1997) investigated the shear strengthening of wood members using FRP. They tested 21 beams, which were designed to fail in shear, and strengthened them using FRP with varying configurations and coverage areas. The study showed that externally bonded FRP can significantly increase the shear capacity of wooden beams, and that the coverage area of FRP may be optimized following the basic principles of mechanics.

Plevris and Triantafillou (1995) conducted a research on creep behavior of FRPreinforced wood members. An analytical study was performed to model the wood beams reinforced with carbon FRP in three point bending. It was observed that creep behavior of FRP-reinforced wood beam was dominated by the creep behavior of wood itself. Also, it 
was noted that FRP would make a significant impact on the creep performance of the wood beam, as it generally decreases the deformations and increases the ultimate strength. 


\section{3 - Component Level Testing}

The component level tests are divided into two parts; (a) tests done to determine the FRP-wood bond strength in shear, and (b) tests on the FRP roof-to-wall connections.

\section{1 - Direct Shear Tests}

\subsection{1 - Test Setup and Specimen Preparation}

The double lap direct shear test was used as a starting point to develop FRP roofto-wall connection. The goal of this set of experiments was to establish the trend in the FRP-wood bond strength in shear (Mode II). For this purpose, 4 in. long nominal $4 \times 4$ in. spruce-pine-fir (SPF) wood of structural grade 2 was used. Two blocks were placed on top of each other with a 1.5 in. spacer in between. Then, the glass FRP was applied to both sides of both blocks using the two-part epoxy in accordance with the manufacturer's specifications. These specimens were allowed to cure for at least one week in the laboratory prior to testing.

The specimens were then connected to a U-shaped metal attachment using screws on top and bottom. Later, the assembly was attached to a universal testing machine using bolts from the top and bottom side through a hole drilled at the center of the metal attachments (Figure 3.1). 


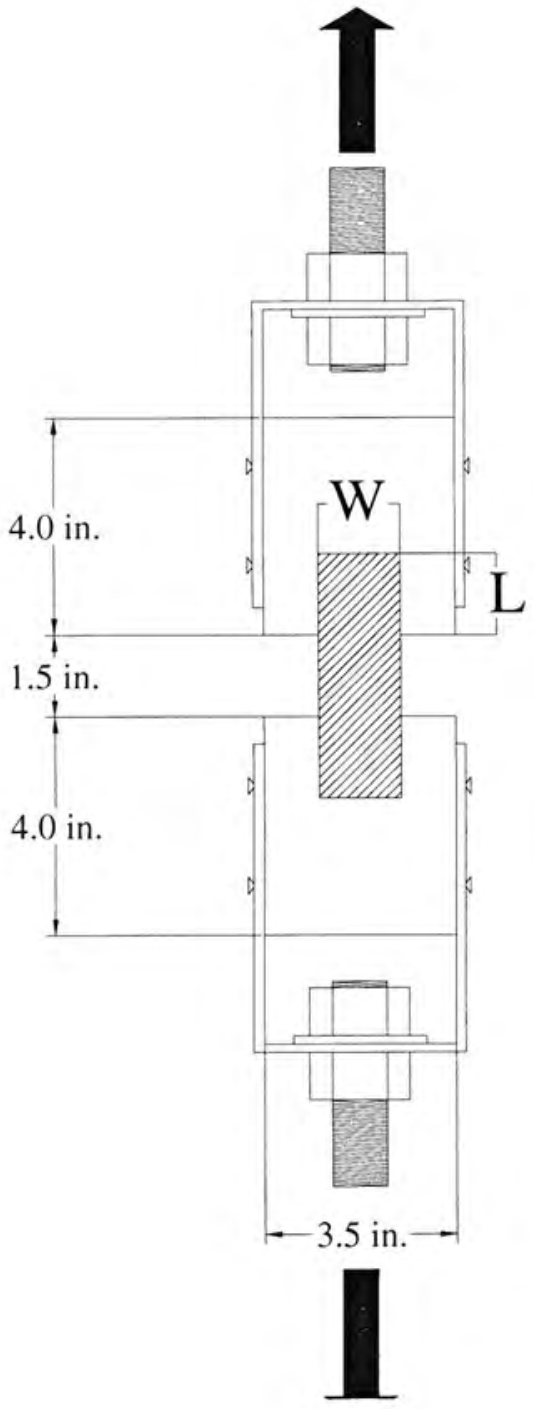

(a)

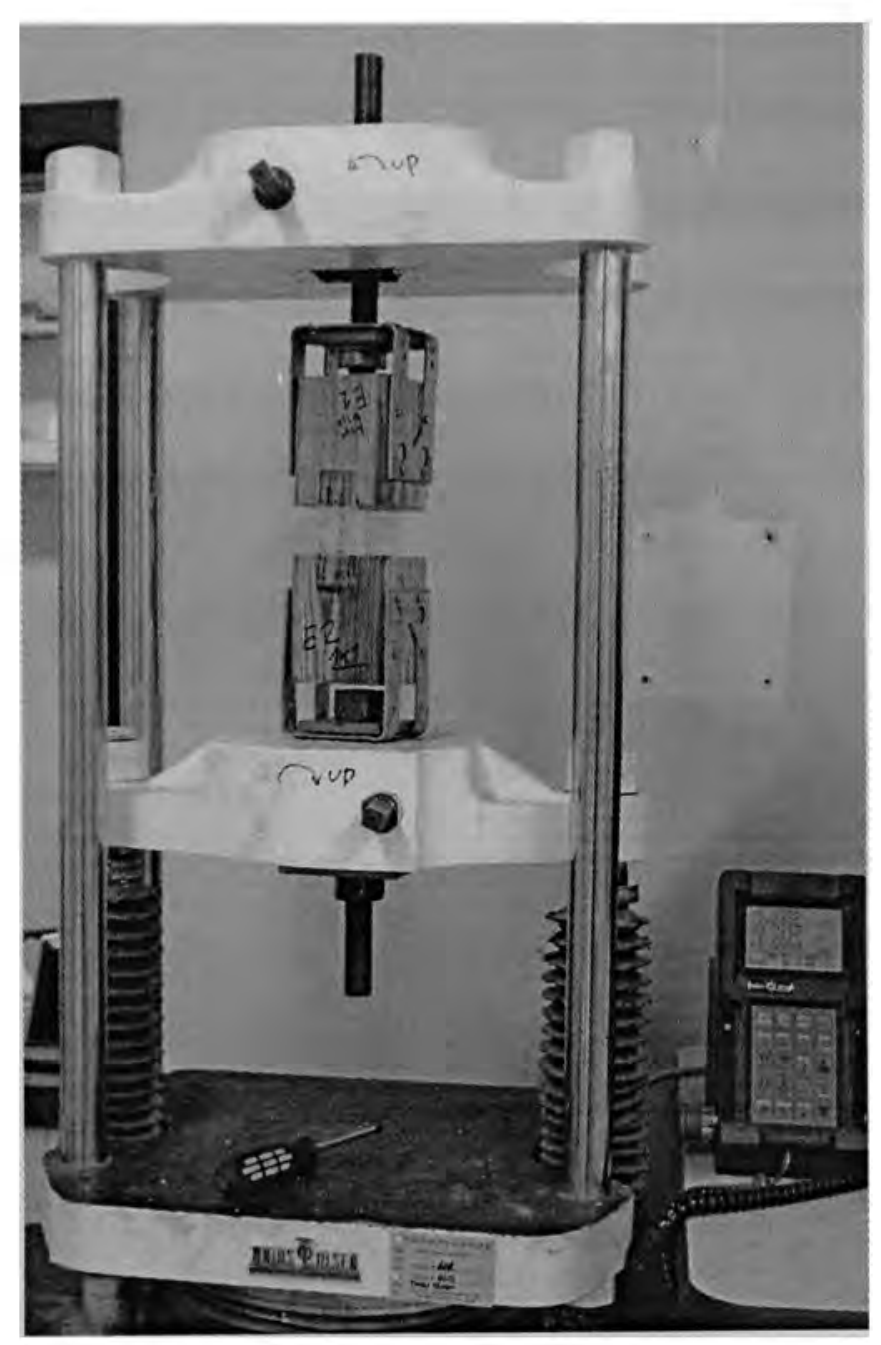

(b)

Figure 3.1 - (a) Schematic representation of direct shear test setup, (b) Specimen placed at universal testing machine

\subsection{2 - Test Observations and Results}

All of the specimens failed due to debonding of FRP placed on wood blocks. When failed specimens were investigated, it was seen that the plane of failure was usually the interface between wood and FRP. Very little separation of fibers from the 
wood was observed (Figures 3.2 and 3.3). In configurations $\mathrm{A}$ and $\mathrm{B}$, which have larger bond areas, the delamination stage could be identified visually and the progressive shearing of FRP from wood could be observed. Following the beginning of debonding, specimens were able to sustain significant portion of their ultimate loads before completely failing. However, in configurations $\mathrm{C}, \mathrm{D}$ and $\mathrm{E}$ the failure was very sudden and there was no indication of failure before the peak load was reached.

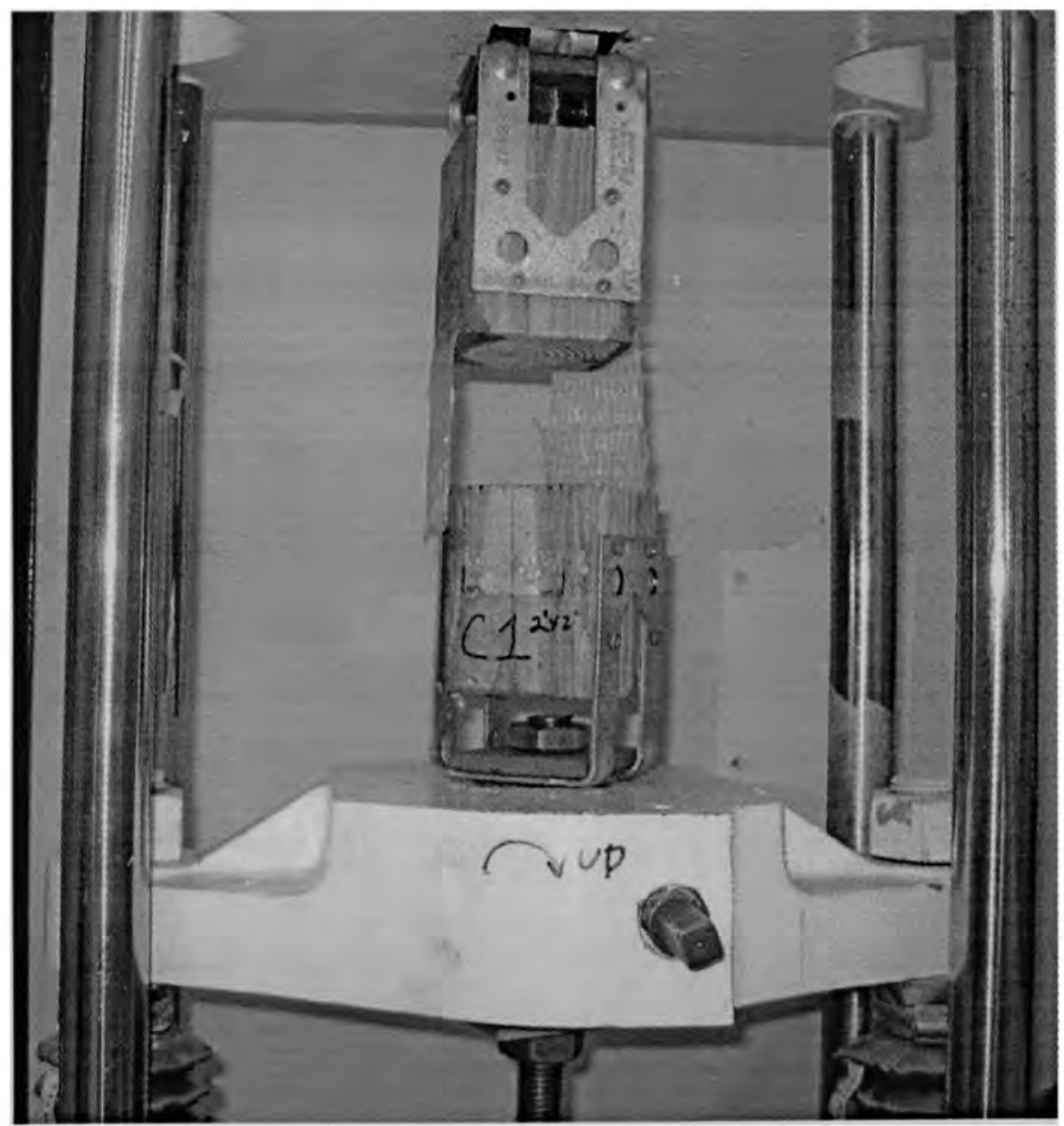

Figure 3.2 - Failure of direct shear specimen 


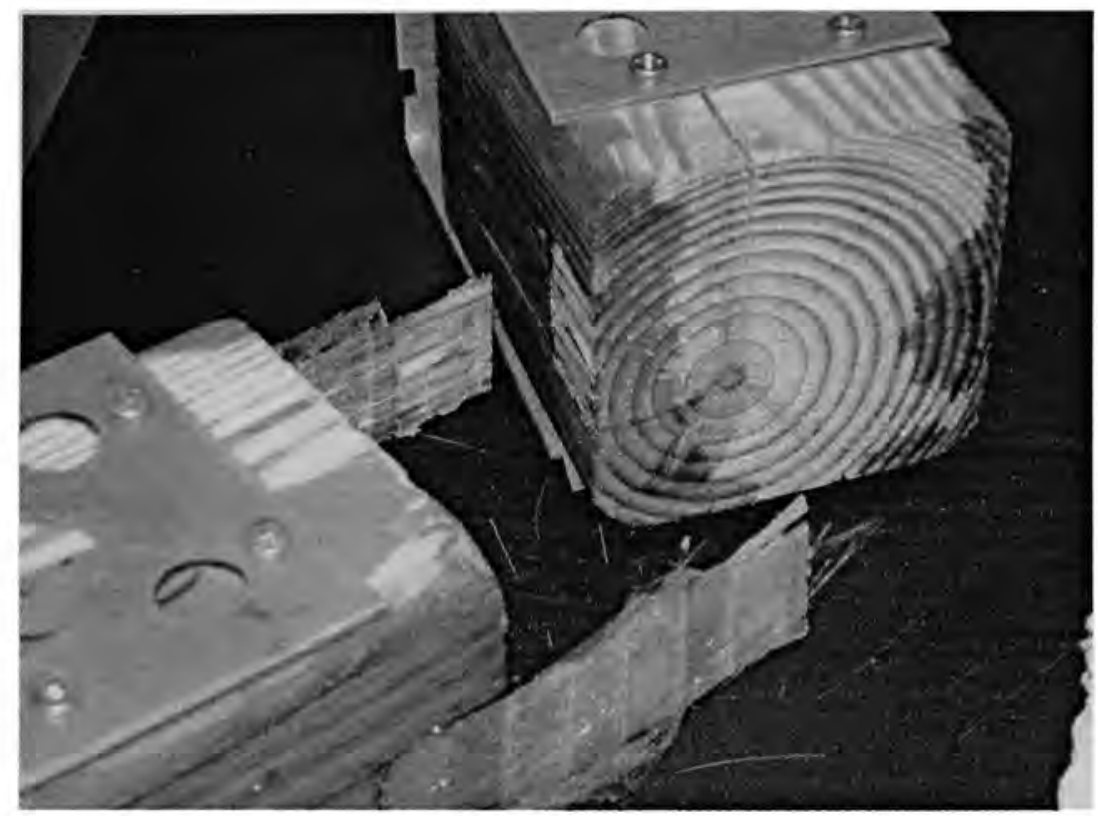

Figure 3.3 - Typical failure of direct shear specimen

Results obtained from the tests are listed in Table 3.1, where W and L represent the width and length of FRP placed on each side of each block for each of the five different configurations.

Table 3.1 -Direct shear test results

\begin{tabular}{|c|c|c|c|c|c|c|c|}
\hline Configuration & $\begin{array}{l}\text { Width } \\
\text { (in.) }\end{array}$ & $\begin{array}{l}\text { Length } \\
\text { (in.) }\end{array}$ & $\begin{array}{c}\text { Specimen } \\
\text { No }\end{array}$ & $\begin{array}{c}\text { Failure } \\
\text { Load } \\
\text { (lbs) }\end{array}$ & $\begin{array}{c}\text { Average } \\
\text { Load (lbs) }\end{array}$ & $\begin{array}{c}\text { Coefficient } \\
\text { of } \\
\text { Variation }\end{array}$ & $\begin{array}{c}\text { Average } \\
\text { Shear } \\
\text { Strength } \\
\text { (psi) }\end{array}$ \\
\hline \multirow{3}{*}{ A } & \multirow{3}{*}{3} & \multirow{3}{*}{3} & $\mathrm{~A}-1$ & 4,380 & \multirow{3}{*}{4,843} & \multirow{3}{*}{0.087} & \multirow{3}{*}{269} \\
\hline & & & A - 2 & 4,950 & & & \\
\hline & & & A - 3 & 5,200 & & & \\
\hline \multirow{3}{*}{ B } & \multirow{3}{*}{2} & \multirow{3}{*}{3} & B - 1 & 4,780 & \multirow{3}{*}{4,773} & \multirow{3}{*}{0.015} & \multirow{3}{*}{398} \\
\hline & & & B - 2 & 4,700 & & & \\
\hline & & & B - 3 & 4,840 & & & \\
\hline \multirow{3}{*}{ C } & \multirow{3}{*}{2} & \multirow{3}{*}{2} & C - 1 & 4,880 & \multirow{3}{*}{4,650} & \multirow{3}{*}{0.103} & \multirow{3}{*}{581} \\
\hline & & & C -2 & 4,100 & & & \\
\hline & & & C -3 & 4,970 & & & \\
\hline \multirow{3}{*}{ D } & \multirow{3}{*}{1} & \multirow{3}{*}{2} & D - 1 & 2,410 & \multirow{3}{*}{2,663} & \multirow{3}{*}{0.083} & \multirow{3}{*}{666} \\
\hline & & & D - 2 & 2,760 & & & \\
\hline & & & D - 3 & 2,820 & & & \\
\hline \multirow{3}{*}{$E$} & \multirow{3}{*}{1} & \multirow{3}{*}{1} & E-1 & 1,399 & \multirow{3}{*}{1,529} & \multirow{3}{*}{0.089} & \multirow{3}{*}{765} \\
\hline & & & $E-2$ & 1,671 & & & \\
\hline & & & $E-3$ & 1,518 & & & \\
\hline
\end{tabular}


Figure 3.4 shows the effect of total bonded area on the failure load. The total bonded area represents the two sides of each block. It can clearly be seen that beyond a threshold of approximately $9 \mathrm{in}^{2}$, no further increase in the failure load can be achieved by increasing the bonded area. For this data set, a trend line with an $\mathrm{R}^{2}$ value of 0.8875 was found, as

$y=1652.9 \ln (x)+540.11$

(Equation 3.1)

where $\mathrm{y}$ is the total load and $\mathrm{x}$ is the bonded area.

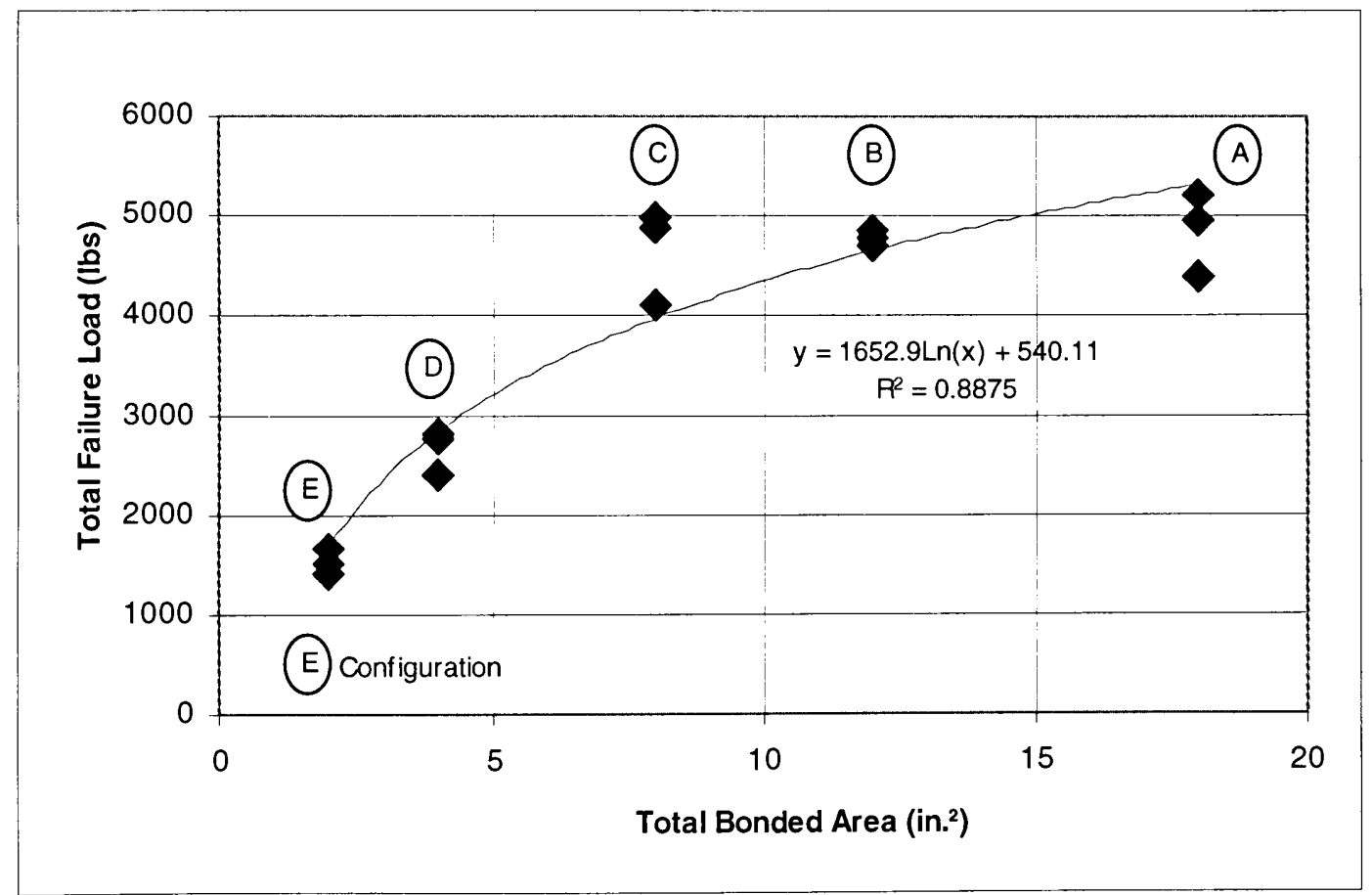

Figure 3.4 - Total failure load vs. bonded area

Figure 3.5 shows the Mode II bond strength versus total bonded area. A trend line with an $\mathrm{R}^{2}$ value of 0.954 was found as

$y=890.85 e^{-0.0656 x}$

where $\mathrm{y}$ is the bond strength in shear and $\mathrm{x}$ is the bonded area. 


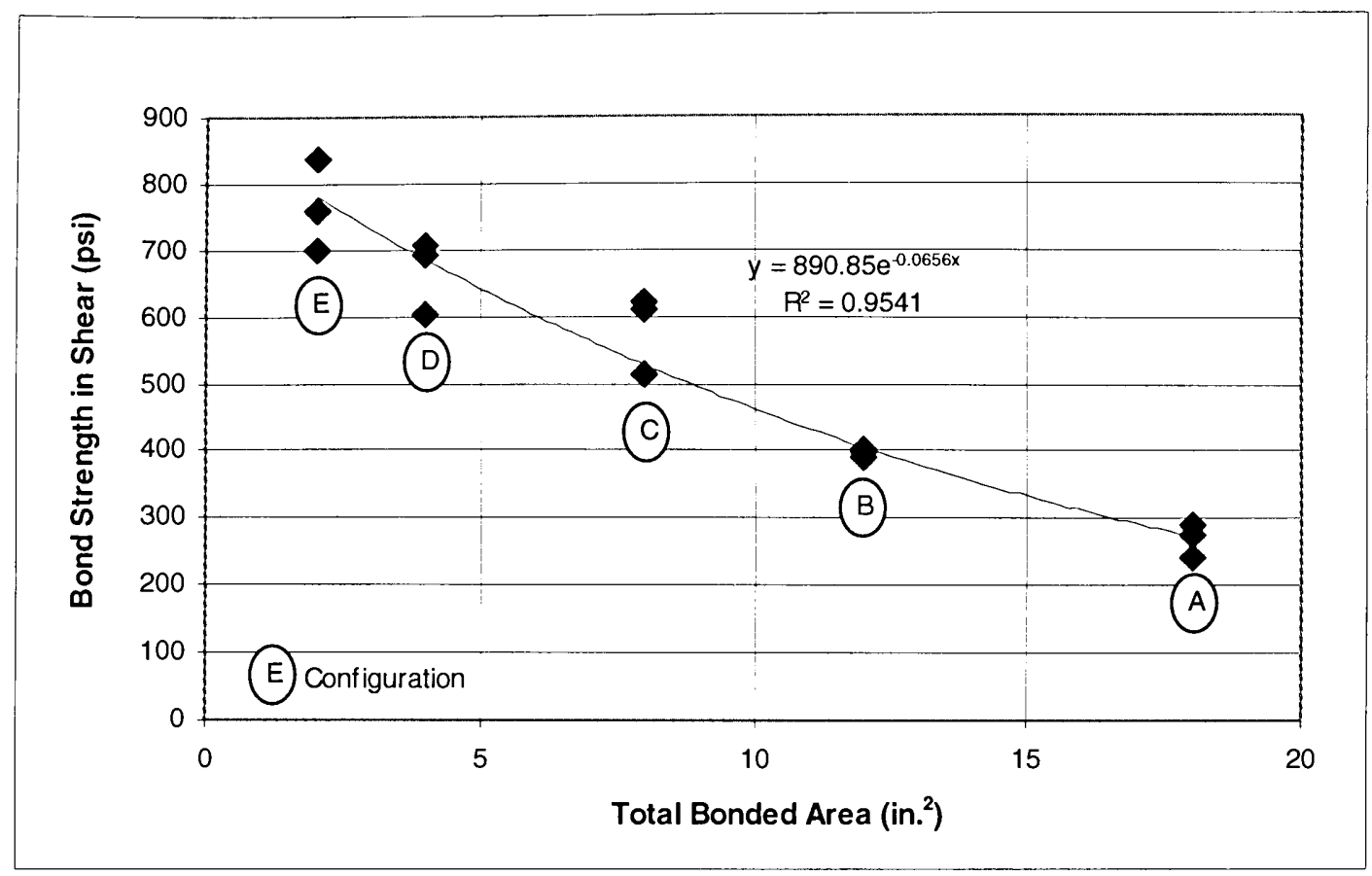

Figure 3.5 - Bond strength in shear vs. bonded area

\section{2 - FRP Tie Development Tests}

\subsection{1 - Test Setup and Specimen Preparation}

For testing of the FRP roof-to-wall connections, ASTM D 1761 standard was used, as followed by most of the hurricane clip manufacturers. The specimens consisted of two 14 in. long double top plates and a 33 in. long joist, all built using $2 \times 6$ in. dimensional lumber with a grade No 2 quality. Type of the lumber used in the first two stages of development was spruce-pine-fire (SPF). In the last stage, southern yellow pine (SYP) was also used in some of the specimens for comparison. Figure 3.6 shows the schematics of test specimen. While preparing the specimens, the double plates were first placed on the ground at a clear spacing of 22 in. The joist was then placed at the center of 
the top plates. Subsequently, the FRP was attached at two ends of the joist using two-part epoxy according to the manufacturer's specifications. The specimens were allowed to cure for at least one week prior to testing. Four types of FRP were used, including unidirectional carbon FRP (CFRP), bidirectional CFRP, unidirectional glass FRP (GFRP) and bidirectional GFRP.

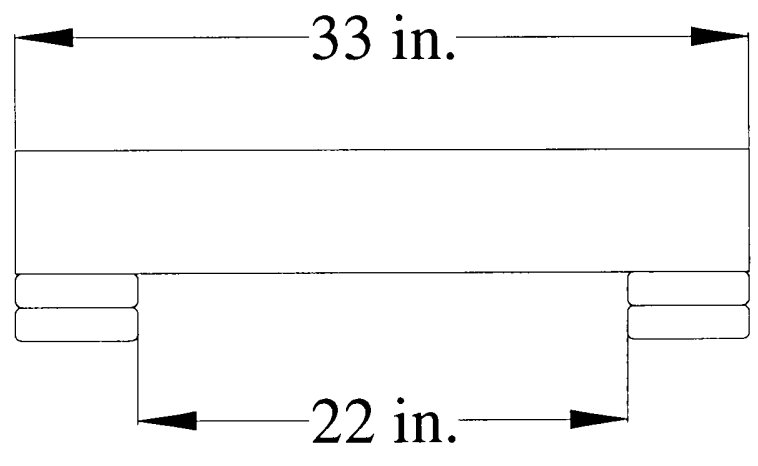

Side View

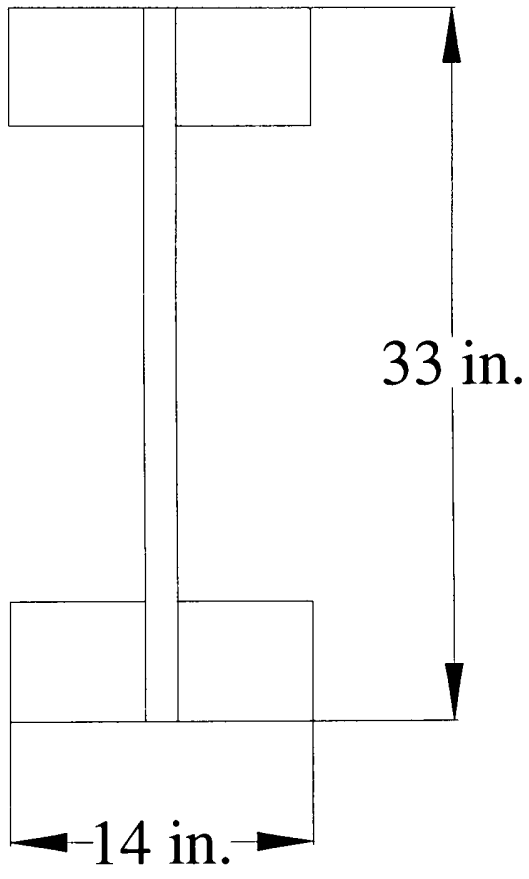

Top View

Figure 3.6 - Top and side views of test specimen

For testing, the specimens were assembled upside down on a steel frame, as shown in Figure 3.7. The specimens were connected to the frame using either four bolts or clamps at the corners of the double top plates. The load was applied at the center on the bottom of the joist, using a universal testing machine at a displacement rate of 0.035 in./min. A 5 in. long rubber was placed under the crosshead to avoid crushing of the wood under the loading point. 
Two dial gages were placed at the two ends of the joist at $1.5 \mathrm{in}$. spacing from the top plates. The load at $1 / 8$ in. deflection, which is a criteria used by the hurricane clip manufacturers, was measured at these points.

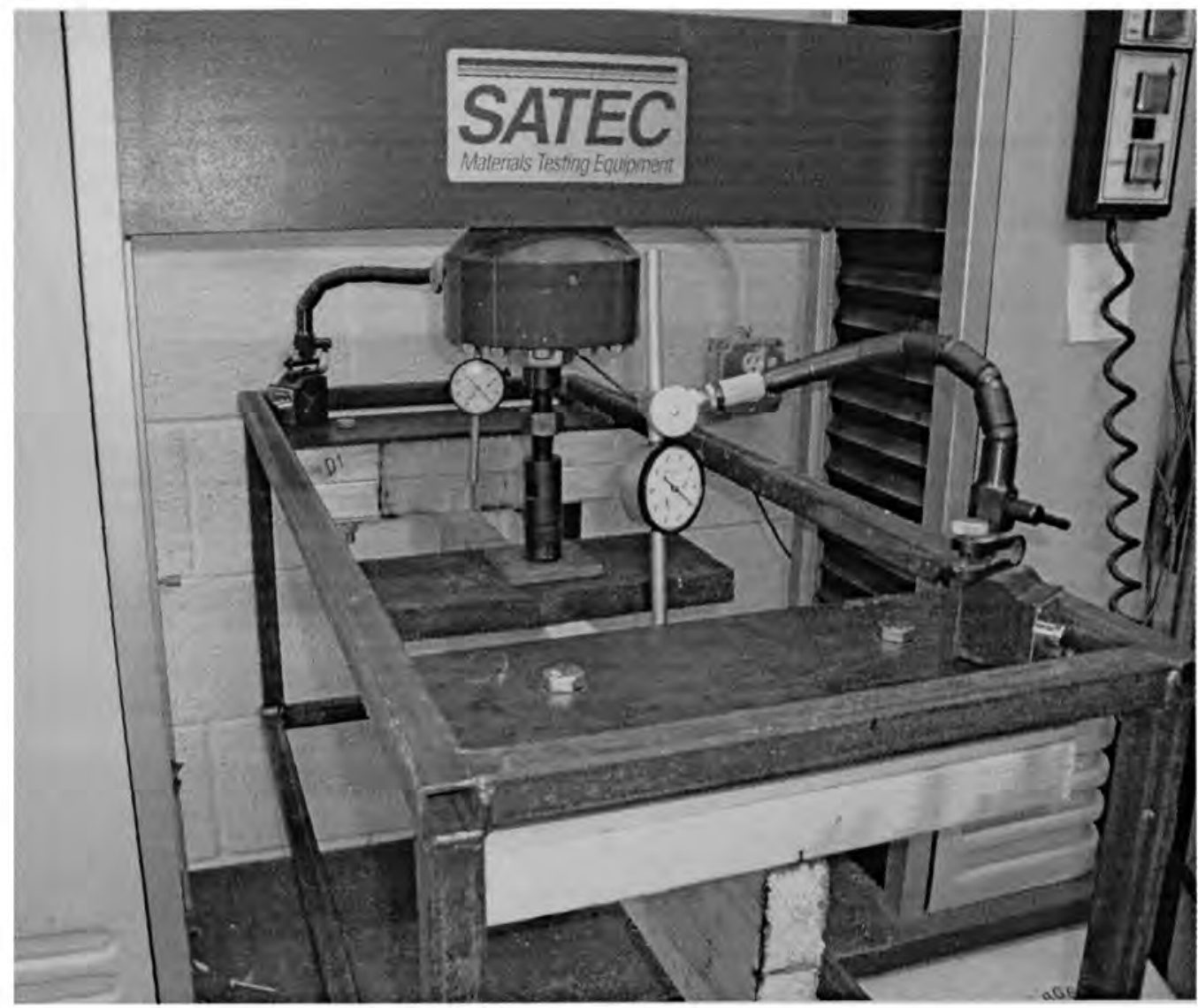

Figure 3.7 - A typical specimen before testing

\subsection{2 - FRP Tie Development: Stage I}

At the first stage of development, five different configurations were tested. The type of FRP used in the first stage was unidirectional GFRP. The various configurations are discussed below.

Configuration I consisted of a 6 in. $x 7$ in. FRP sheet, cut and folded as shown in Figure 3.8 to wrap the joist and the double top plates. The failure of the connection was 
observed at 1,120 lbs before the 1/8 in. deflection limit was reached. Since there is one connection at each end of the joist, the load per connection was $560 \mathrm{lbs}$. The failure mode of the connection, as shown in Figure 3.9, was peeling (Mode I) and rupture of FRP at the edges of the joist.
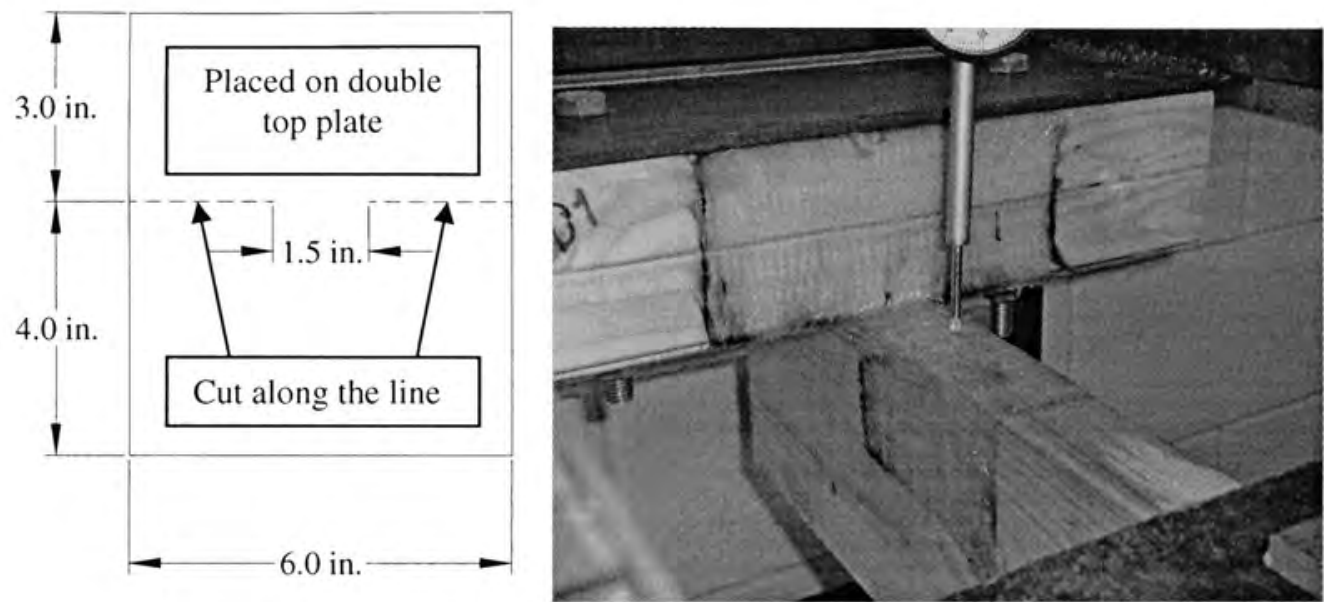

Figure 3.8 - Schematics and application of FRP tie Configuration I

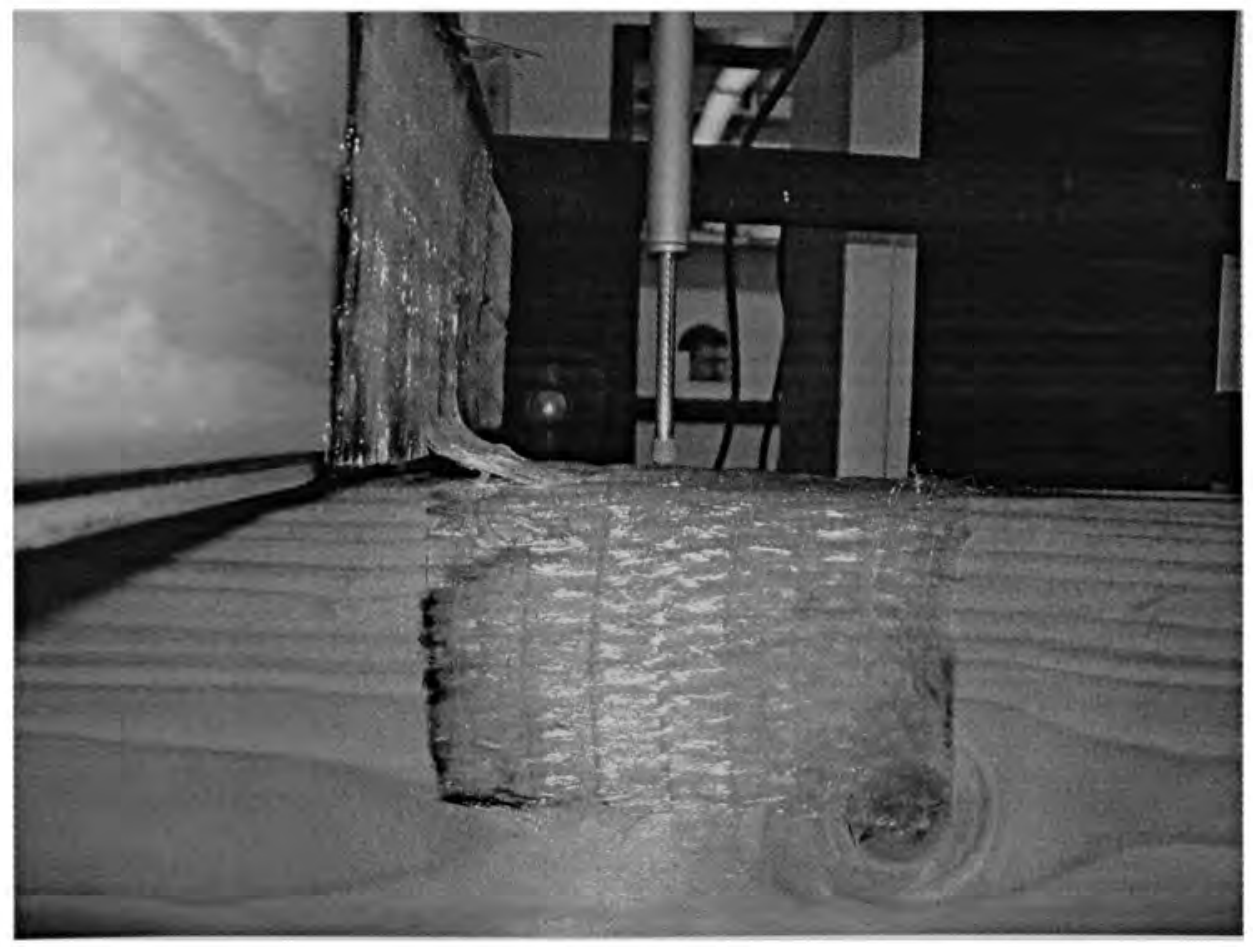

Figure 3.9 - Failure of FRP tie Configuration I 
Configuration II was very similar to Configuration I in terms of the load transfer mechanism. Three pieces of FRP were cut and applied to the connection point, as shown in Figure 3.10. The first piece, 1.5 in. $x 6$ in., was placed as an angle on top the plate and the joist. The second piece, 2 in. $x 7$ in., was placed on the joist. The third piece, 3 in. $\times 5$ in., was attached onto the top plate. The total failure load was $1,280 \mathrm{lbs}$, or $640 \mathrm{lbs}$ per connection, and it occurred before 1/8 in. deflection was reached. The failure mode of the specimen, as shown in Figure 3.11, was by rupture of FRP in the first piece.
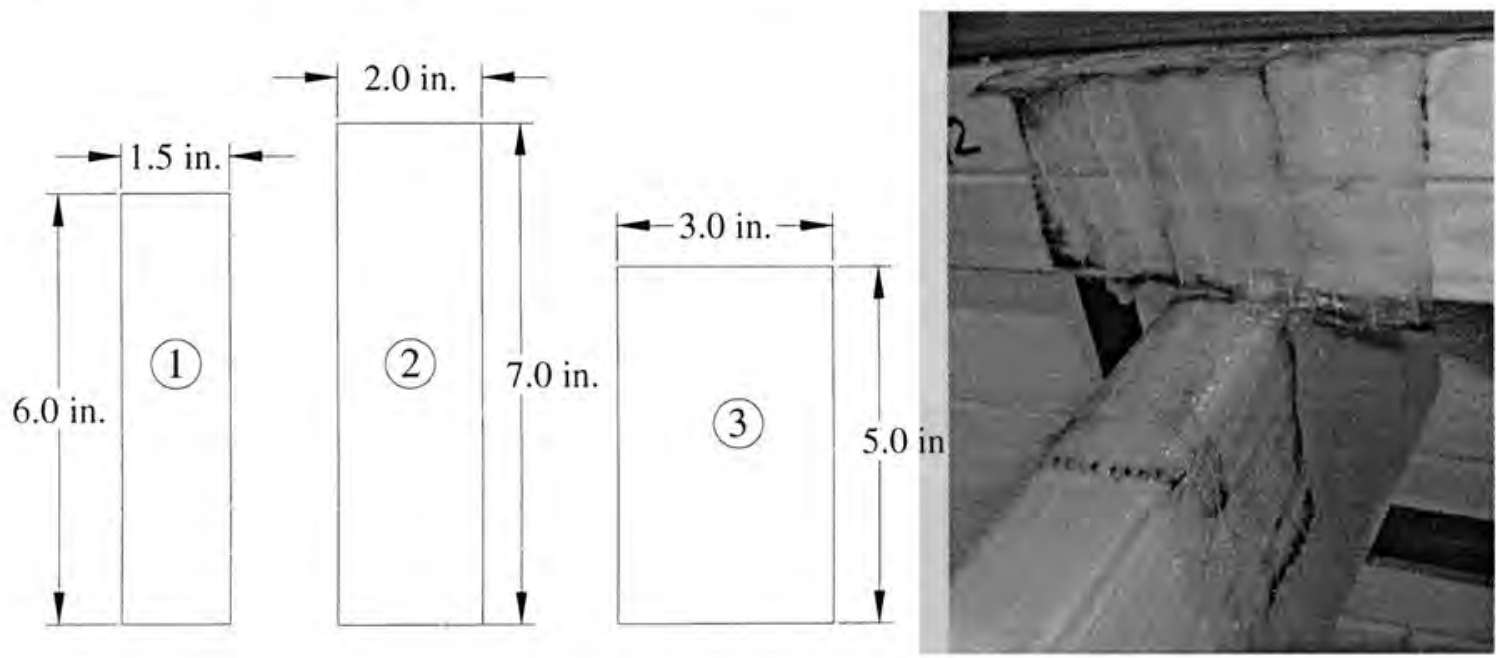

Figure 3.10 - Schematics and application of FRP tie Configuration II

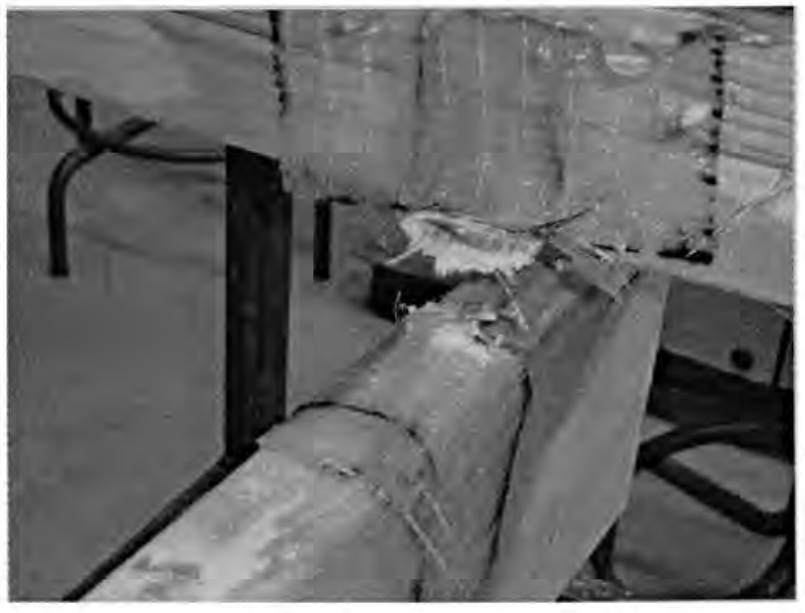

Figure 3.11 - Failure of FRP tie Configuration II 
Configuration III included L-shaped FRP pieces, as shown in Figure 3.12. Two independent ties were used at each end of the joist. The failure was observed at a total load of 3,100 lbs or 1,550 lbs per connection, as FRP ruptured along its weak direction and peeled off from the top plate (Figure 3.13). Again, the $1 / 8$ in. deflection was not reached before the failure.
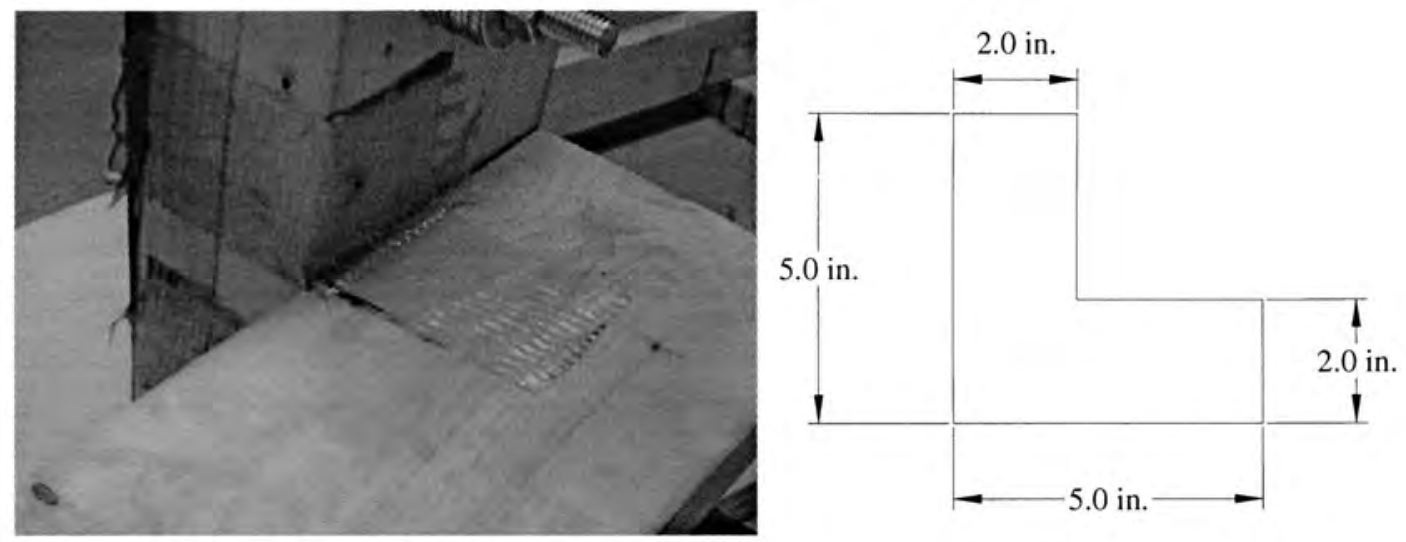

Figure 3.12 - Schematics and application of FRP tie Configuration III

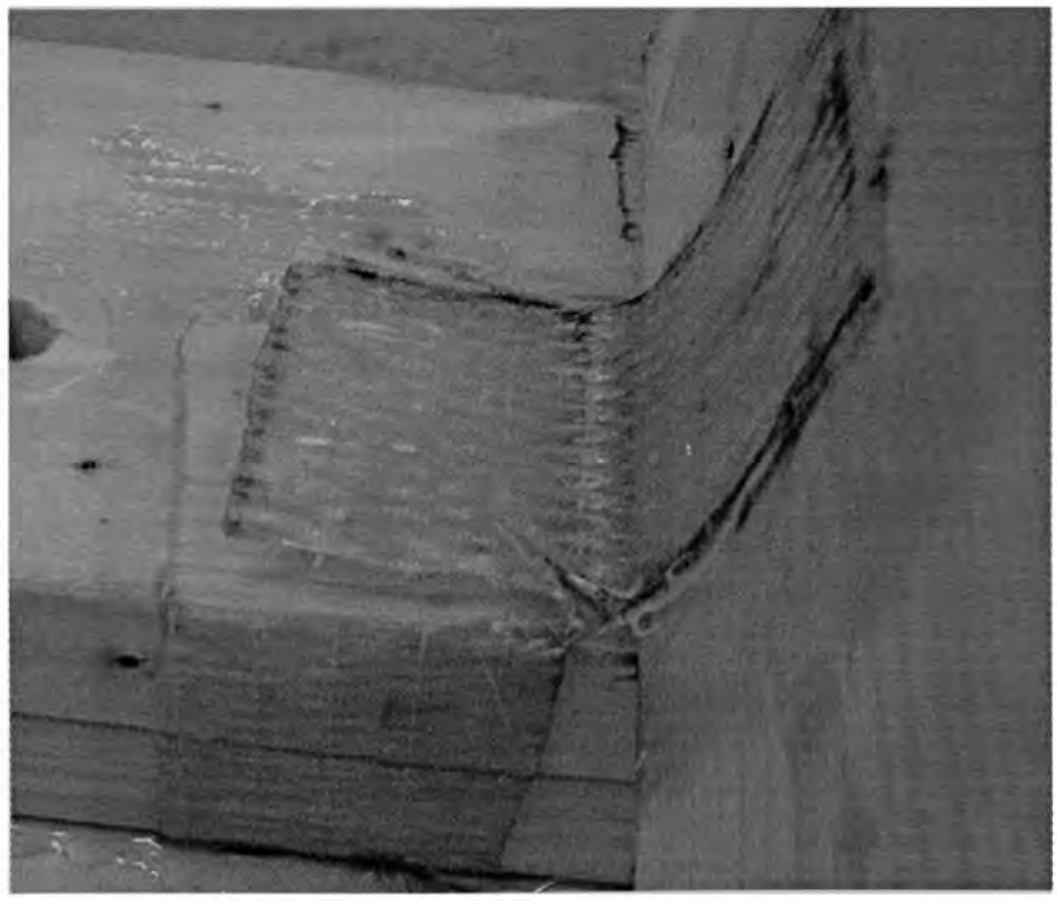

Figure 3.13 - Failure of FRP tie Configuration III 
Configuration IV consisted of a 3 in. $x 7$ in. rectangular piece of FRP, as shown in Figure 3.14. The piece was cut along the dashed line, and placed such that the 3 in. portion will be on the top plate. The load transfer from the double top plate to the joist was achieved through the $1 / 2$ in. wide FRP section. The failure was observed at a total load of 3,190 lbs or 1,595 lbs per connection, as FRP ruptured before the $1 / 8 \mathrm{in}$. deflection was reached (Figure 3.15).
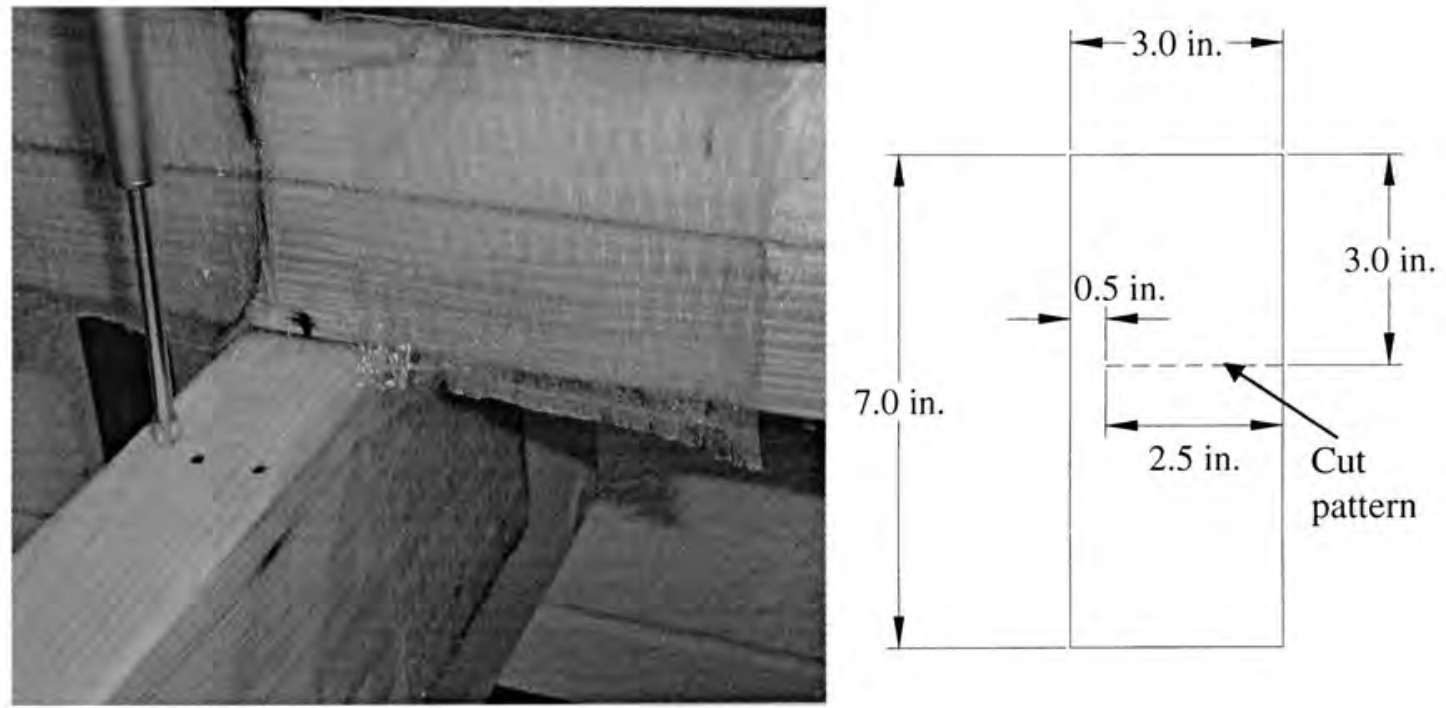

Figure 3.14 - Schematics and application of FRP tie Configuration IV

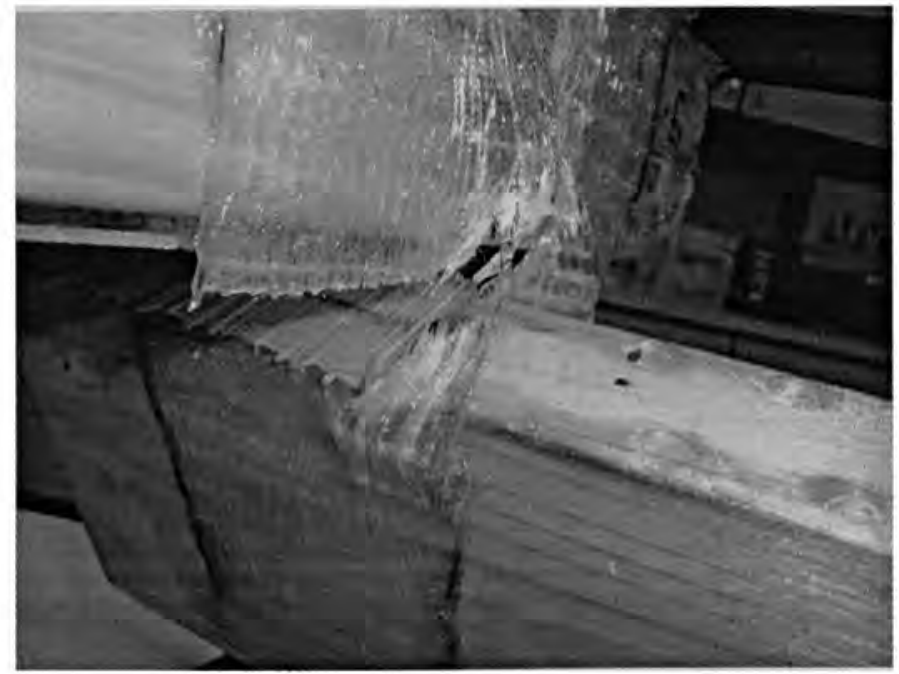

Figure 3.15 - Failure of FRP tie Configuration IV 
Configuration V consisted of a 4 in. $x 6$ in. rectangular piece of FRP applied such that half of the FRP will be on the top plate and the other half on the joist, as shown in Figure 3.16. These pieces were placed on each side at ends of joist as an angle, making 4 FRP pieces per specimen. The failure of this connection occurred at 5,560 lbs, or 2,780 lbs per connection, before the $1 / 8$ in. deflection limit was reached. The mode of failure was identified as peeling off of FRP placed on the top plates as shown in Figure 3.17. It was observed that significant amount of wood fibers peeled as the FRP detached from the top plate.
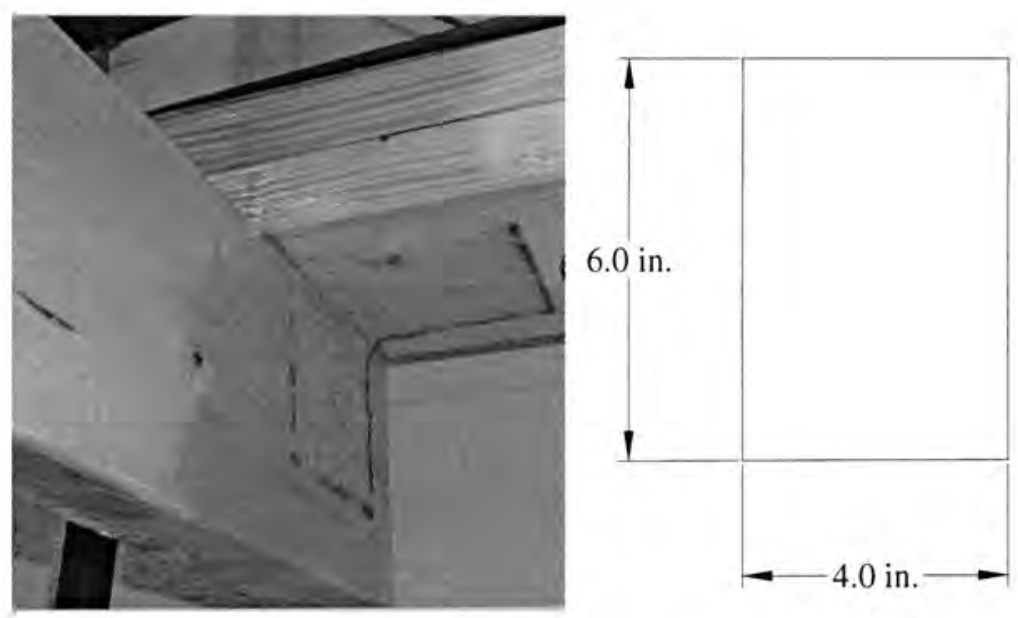

Figure 3.16 - Schematics and application of FRP tie Configuration V

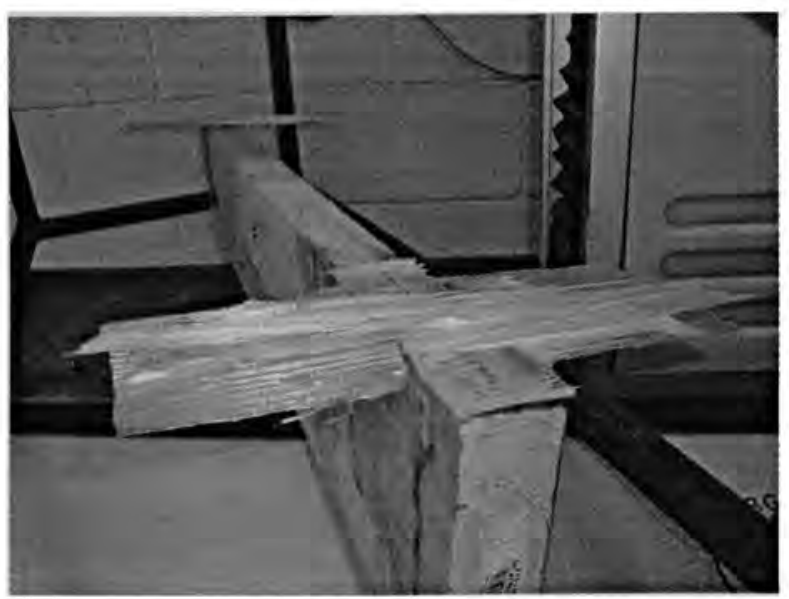

Figure 3.17 - Failure of FRP tie Configuration V 


\subsection{3 - FRP Tie Development: Stage II}

In the second stage of FRP tie development, three configurations were considered. Configurations III, IV and V of Stage I were modified and strengthened based on the modes of failures observed in the tests, while configurations I and II were eliminated from further consideration. Two types of FRPs were used with each configuration, making six sets of test specimens. Each set consisted of three identical samples to assess repeatability of test results. Dimensions and types of FRPs used for Configurations A, B and $\mathrm{C}$ are listed in Table 3.2.

Table 3.2 - Schematics and types of FRP connections tested in Stage II

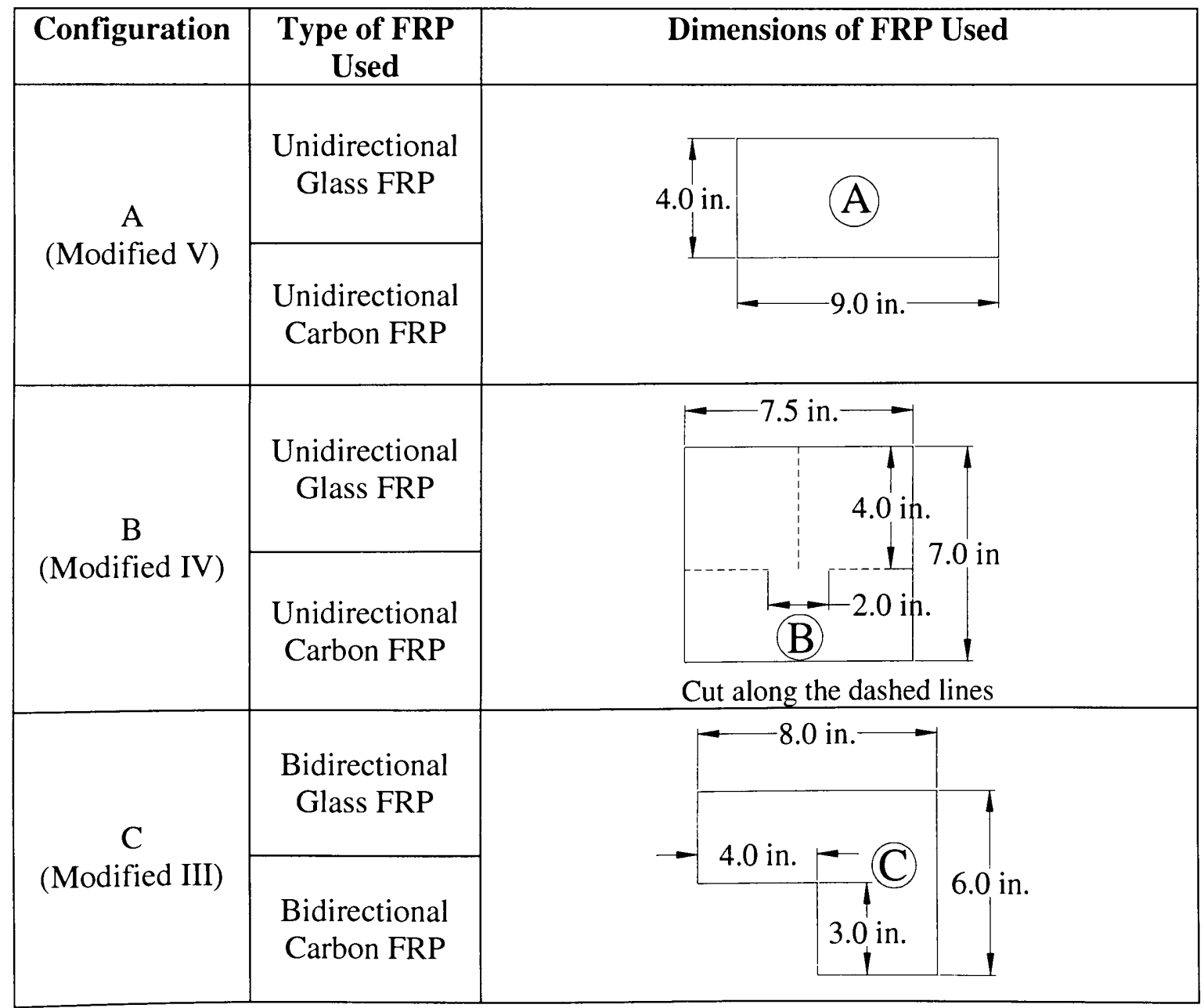


Configuration A was developed by enlarging the contact area of FRP that was used in Configuration V of Stage I. The top plates were connected to the joist using four 4 in. $x 9$ in. FRP pieces. Each FRP piece was placed, such that half will be on the top plate and the other half on the joist. The specimens prepared by GFRP and CFRP are shown in Figure 3.18. It was seen that modes of failures were very similar for glass and carbon. In all specimens, the FRP peeled off from the top plate came while detaching wood fibers (Figure 3.19). It was observed that ultimate load for carbon FRP was approximately $20 \%$ higher than that of glass FRP. Also, the separation of wood fibers from the top plate was more obvious in CFRP ties.
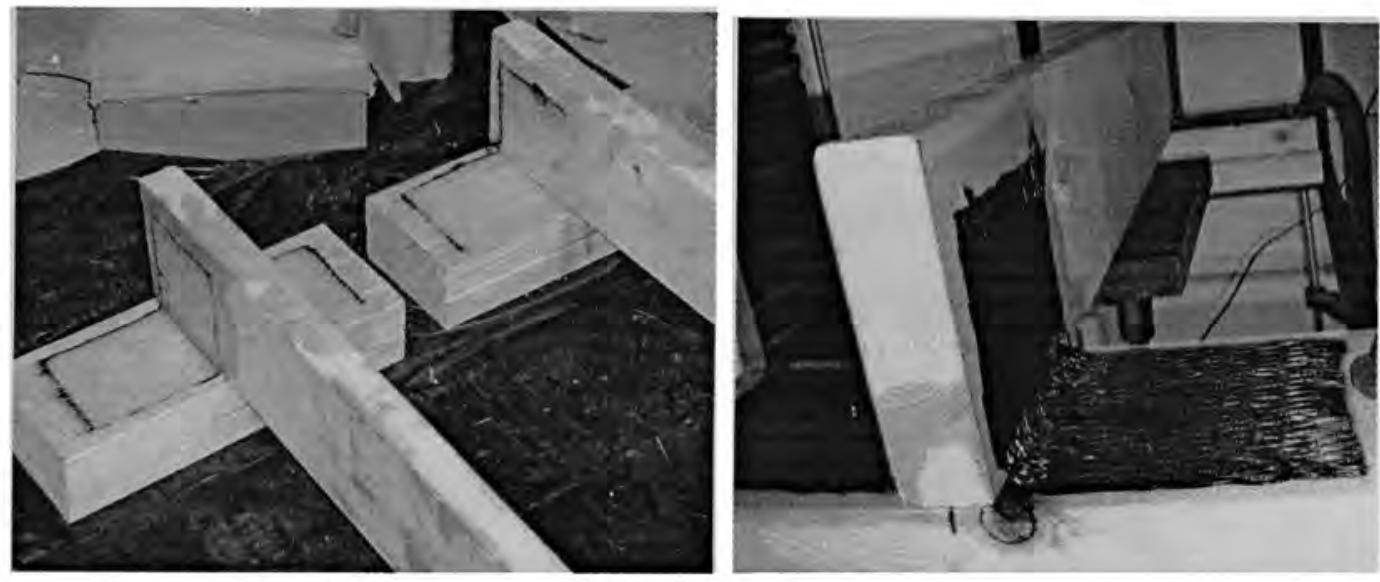

Figure 3.18 - Configuration A with GFRP (left) and CFRP (right) before testing
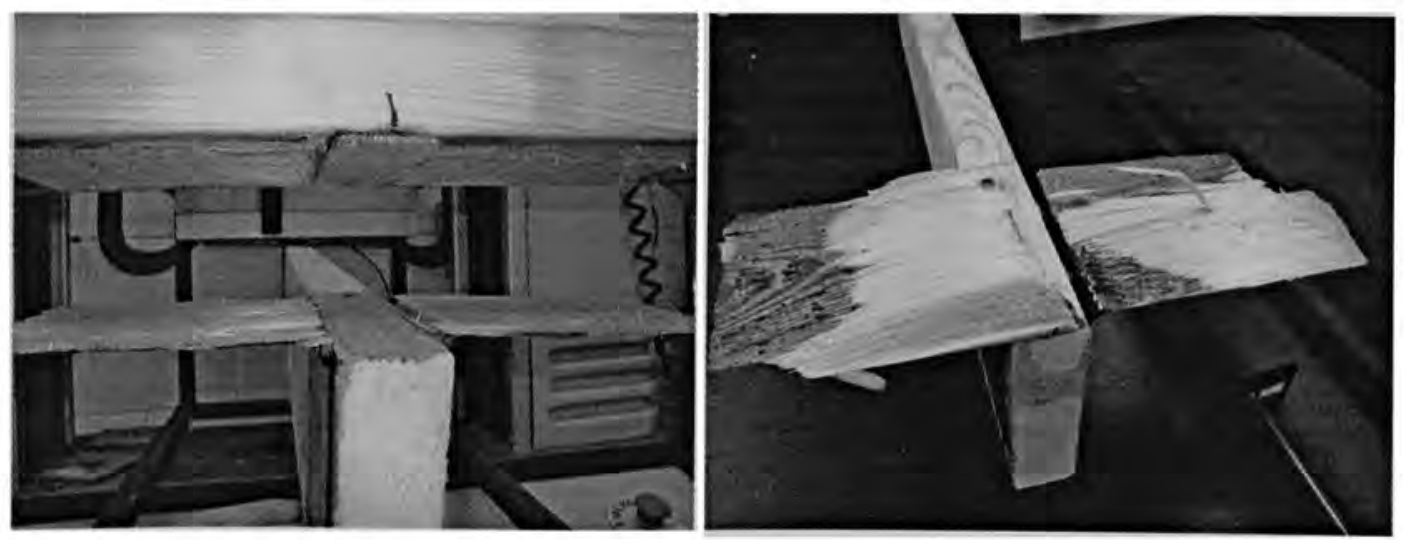

Figure 3.19 - Failure of Configurations A with GFRP (left) and CFRP (right) 
Configuration B was a modified version of Configuration IV of Stage I. The FRP used for each connection was made with one piece instead of two and the load transfer width was increased from $1 / 2$ in. to 1 in. Also, the area bonded to the top plate was increased. The specimens prepared with CFRP and GFRP are shown in Figure 3.20.
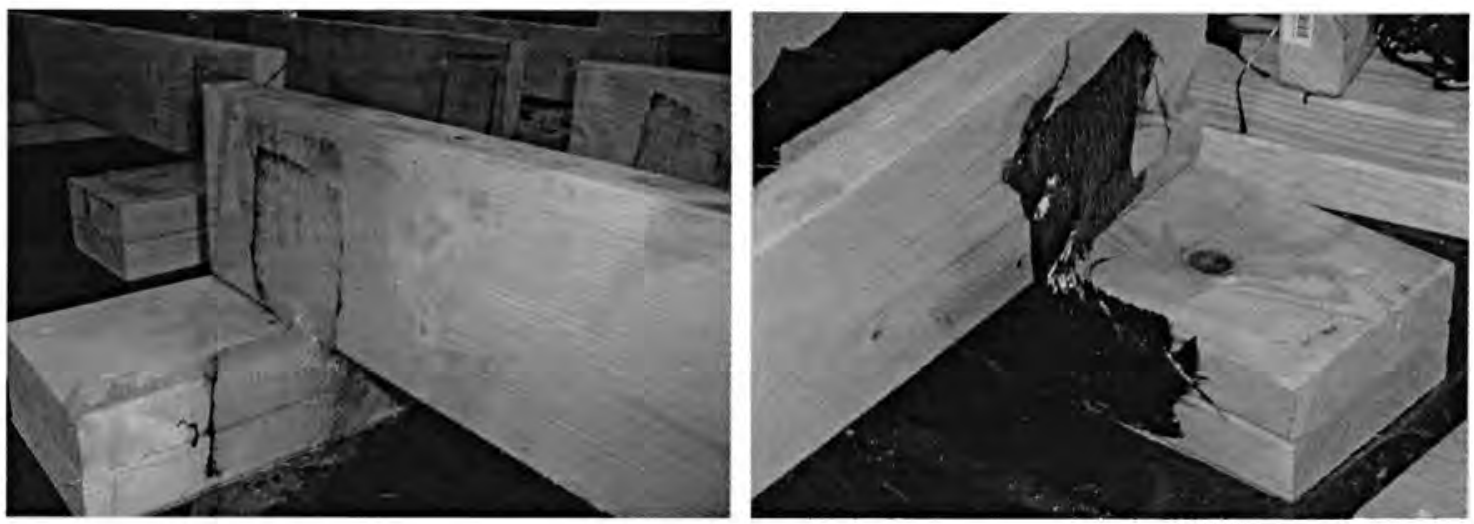

\section{Figure 3.20 - Configuration B with GFRP (left) and CFRP (right) before testing}

With configuration $\mathrm{B}$, two different modes of failure were observed as shown in Figure 3.21. In Figure 3.21a, it can be seen that the FRP under the load transferring piece peeled off as a block, while in the other specimen the load transferring piece ruptured and a portion of FRP separated from the top plate (Figure 3.21b).

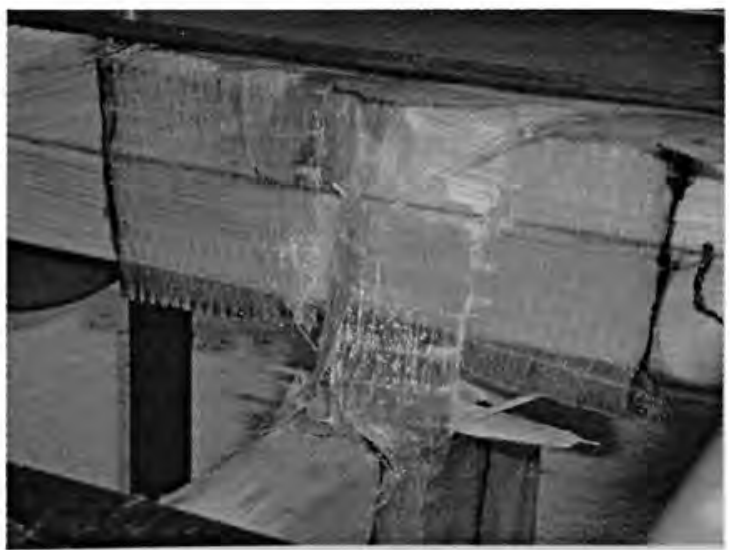

(a)

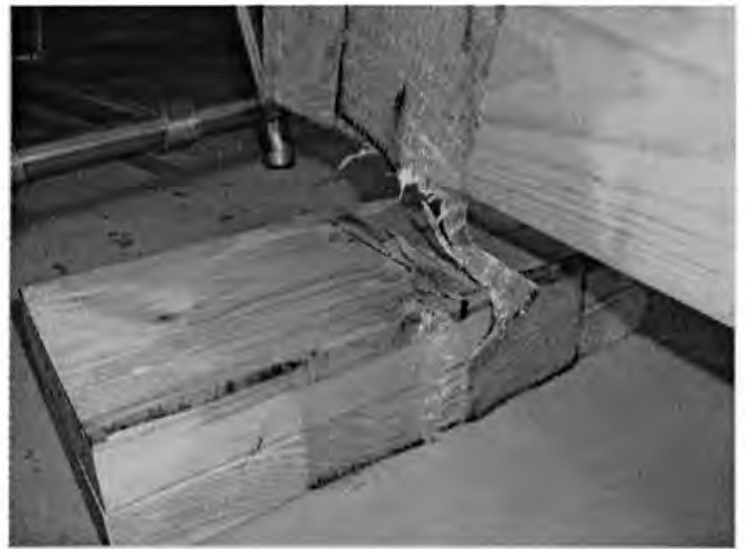

(b)

Figure 3.21 - Two modes of failure observed in Configuration B 
Connections $\mathrm{C}$ was made using bidirectional glass or carbon FRP to improve the mode of failure that was observed in Configurations III of Stage I. The L shaped FRP was placed on each side at the end of the joist, as shown in Figure 3.22.
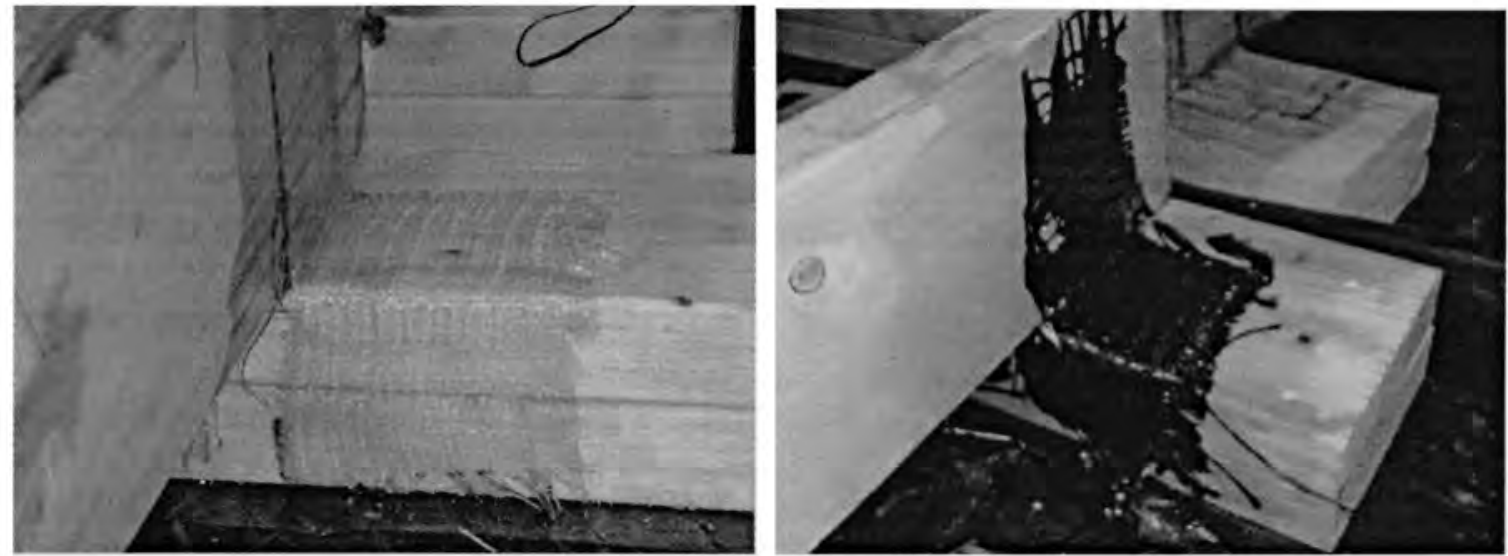

Figure 3.22 - Configuration C with GFRP (left) and CFRP (right) before testing

The mode of failure was very similar in specimens prepared with GFRP and CFRP. The connection failed as the FRP ruptured along the bent line on the top plate, and subsequently peeled off (Figure 3.23).
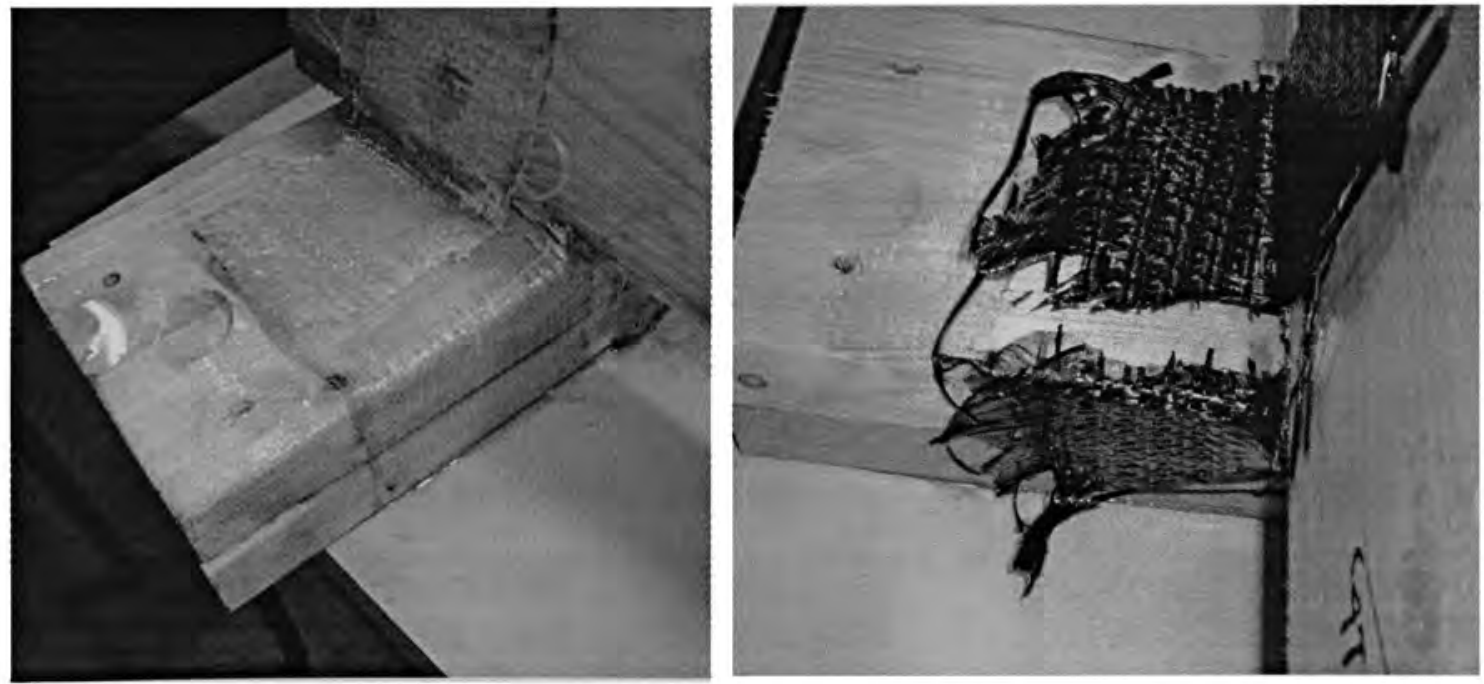

Figure 3.23 - Failure of Configurations C with GFRP (left) and CFRP (right) 
The results obtained from all tests conducted at Stage II are summarized in Table 3.3. Test results are also depicted in Figure 3.24. It can be seen that Configurations A yielded more favorable results, when compared to the others. The failure loads obtained with CFRP were $20 \%$ higher. Still, considering the fact that the price of CFRP tie is approximately 5 times higher than that of GFRP tie, Configuration A with GFRP was selected as the best alternative for further development. A cost analysis based on the quotes obtained from a local supplier of FRP and epoxy materials and the manufacturer data sheets was prepared for Configuration A with GFRP and CFRP, as listed in Table 3.3. The resin consumption rate used here was not measured during the experiments, but was rather obtained from manufacturer data sheets.

It should be noted that Florida Building Code (FBC 2004, Section 2321.7) requires a minimum design uplift load of $700 \mathrm{lbs}$ with four $16 \mathrm{~d}$ nails in each member for wood to wood anchorages in High Velocity Hurricane Zones (HVHZ). Also, hurricane clip manufacturers generally use a factor of safety of 3 for their products to meet code requirements. These two factors translate into a minimum uplift capacity of $2,100 \mathrm{lbs}$ per connection or 4,200 lbs for the type of the specimens tested in Stages I and II. Therefore, only Configuration A (GFRP and CFRP) and C (CFRP) met the minimum threshold of 4,200 lbs.

Table 3.3 - Cost analysis for Configuration A with GFRP and CFRP

\begin{tabular}{|c|c|c|c|c|}
\hline $\begin{array}{c}\text { Type of FRP } \\
\text { Used }\end{array}$ & $\begin{array}{c}\text { Price of FRP } \\
\text { without epoxy } \\
\left(\$ / \mathbf{i n}^{2}\right)\end{array}$ & $\begin{array}{c}\text { Resin } \\
\text { Consumption } \\
\left.\text { (gal/in }^{2}\right)\end{array}$ & $\begin{array}{c}\text { Price of Epoxy } \\
\text { for 4 Gallons } \\
\text { Kit } \mathbf{( \$ )}\end{array}$ & $\begin{array}{c}\text { Cost of a } \\
\text { Single FRP Tie } \\
\text { with Epoxy (\$) }\end{array}$ \\
\hline GFRP & 0.013 & 0.0001102 & 272.41 & 0.73 \\
\hline CFRP & 0.0123 & 0.0001102 & 272.41 & 4.71 \\
\hline
\end{tabular}


Table 3.4 - Results of tests conducted at FRP tie development Stage II

\begin{tabular}{|c|c|c|c|c|c|}
\hline Configuration & $\begin{array}{l}\text { FRP } \\
\text { Type }\end{array}$ & $\begin{array}{c}\text { Specimen } \\
\text { No. }\end{array}$ & $\begin{array}{l}\text { Ultimate } \\
\text { Load (lbs) }\end{array}$ & $\begin{array}{c}\text { Average } \\
\text { Ultimate } \\
\text { Load (lbs) }\end{array}$ & $\begin{array}{c}\text { Coefficient } \\
\text { of } \\
\text { Variation }\end{array}$ \\
\hline \multirow{6}{*}{ A } & \multirow{3}{*}{ GFRP } & AG1 & 4,650 & \multirow{3}{*}{4,320} & \multirow{3}{*}{0.089} \\
\hline & & AG2 & 3,900 & & \\
\hline & & AG3 & 4,410 & & \\
\hline & \multirow{3}{*}{ CFRP } & $\mathrm{ACl}$ & 5,280 & \multirow{3}{*}{5,187} & \multirow{3}{*}{0.022} \\
\hline & & $\mathrm{AC} 2$ & 5,220 & & \\
\hline & & $\mathrm{AC} 3$ & 5,060 & & \\
\hline \multirow{6}{*}{ B } & \multirow{3}{*}{ GFRP } & BG1 & 3,000 & \multirow{3}{*}{2,273} & \multirow{3}{*}{0.277} \\
\hline & & $\mathrm{BG} 2$ & 1,870 & & \\
\hline & & BG3 & 1,950 & & \\
\hline & \multirow{3}{*}{ CFRP } & $\mathrm{BC} 1$ & 2,530 & \multirow{3}{*}{3,067} & \multirow{3}{*}{0.251} \\
\hline & & $\mathrm{BC} 2$ & 3,950 & & \\
\hline & & $\mathrm{BC} 3$ & 2,720 & & \\
\hline \multirow{6}{*}{$\mathrm{C}$} & \multirow{3}{*}{ GFRP } & CG1 & 4,070 & \multirow{3}{*}{3,200} & \multirow{3}{*}{0.238} \\
\hline & & CG2 & 2,660 & & \\
\hline & & CG3 & 2,870 & & \\
\hline & \multirow{3}{*}{ CFRP } & $\mathrm{CCl}$ & 3,880 & \multirow{3}{*}{4,490} & \multirow{3}{*}{0.124} \\
\hline & & $\mathrm{CC} 2$ & 4,620 & & \\
\hline & & $\mathrm{CC} 3$ & 4,970 & & \\
\hline
\end{tabular}




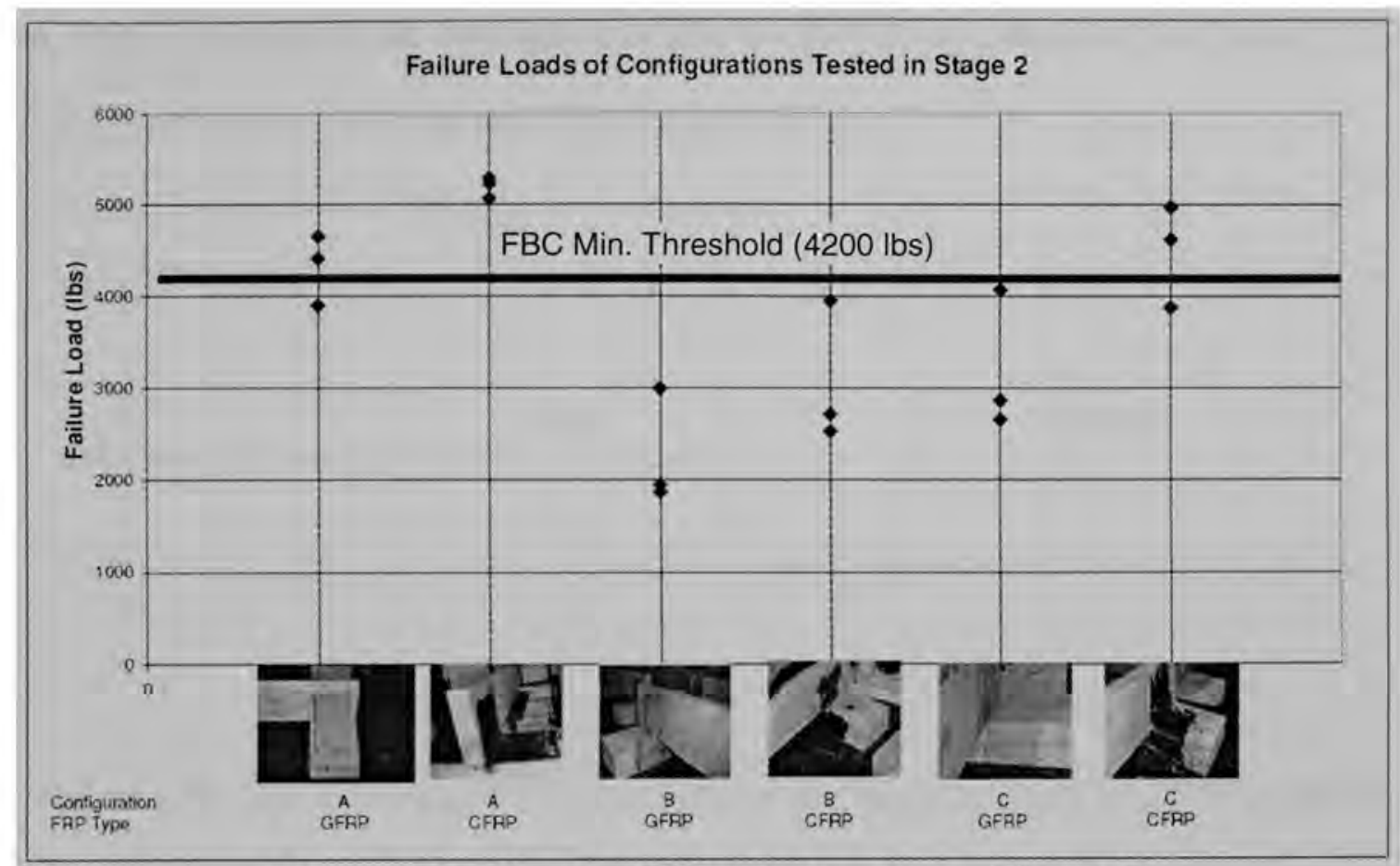

Figure 3.24 - Results of FRP tie development Stage II

\subsection{4 - FRP Tie Development: Stage III}

Configuration A with GFRP was selected as the most feasible alternative from

Stage II. In the third stage, the goal was to seek ways to strengthen this configuration and to assess the performance of the connection for different types of lumber and different sizes of FRP ties. Also, a separate set of tests was performed to determine the capacity of FRP tie when it is subjected to lateral load.

In the previous stage, it was seen that failure of Configuration A with GFRP occurred with peeling of FRP from the top plate. In order to overcome this problem, specimens having a larger FRP-wood connection area on the top plate were prepared. For this set of experiments, the top plates of specimens were increased to 23 in. and the length of one FRP tie was increased to 14 in. The portion of FRP which is placed on the joist remained the same at 4.5 in., while the potion on the top plate was increased to 9.5 
in. The schematics of the new specimen and the FRP tie are shown in the Figure 3.25.

Figure 3.26 shows one of the specimens before testing.

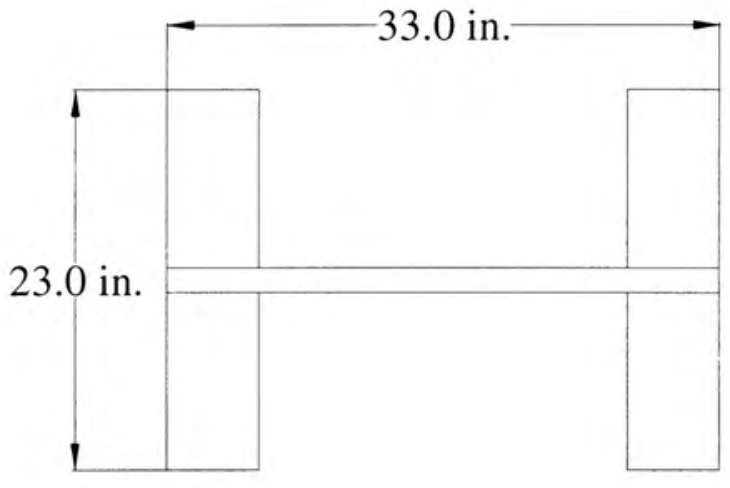

(a)

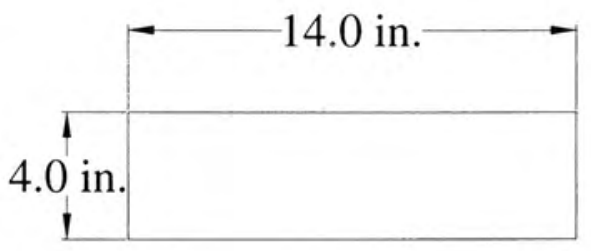

(b)

Figure 3.25 - (a) Top view of test specimen to accommodate longer ties, (b) Longer

FRP tie

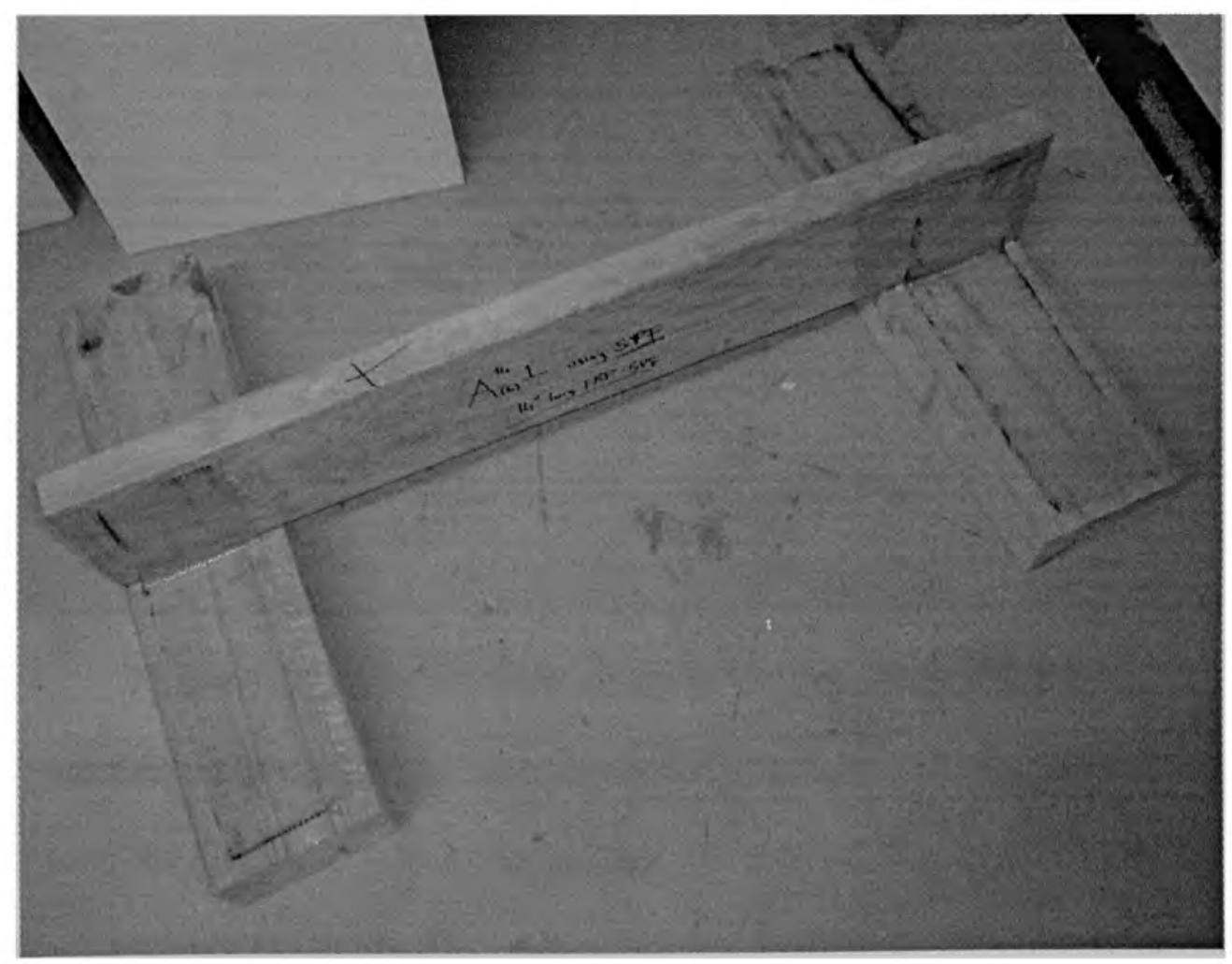

Figure 3.26 - Specimen with longer FRP ties 
Three tests were conducted with each SPF and SYP. The mode of failure changed from peeling off of FRP on the top plate to bond failure of FRP placed on the joist in shear (Figure 3.27). However, there was almost no increase in the ultimate load as compared to the specimens with shorter FRP ties. Also, it was seen that the results obtained from specimens with SPF wood were higher and more consistent than those with SYP wood.

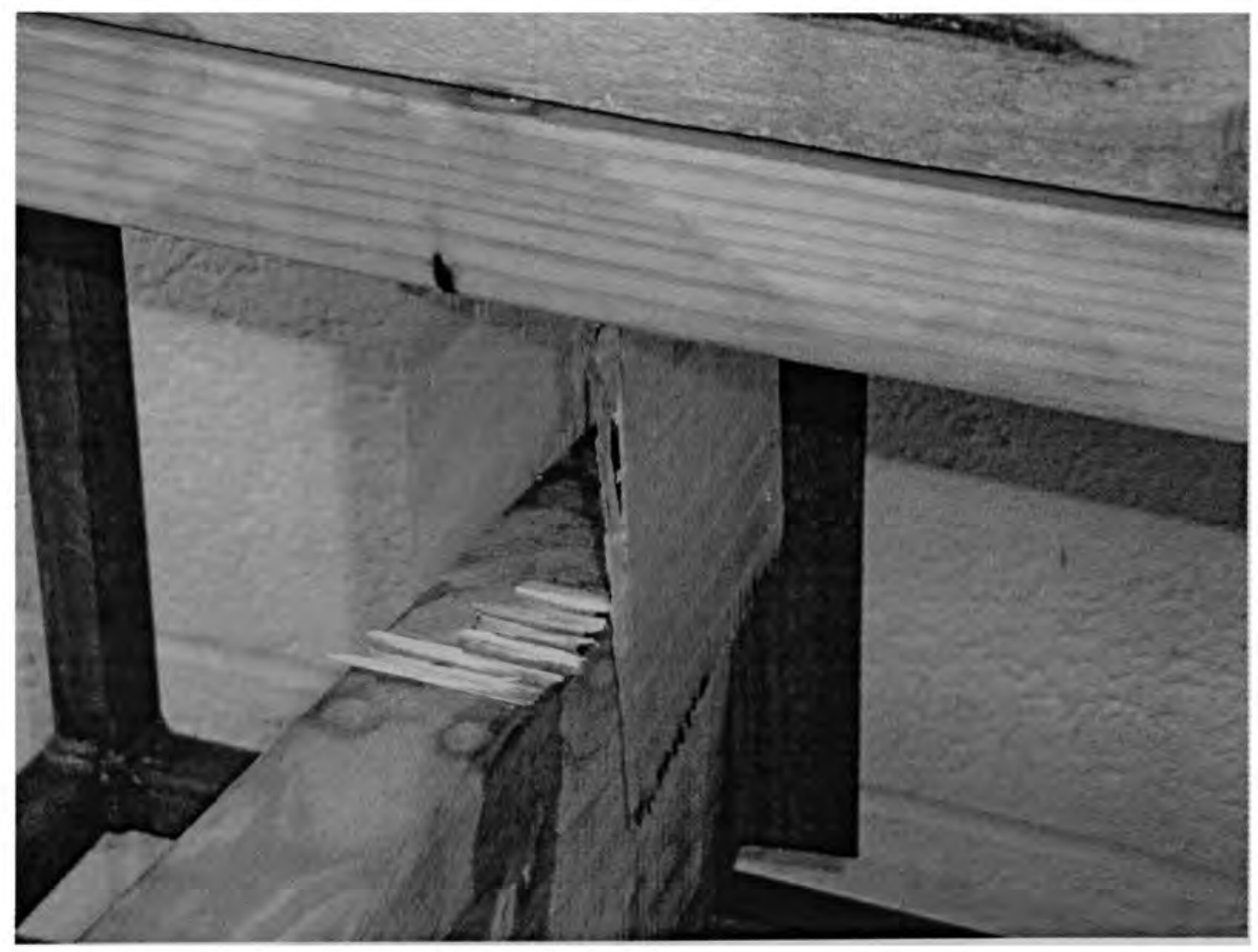

Figure 3.27 - Shear failure of specimen with longer FRP ties

Another method used for strengthening of Configuration A was using straps to further wrap the FRP tie and the top plate. The aim of using straps was altering the mode of failure by increasing the bonded area on the top plate. The FRP tie was the same as that in Configuration A of Stage II. In addition, an 8 in. $x 4$ in. FRP piece was placed on 
the portion of the tie on the top plate. It was noted that the strap worked quite well in terms of changing the mode of failure and holding the FRP tie onto the top plate. However, the increase in the ultimate load was not significant. The mode of failure was identified as bond failure in shear on the plane where FRP is connected to the joist (Figures 3.28 and 3.29). Again, the specimens prepared with SYP wood yielded a lower average ultimate load with a larger scatter, as compared with those with SPF wood.

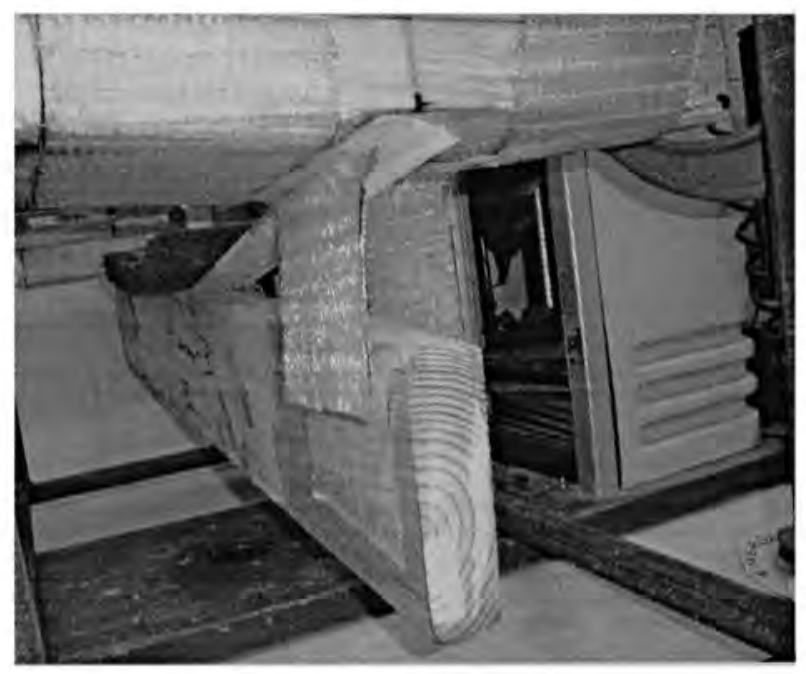

Figure 3.28 - Failure of specimen strengthened with straps

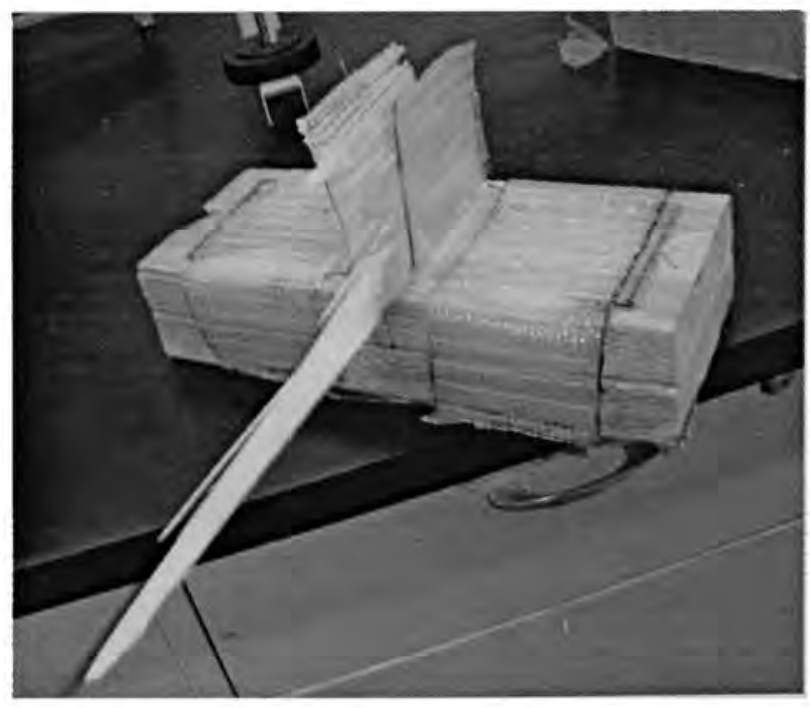

Figure 3.29 - One of the top plates after testing 
A set of test was conducted to see the trend in the ultimate load, when one FRP tie of Configuration A was used per top plate instead of two. The FRP ties were placed diagonally at two ends of the joist. It was seen that the ultimate failure load decreased by about $25 \%$ as compared to the specimens with two ties on each top plate. The mode of failure remained the same as FRP ties peeled off from the top plate (Figure 3.30).

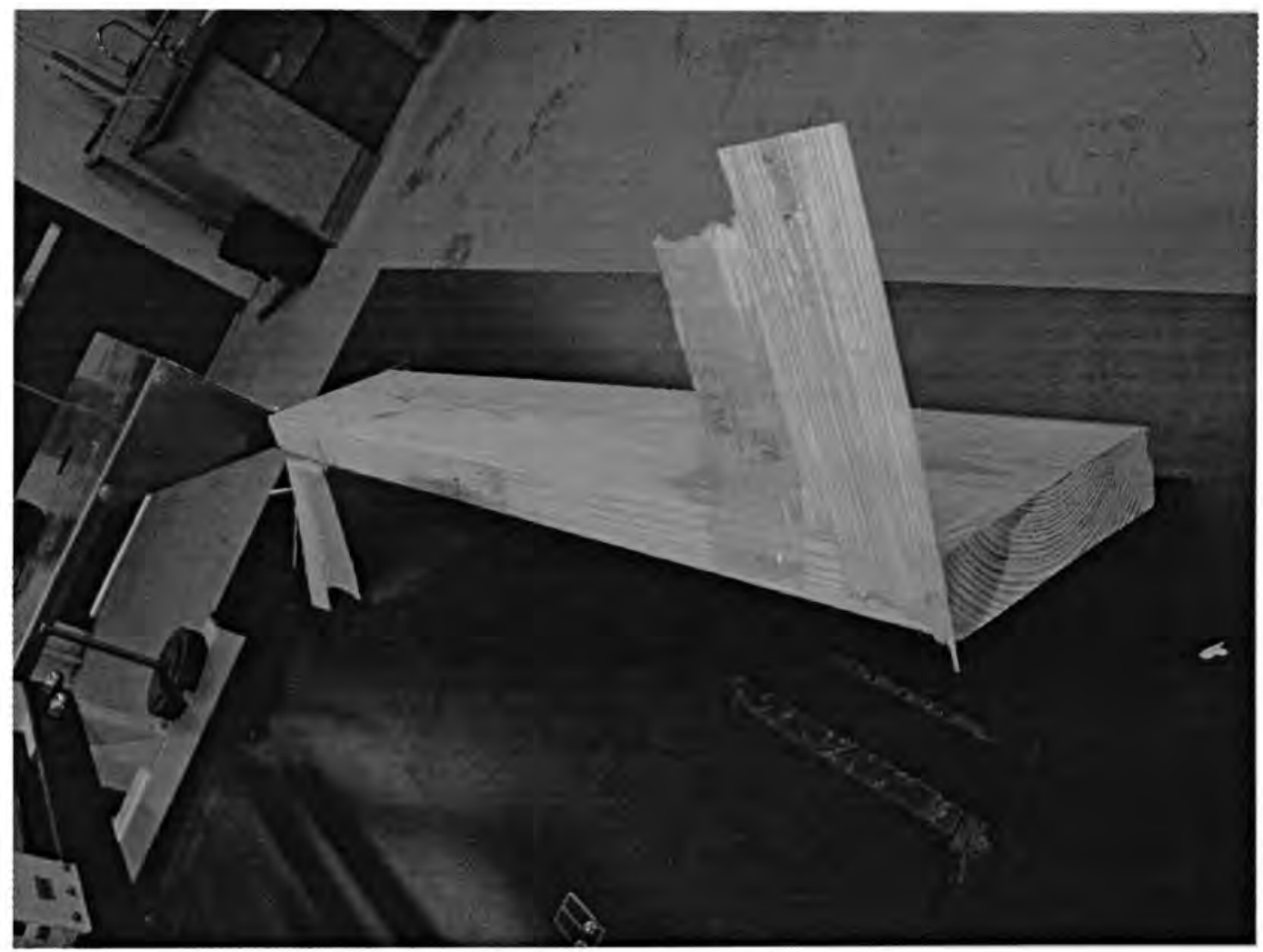

Figure 3.30 - Joist separating from top plates with FRP ties peeled off

The same set of tests for Configuration A in Stage II was conducted with SYP wood to evaluate the effect of wood type. Even though the mode of failure was the same, the ultimate loads of specimens with SYP wood were notably lower than those with SPF wood. Moreover, the amount of wood fibers peeling off from the top plate was very little for SYP wood (Figure 3.31). 


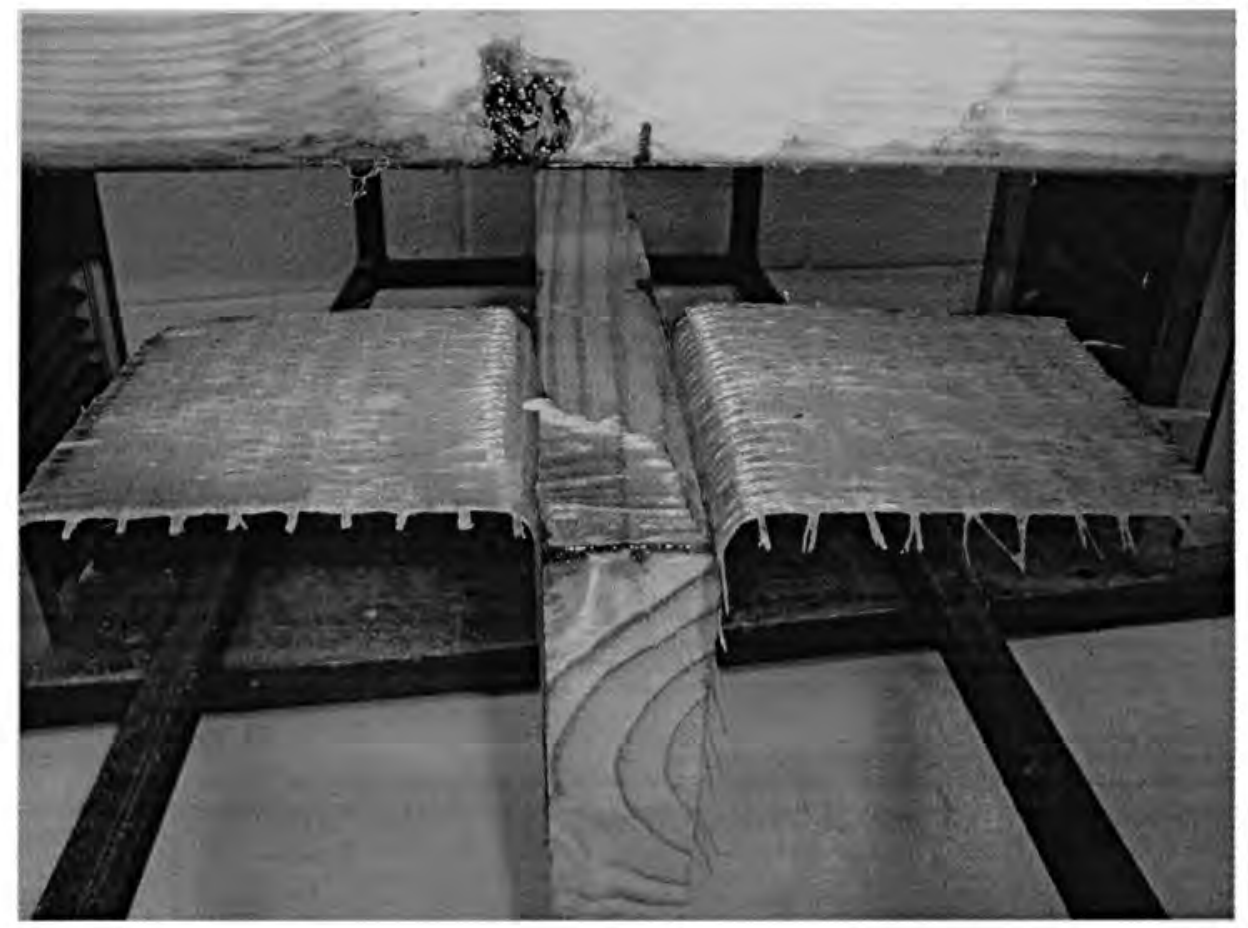

Figure 3.31 - Failure of specimen with SYP wood

For investigating the performance of Configuration under lateral loads, a test setup was adopted similar to that commonly used by hurricane clip manufacturers. Two ties were placed at the centerline of the nominal 2 in. $x 10$ in. SYP wood, as shown in Figures 3.32 and 3.33. The load was applied using an inverted U-shaped wood element (Figure 3.34).

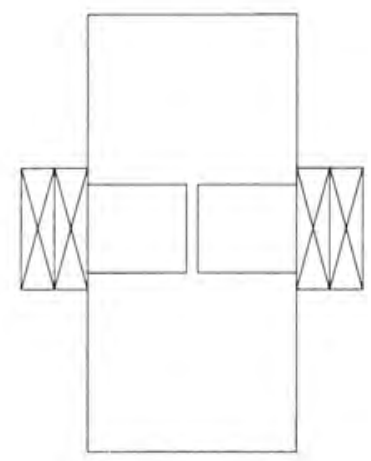

Top View

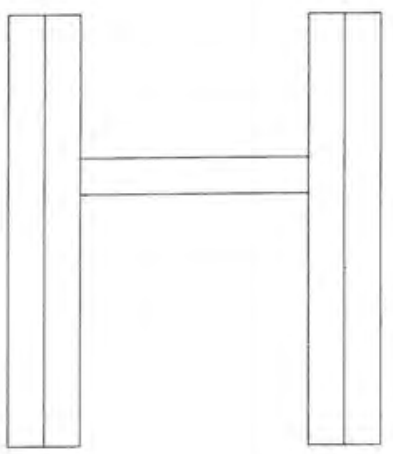

Side View

Figure 3.32 - Top and side views of specimen tested for lateral loading 


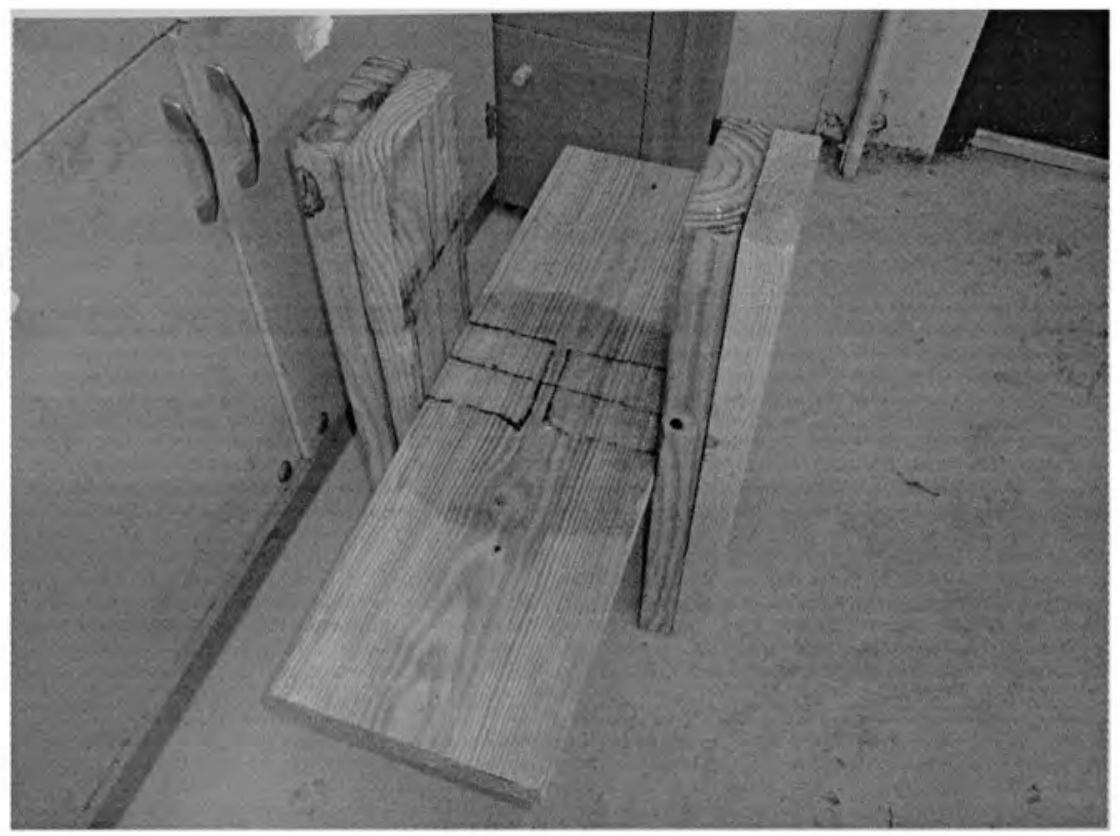

Figure 3.33 - Specimen used for lateral loading tests

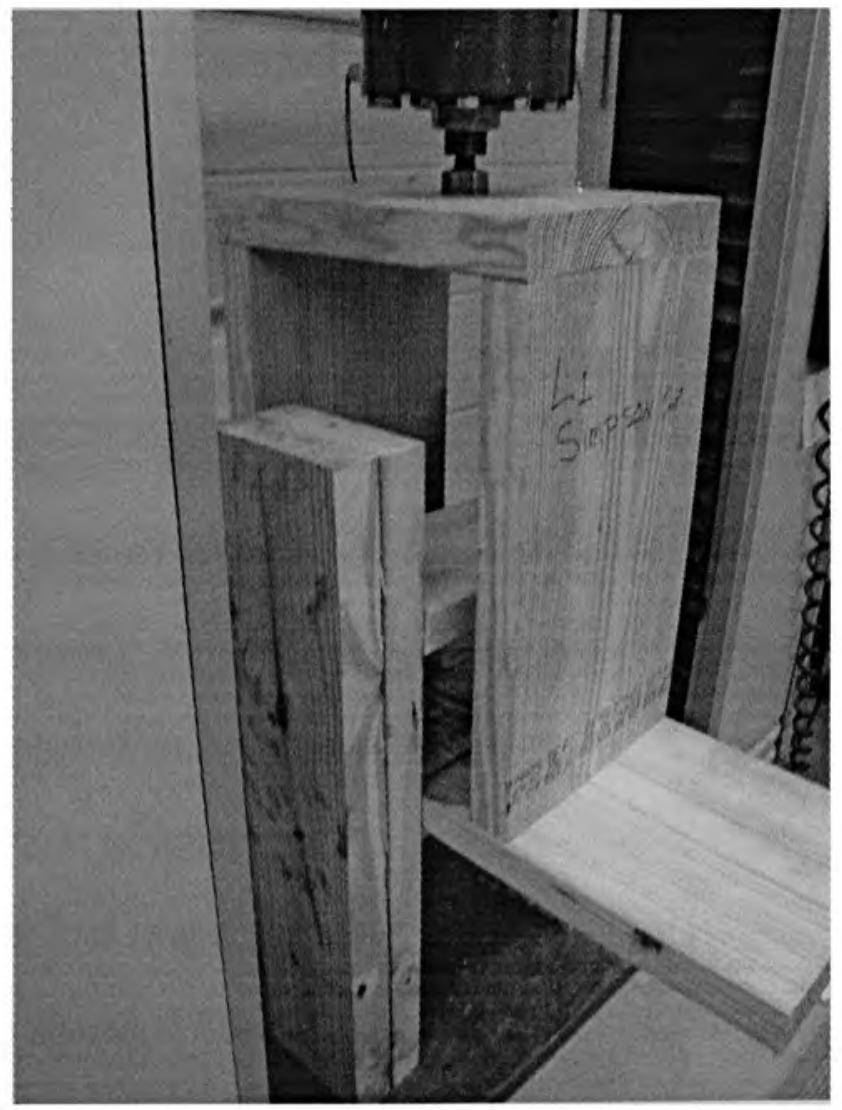

Figure 3.34 - Application of load in lateral loading test 
The average ultimate load of the three specimens was 2,290 lbs, yielding a value of $1,145 \mathrm{lbs}$ per connection in the lateral direction. This value is much higher than the lateral capacity of most hurricane clips. Generally speaking, the allowable lateral load for hurricane clips is in the range of 100 to $200 \mathrm{lbs}$. The typical mode of failure for FRP ties is shown in Figure 3.35, which clearly is peeling off.

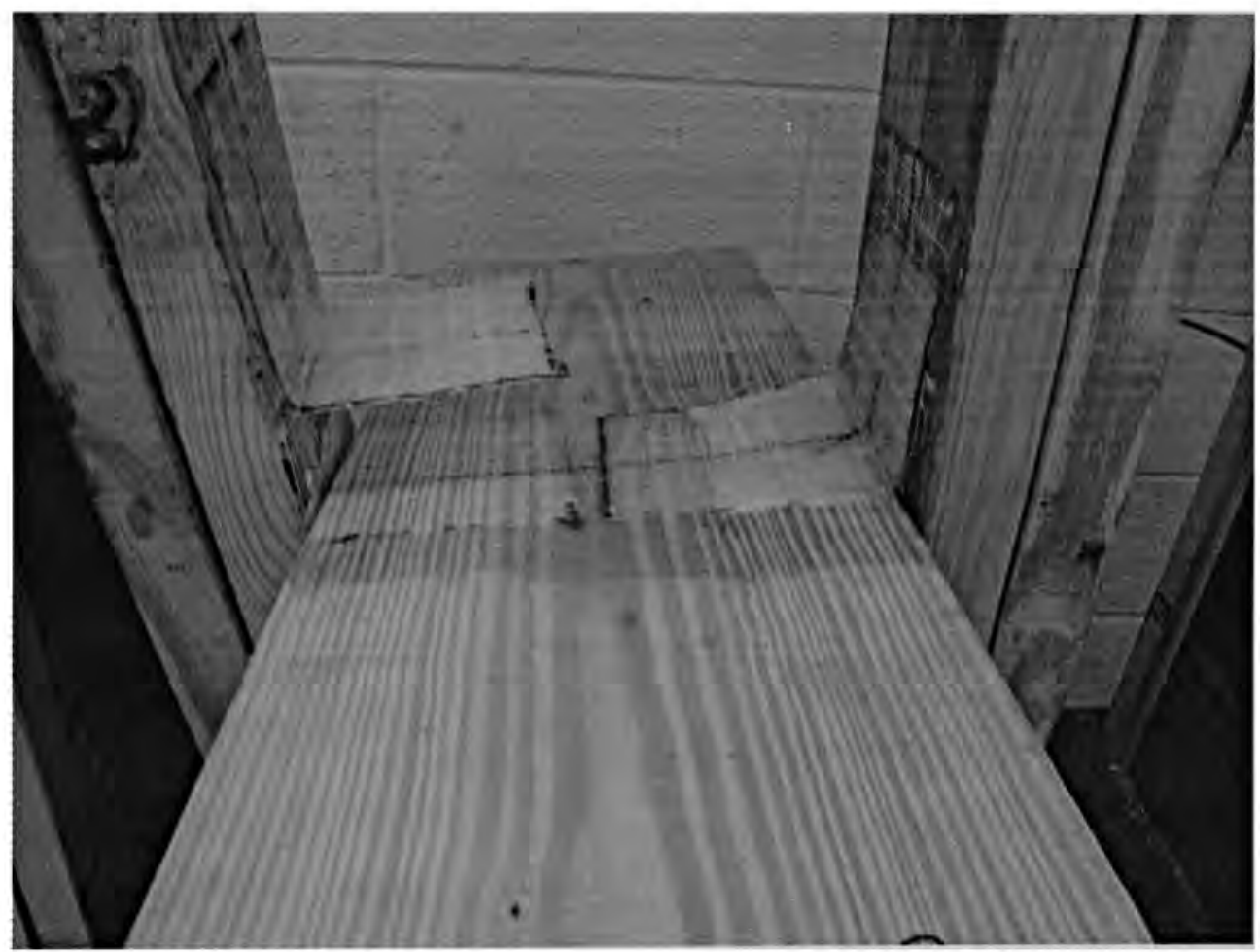

Figure 3.35 - Typical mode of failure under lateral loading

The results obtained from all of the tests conducted in this stage are summarized in Table 3.4. In Configuration A, the area of FRP placed on the joist and on the top plate was equal and the mode of failure was peeling off (Mode I) of FRP on the top plate. In tests with longer ties and straps, the FRP area on the top plates was increased and the mode of failure was altered to bond failure of FRP on the joist in shear (Mode II). Since there was a little increase in the ultimate loads of configurations with longer ties and 
straps as compared with original configuration, it can be concluded that FRP-wood bond strength in Mode I and Mode II are quite close. Also, the tests with SYP indicate that type of wood has a considerable effect on the bond strength of FRP-wood interface. Test results with SYP wood were notably lower than those with SPF wood, and the scatter of results for SYP wood was higher as compared to those with SPF wood.

Table 3.5 - Results of FRP tie development: Stage III

\begin{tabular}{|c|c|c|c|c|c|c|c|}
\hline Configuration & $\begin{array}{l}\text { FRP } \\
\text { Type }\end{array}$ & $\begin{array}{c}\text { FRP } \\
\text { System }\end{array}$ & $\begin{array}{l}\text { Wood } \\
\text { Type }\end{array}$ & $\begin{array}{c}\text { Specimen } \\
\text { No. }\end{array}$ & $\begin{array}{c}\text { Ultimate } \\
\text { Load } \\
\text { (lbs) }\end{array}$ & $\begin{array}{c}\text { Average } \\
\text { Ultimate } \\
\text { Load } \\
\text { (lbs) }\end{array}$ & $\begin{array}{c}\text { Coefficient } \\
\text { of } \\
\text { Variation }\end{array}$ \\
\hline \multirow{3}{*}{ A } & \multirow{3}{*}{ GFRP } & \multirow{3}{*}{$\begin{array}{l}\text { Same } \\
\text { as } \\
\text { Stage } \\
\text { II } \\
\end{array}$} & \multirow{3}{*}{ SYP } & 1 & 2,950 & \multirow{3}{*}{3,033} & \multirow{3}{*}{0.042} \\
\hline & & & & 2 & 2,970 & & \\
\hline & & & & 3 & 3,180 & & \\
\hline \multirow{3}{*}{ A } & \multirow{3}{*}{ GFRP } & \multirow{3}{*}{$\begin{array}{l}\text { Two } \\
\text { Ties }\end{array}$} & \multirow{3}{*}{ SPF } & 1 & 3,480 & \multirow{3}{*}{3,313} & \multirow{3}{*}{0.100} \\
\hline & & & & 2 & 3,530 & & \\
\hline & & & & 3 & 2,930 & & \\
\hline \multirow{3}{*}{ A } & \multirow{3}{*}{ GFRP } & \multirow{3}{*}{ Straps } & \multirow{3}{*}{ SPF } & 1 & 4,710 & \multirow{3}{*}{4,650} & \multirow{3}{*}{0.080} \\
\hline & & & & 2 & 4,990 & & \\
\hline & & & & 3 & 4,250 & & \\
\hline \multirow{3}{*}{ A } & \multirow{3}{*}{ GFRP } & \multirow{3}{*}{ Straps } & \multirow{3}{*}{ SYP } & 1 & 5,930 & \multirow{3}{*}{4,117} & \multirow{3}{*}{0.401} \\
\hline & & & & 2 & 2,700 & & \\
\hline & & & & 3 & 3,720 & & \\
\hline \multirow{3}{*}{ A } & \multirow{3}{*}{ GFRP } & \multirow{3}{*}{$\begin{array}{l}\text { Long } \\
\text { Ties }\end{array}$} & \multirow{3}{*}{ SPF } & 1 & 4,420 & \multirow{3}{*}{4,343} & \multirow{3}{*}{0.063} \\
\hline & & & & 2 & 4,040 & & \\
\hline & & & & 3 & 4,570 & & \\
\hline \multirow{3}{*}{ A } & \multirow{3}{*}{ GFRP } & \multirow{3}{*}{$\begin{array}{l}\text { Long } \\
\text { Ties }\end{array}$} & \multirow{3}{*}{ SYP } & 1 & 3,460 & \multirow{3}{*}{4,143} & \multirow{3}{*}{0.147} \\
\hline & & & & 2 & 4,340 & & \\
\hline & & & & 3 & 4,630 & & \\
\hline
\end{tabular}

Test results from Stage III clearly show that straps and longer ties did not make a significant contribution commensurate with the increase in the additional FRP material. Since the aim is to develop a cost-effective connection, these configurations were 
therefore eliminated. Configuration A with GFRP and SPF wood was selected as the best alternative, in terms of cost and applicability, for validation in the full-scale tests.

When the literature on roof-to-wall connections is investigated, it is seen that the FRP tie chosen for full-scale testing exceeds the uplift capacity of most of the connection types. In the study conducted by Riley and Sadek (NISTIR 6938, 2004), the maximum uplift capacity per connection was $600 \mathrm{lbs}$ for the toe-nailed connection and 1,056 lbs for hurricane clips. When the results of the research by Reed et al. (1997) are considered, out of 19 different configurations tested, only two exceeded the capacity of the FRP tie. It was reported that the connection formed of toe nails and experimental large strap yielded an average ultimate load of 2,740 lbs and the connection consisting of toe nails and 3.5 in x 3.5 in wood blocks attached to the sides of joist using epoxy had an average ultimate load of 2,170 lbs. However, the coefficients of variation for these types of connection were much higher than that of FRP ties.

\section{3 - Discussion of Test Results}

In Figure 3.36 the bond strengths in shear are plotted against the total bonded area. In this figure, the results obtained from direct shear tests are incorporated with the component level tests where FRP-wood bond failure mode was shearing off (longer FRP ties and ties with straps). It can be seen that increasing the bonded area decreases the bond strength at the FRP-wood interface. A natural logarithmic fit was obtained using a regression analysis for SPF specimens with an $\mathrm{R}^{2}$ value of 0.959 , as given by

$y=-205.61 \operatorname{Ln}(x)+931.79$

Equation 3.3

Where $\mathrm{x}$ is the bonded area and $\mathrm{y}$ is the bond strength in shear. 


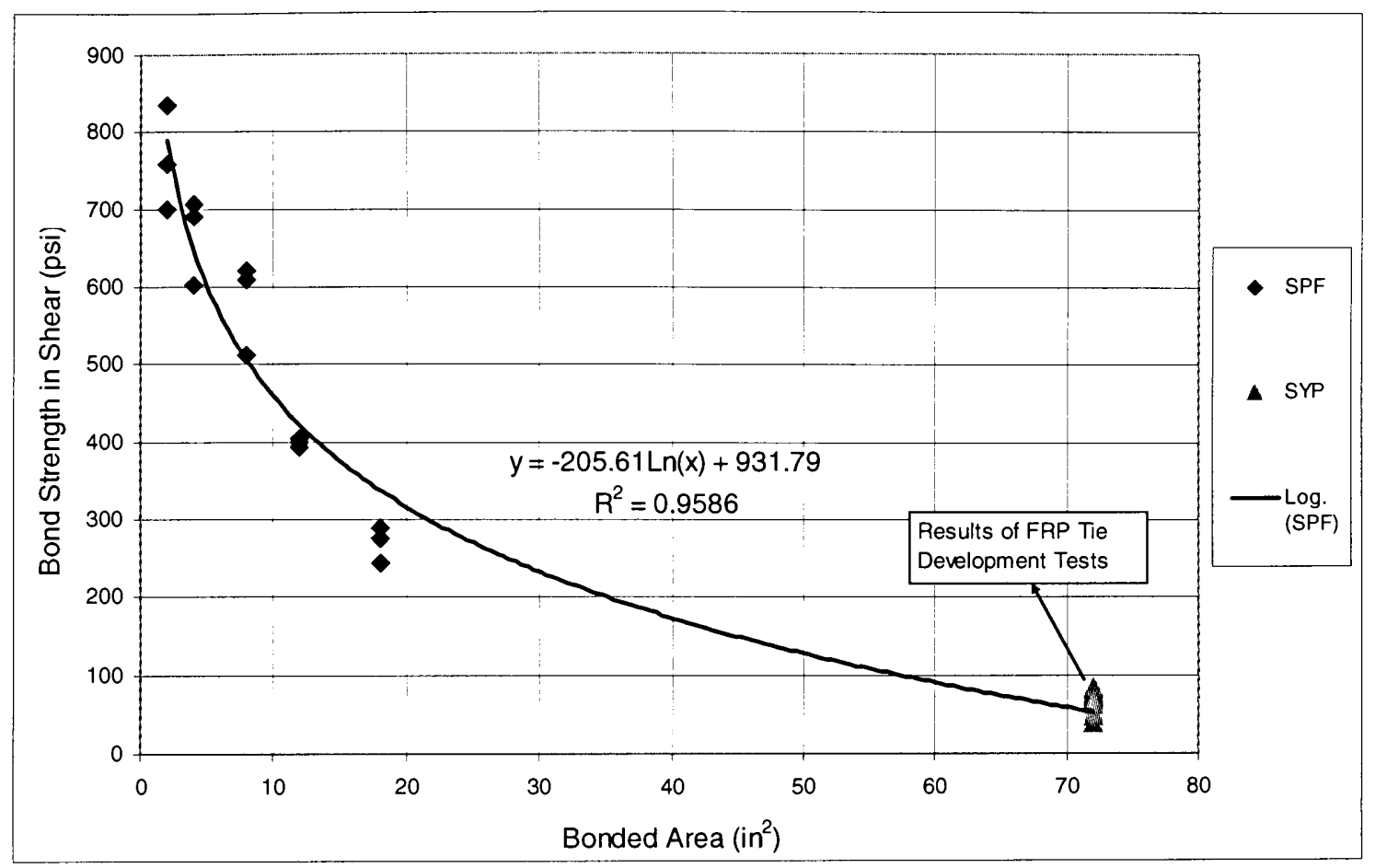

Figure 3.36 - FRP-wood bond strength in shear vs. bonded area

Figure 3.37 shows total ultimate failure load is plotted versus total bonded area. In this figure, results of direct shear tests are presented along with the FRP tie development tests in which failed as FRP sheared off from wood. As expected, the ultimate load does not increase proportional to the bonded area. After a threshold value of $9 \mathrm{in.}^{2}$, the increase in the ultimate load is little or none. The variation of ultimate load in specimens prepared with SYP wood can also be observed in the figure. A power function fit is obtained using a regression analysis for SPF specimens, with an $R^{2}$ value of 0.474 , as given by $y=2024.7 x^{0.2219}+49.52$

where $\mathrm{x}$ is the bonded area, and $\mathrm{y}$ is the total ultimate load. 


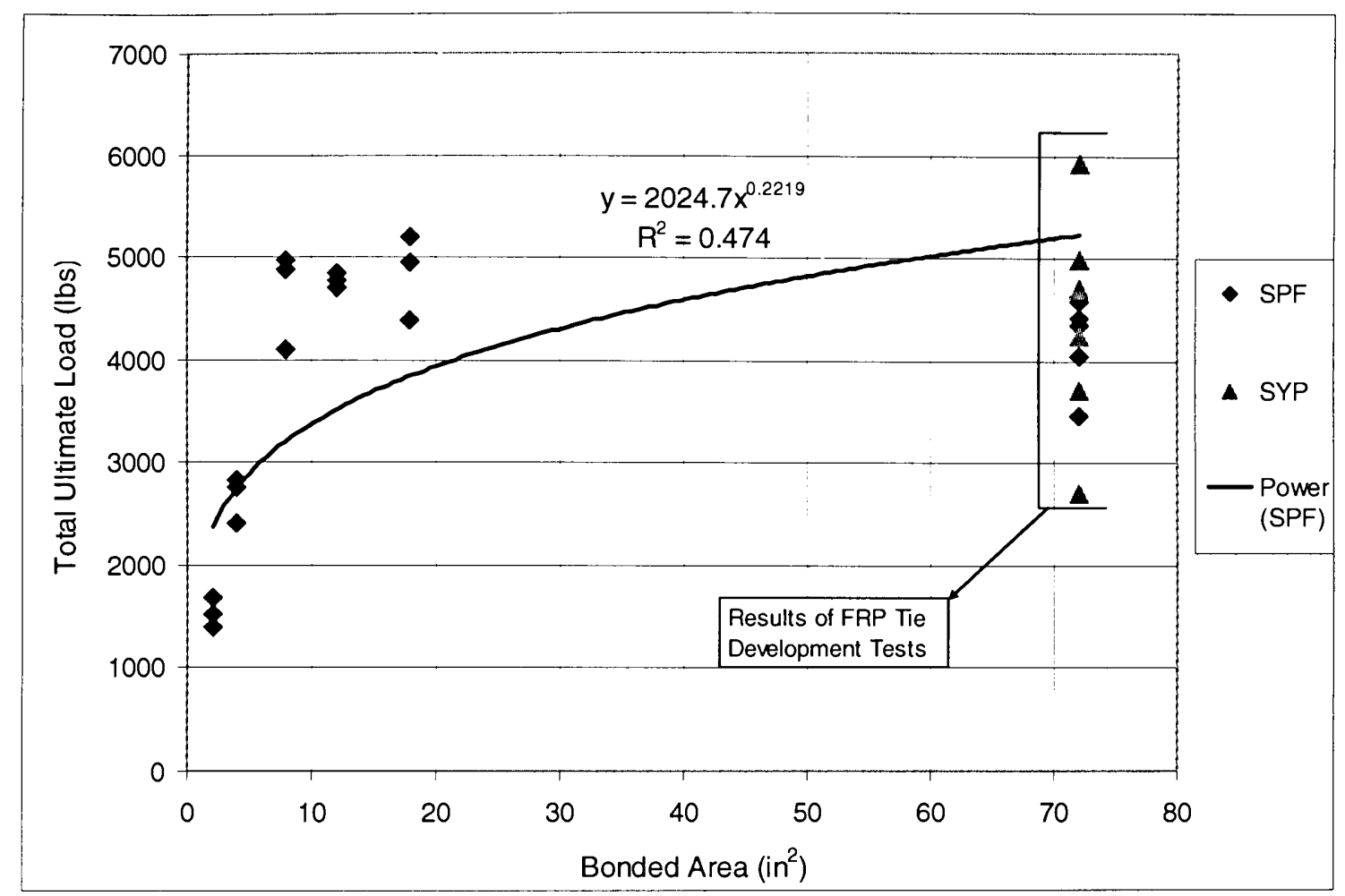

Figure 3.37 - Total ultimate load versus bonded area

In Figure 3.38, the FRP-wood bond strength in peeling is shown against the total bonded area for the specimens which failed as FRP peeled off from the top plate. It can be seen that, CFRP has a better bonding capability than GFRP. Also, SPF performs better than SYP in terms of bond strength. Moreover, a data point obtained from the study conducted by Lyons and Ahmed (2005) is included in this graph. This point represents the bond strength obtained from dry prepared specimen, which was cured in laboratory conditions and tested using a 2 in. diameter pull-off tester. A natural logarithmic fit was obtained using regression analysis for all data points with and $\mathrm{R}^{2}$ values of 0.947 , as given by

$y=-111.14 \operatorname{Ln}(x)+524.47$

Equation 3.5

Where $\mathrm{x}$ is the bonded area and $\mathrm{y}$ is the bond strength in peeling. 


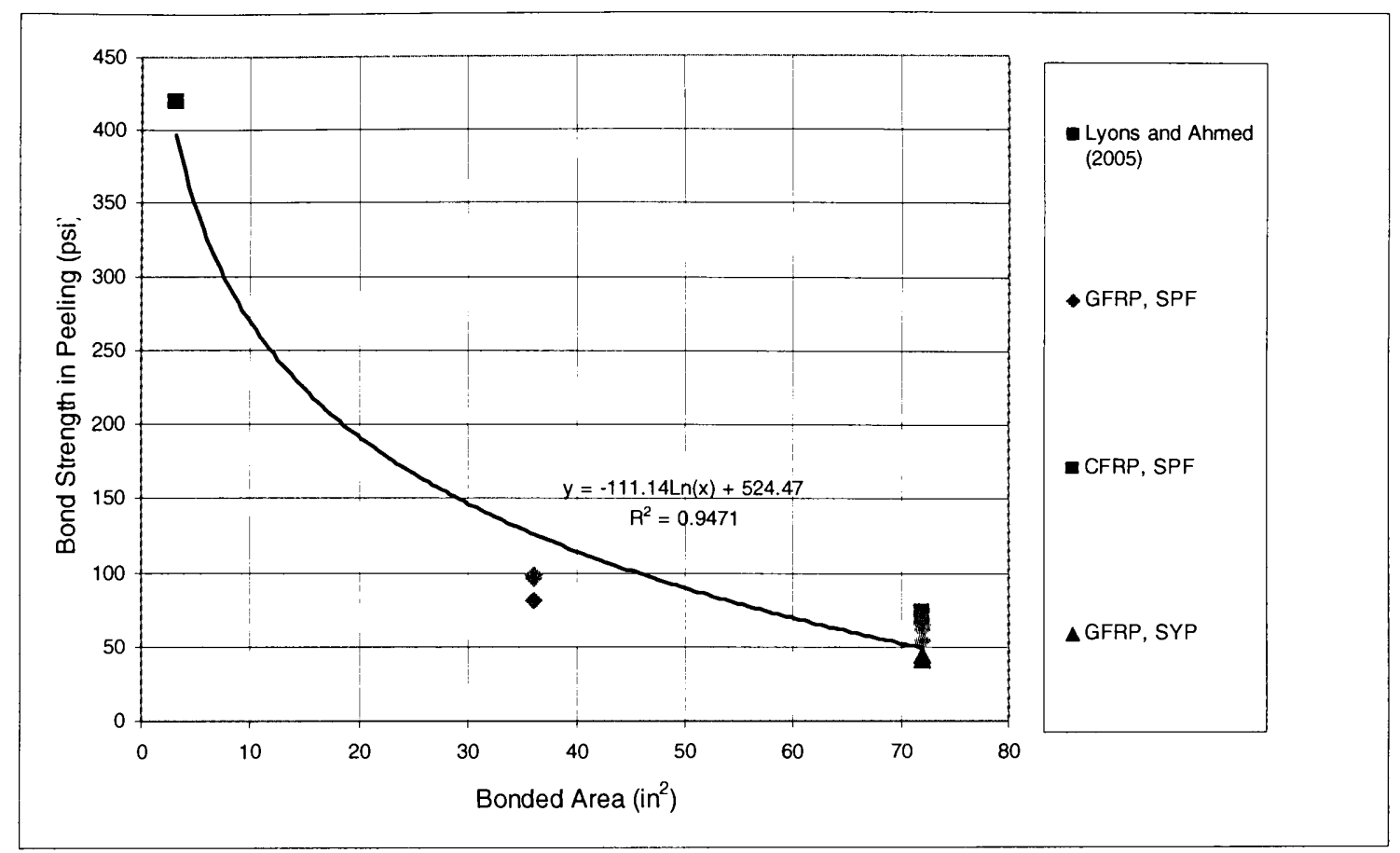

Figure 3.38 - Bond strength in peeling versus bonded area 


\section{4 -Full-Scale Testing}

A full-scale specimen was tested to evaluate the in-situ performance of the FRP tie developed in Chapter 3 under uplift forces. Test setup section describes the test specimen, application of uplift forces and instrumentation of the specimen. The results of the test and observations made are presented in the second section of the chapter.

\section{1 - Test Setup and Specimen Preparation}

In order to assess the in-situ performance of the FRP tie under uplift forces, a fullscale test was carried out. The specimen was constructed using spruce pine fir (SPF) 2 in. x 6 in. dimensional lumber with a grade of No. 2 or better. The specimen consisted of two $8 \mathrm{ft} .-3$ in. high, $8 \mathrm{ft}$. long shear walls, with a center to center spacing of $17 \mathrm{ft}$. The shear walls were supported by five $\mathrm{W}$ type trusses, as shown in Figures 4.1 and 4.2 . The shear walls had $9 \mathrm{ft}$. long double top plates, five vertical studs and a single $8 \mathrm{ft}$. long bottom plate. The double top plate had a 6 in. overhang at the ends for the placement of FRP tie (Figure 4.1, 4.2 and 4.3). The APA-rated 19/32 in. thick $4 \mathrm{ft} . \mathrm{x} 8 \mathrm{ft}$. plywood was used as sheathing on the outer walls and the roof. On the roof, the sheathing was placed such that the $8 \mathrm{ft}$. sides were parallel to the ridge. On the outer walls, the sheathing was placed such that the $8 \mathrm{ft}$. sides were parallel to the studs. The sheathing was attached to the roof and the outer walls using \#8 size, 2 in. long screws spaced every 6 in. 


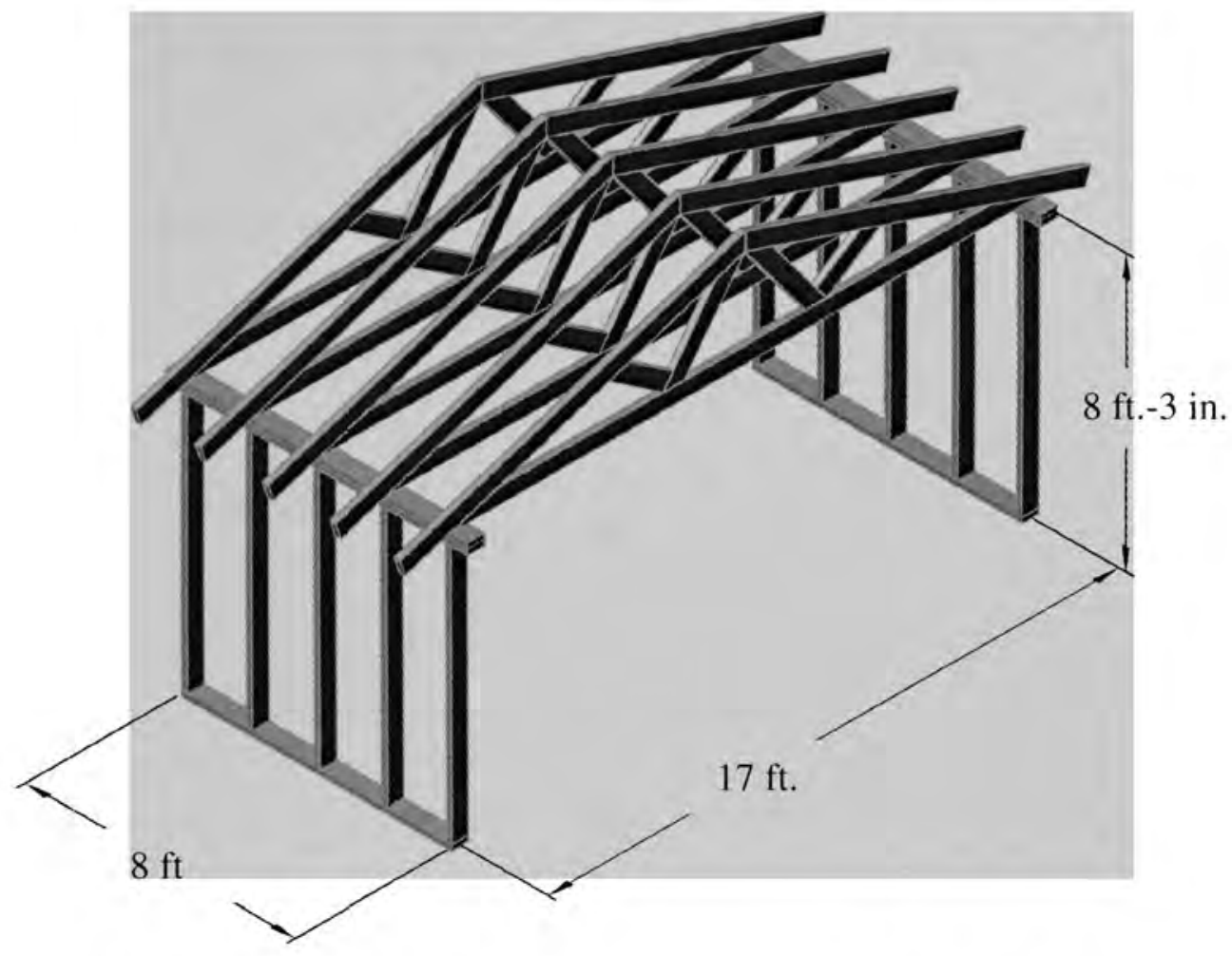

Figure 4.1 - The full-scale test specimen without sheathing

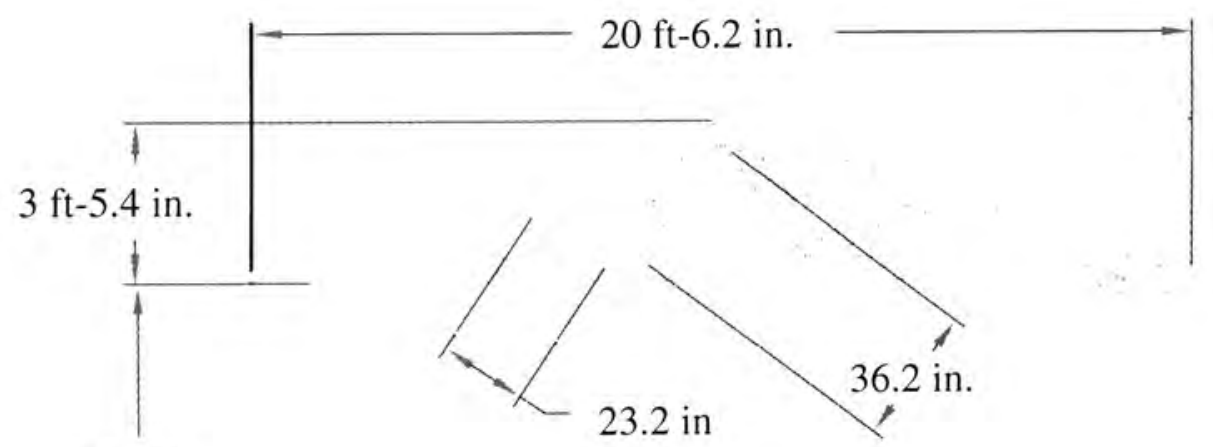

$8 \mathrm{ft} .-3 \mathrm{in}$.

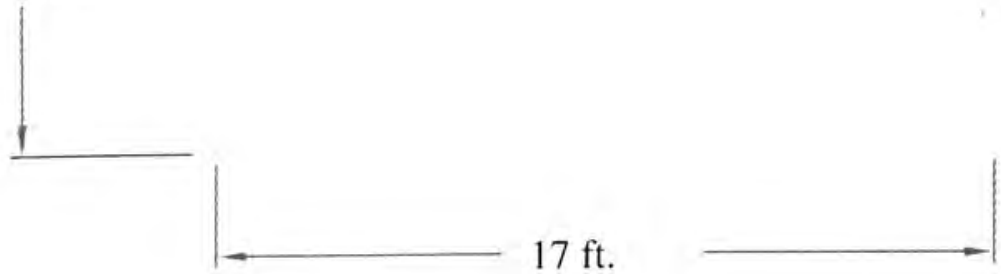

Figure 4.2 - Front view of test specimen 


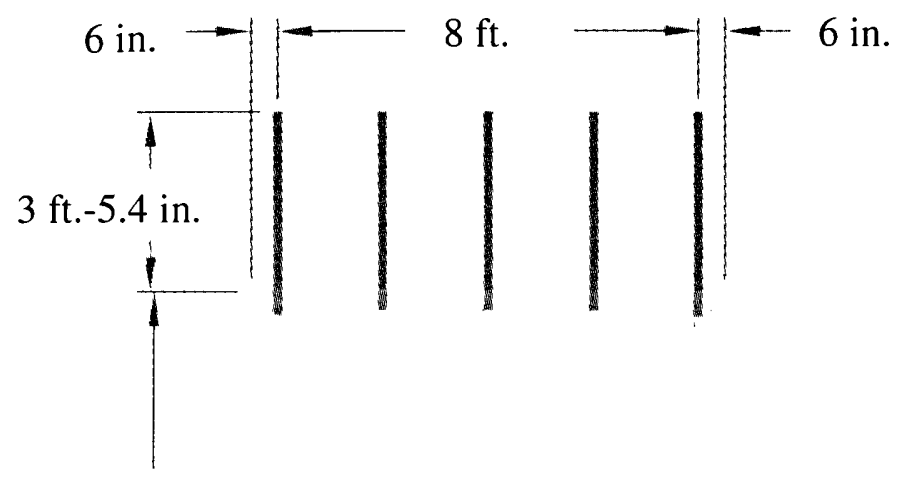

$8 \mathrm{ft} .-3$ in.

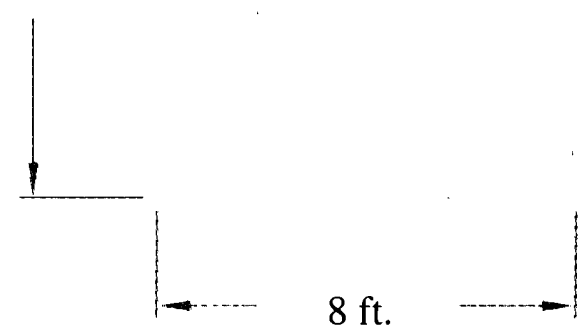

Figure 4.3 - Side view of test specimen

The specimen was constructed by a professional carpenter. Some parts of the structure were intentionally strengthened beyond normal construction practice to ensure failure is limited to the FRP connection. U-shaped straps were used at the top and bottom of shear walls to connect the plates to the studs using twelve 1.5 in. long $10 \mathrm{~d}$ nails. Also, the possible separation of double top plate was avoided using a U-shaped metal connector holding the top plates together by nine $1.5 \mathrm{in}$. long $8 \mathrm{~d}$ nails spaced at $24 \mathrm{in}$. (Figure 4.4). Moreover, the ridge on the roof was strengthened using V-shaped metal straps to avoid opening up at high loads. 


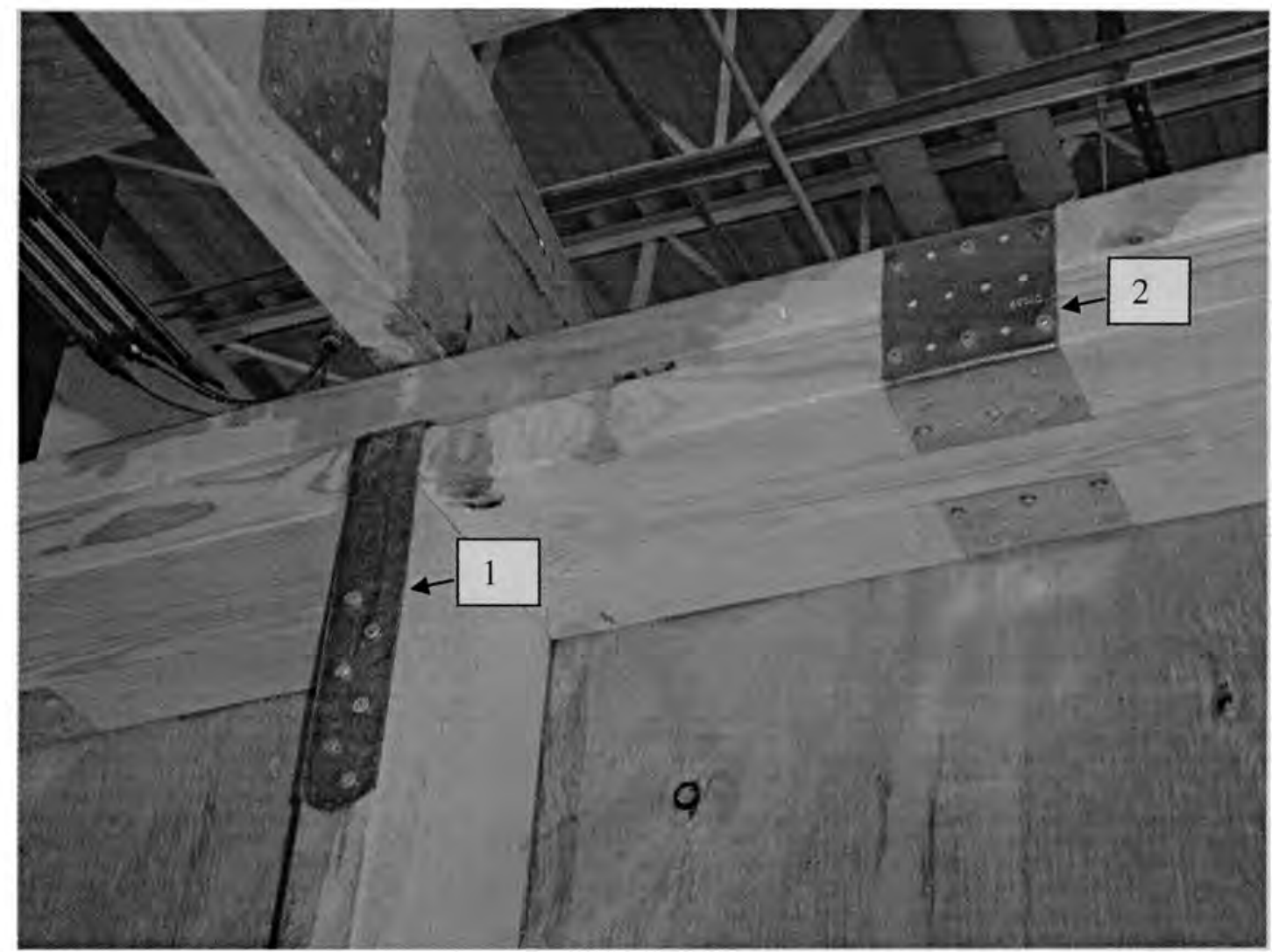

Figure 4.4 - (1) Strap holding the stud and the lower top plate together; and (2) Ushaped metal plates holding the upper and lower top plates together

The test specimen was affixed to the strong floor in the laboratory using two steel channel sections under the two shear walls, using bolts on the bottom plate spaced at 24 in. The load was applied onto the roof using 8 hydraulic jacks connected to a single electric pump equipped with a speed control valve. Four of the jacks were applying force to the north part of the roof and four to the south part of the roof. The spacing between the jacks was $2 \mathrm{ft}$. in east-west direction and $6 \mathrm{ft}$. in north-south direction (Figure 4.5). A steel loading frame was fabricated to mount the hydraulic jacks. The jacks were first bolted to $1 / 2$ in. thick steel plates. Subsequently, the plates were bolted to four $12 \mathrm{in}$. long $3 / 4$ in. diameter threaded rods. The steel plates of the same size as those on the top were 
bolted at the bottom. Load cells were placed on the top beam of the loading frame, such that it will be on the same vertical axis with the jack. The jack system was placed on the loading frame through the holes on the top beam, such that the load cells will be sandwiched between the bottom plates and the loading frame (Figure 4.6). In order to distribute the load, $8 \mathrm{ft}$. long channel members were constructed using four 2 in. $\mathrm{x} 6$ in. dimensional lumbers. Steel angles were screwed to the wooden channel, and the entire section was connected to the clevis eyes placed on top of the jacks using a bolt (Figure 4.7). This connection system allowed the wooden member to rotate freely about the clevis.

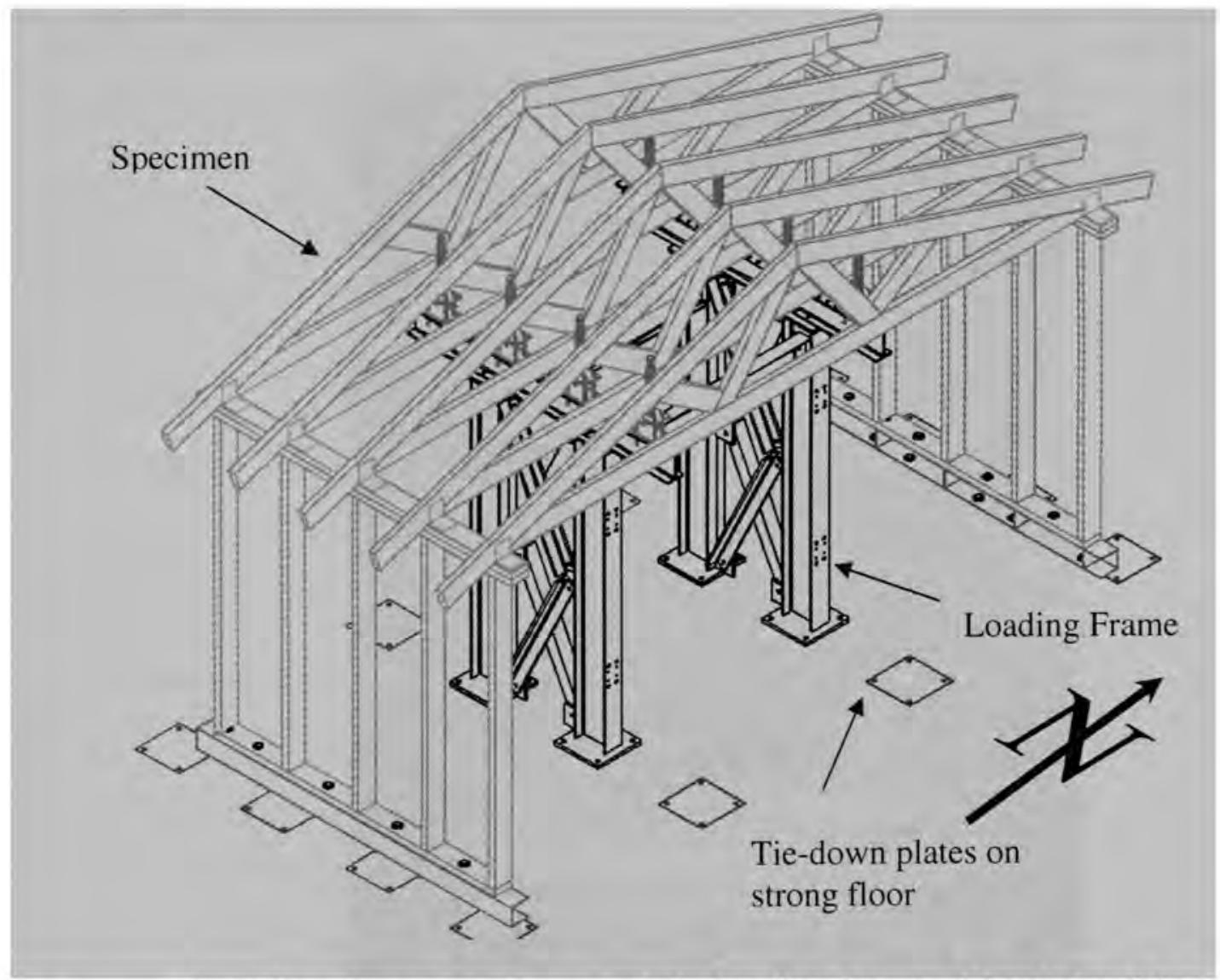

Figure 4.5 - Full-scale test specimen and the loading frame without sheathing and instrumentation 


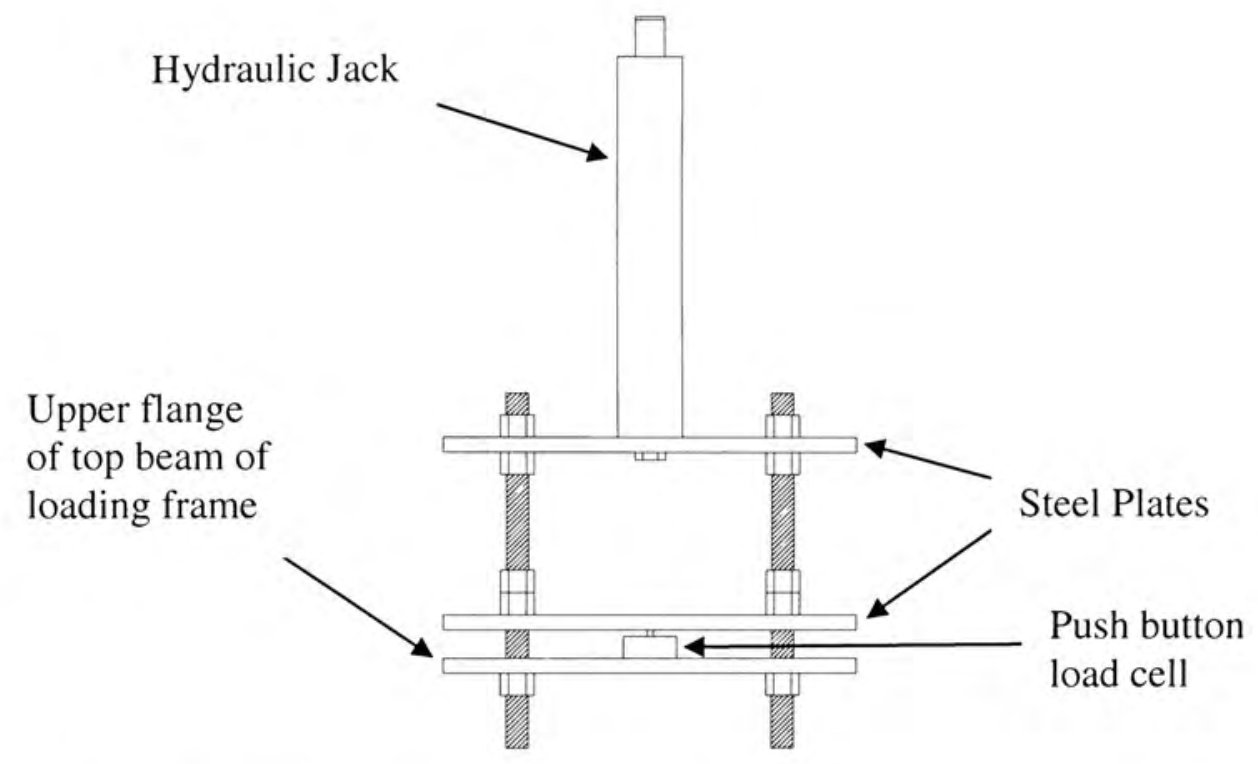

Figure 4.6 - Placement of load cell between the loading frame and steel plate

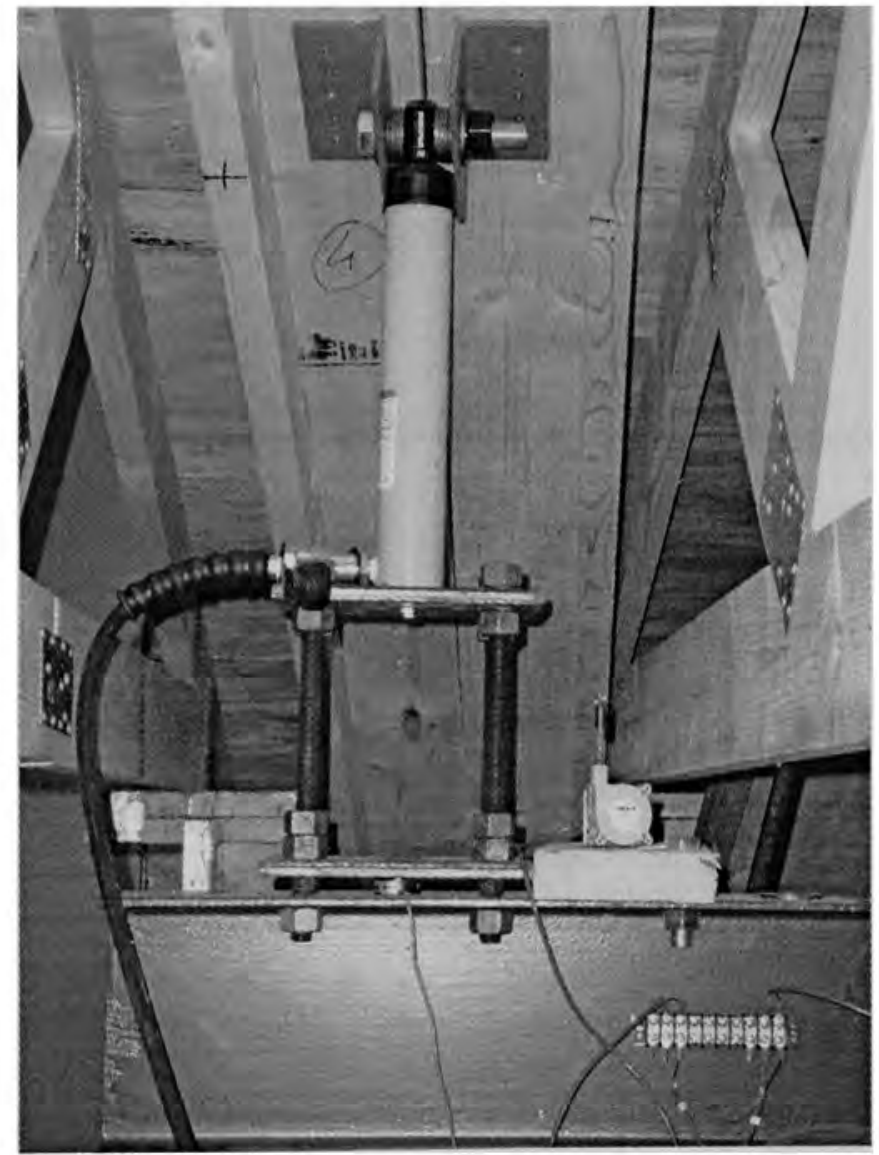

Figure 4.7 - Jack with the load distribution channel mounted on top 
The FRP ties used in the full-scale test followed Configuration A with GFRP, as described in the previous chapter. As in the component-level tests, the FRP tie was applied at each side of the joists at each end, making for a total of 20 FRP ties.

The instrumentation for the full-scale specimen consisted of twenty three string pots, eight strain gages and eight load cells. The numbering and schematic representation of sensors are summarized in Table 4.1 and shown in Figure 4.8. The sensors are numbered starting from the load cells, to string pots and finally to strain gages. The numbering sequence starts from northeast corner and moves in the clockwise direction. A push-button load cell was placed under the vertical axis of each jack to measure applied load. String pots 9-13 and 27-31 were placed on the outer wall, to measure the displacement of each truss at 1.5 in. away from the wall on the outside. String pots 18-22 were connected to the $8 \mathrm{ft}$. long wooden member assembled on the loading frame to measure the displacements at the center of the bottom chord of the truss. String pots 1417 and 23-26 were directly connected to the loading frame to measure the displacements at loading points on the axis of rotation of the wooden channel members. Eight $60 \mathrm{~mm}$ strain gages were used to measure the strains centered on the vertical legs of the FRP ties. These strain gages were measuring the strains at FRP ties located at four corners of test specimen. Figure 4.9 shows a sketch of the instrumented specimen before testing. 
Table 4.1 - Sensor list

\begin{tabular}{|c|c|c|}
\hline Sensor No. & Sensor Type & Measurement \\
\hline $1,2,3,4$ & Load cells & $\begin{array}{c}\text { Located under the jacks on the north side of the } \\
\text { structure to measure the applied load }\end{array}$ \\
\hline $5,6,7,8$ & Load cells & $\begin{array}{c}\text { Located under the jacks on the south side of the } \\
\text { structure to measure the applied load }\end{array}$ \\
\hline $\begin{array}{c}9,10,11,1 \\
12,13\end{array}$ & String pots & $\begin{array}{c}\text { Connected to the northern outer wall, } 4 \mathrm{ft} \text { above } \\
\text { the ground to measure the displacement of the } \\
\text { truss at a distance of } 1.5 \text { in. from top plate }\end{array}$ \\
\hline $\begin{array}{c}14,15,16, \\
17\end{array}$ & String pots & $\begin{array}{c}\text { Connected to the loading frame to measure the } \\
\text { displacements at the loading points on the north } \\
\text { side of the test specimen }\end{array}$ \\
\hline $\begin{array}{c}18,19,20,22 \\
21,22\end{array}$ & String pots & $\begin{array}{c}\text { Connected to the loading frame to measure the } \\
\text { displacements at the center of the bottom chord } \\
\text { of the trusses }\end{array}$ \\
\hline $\begin{array}{c}23,24,25, \\
26\end{array}$ & String pots & $\begin{array}{c}\text { Connected to the loading frame to measure the } \\
\text { displacements at the loading points on the south } \\
\text { side of the test specimen }\end{array}$ \\
\hline $\begin{array}{c}27,28,29, \\
30,31\end{array}$ & String pots & $\begin{array}{c}\text { Connected to the southern outer wall, } 4 \text { ft above } \\
\text { the ground to measure the displacement of the } \\
\text { truss at a distance of 1.5 in. from top plate }\end{array}$ \\
\hline $\begin{array}{c}32,33,34, \\
35,36,37, \\
38,39\end{array}$ & Strain gages & $\begin{array}{c}\text { Attached to FRP ties at } 4 \text { corners of the test } \\
\text { specimen to measures the strain on center line of } \\
\text { the vertical leg of the tie placed on the joist }\end{array}$ \\
\hline
\end{tabular}

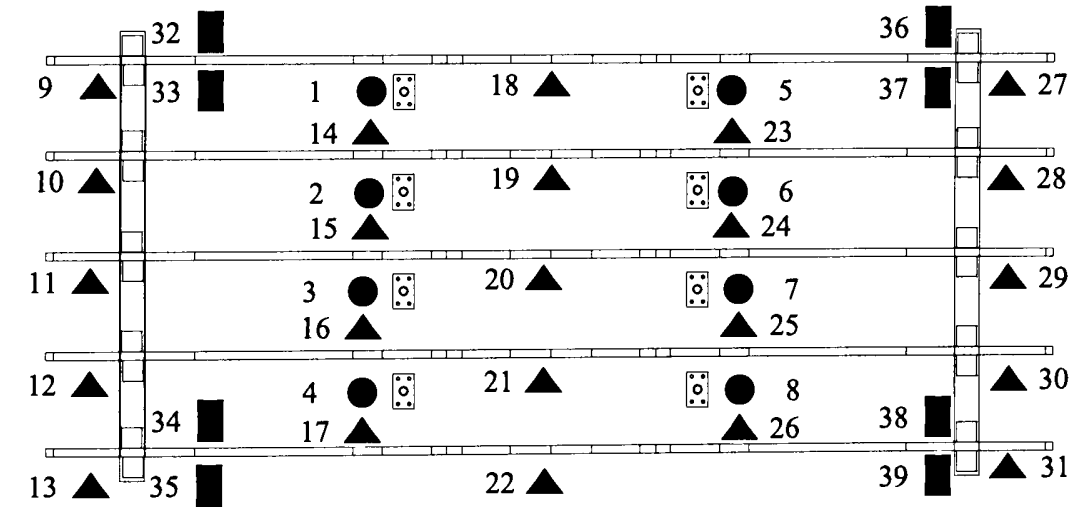

Legend:

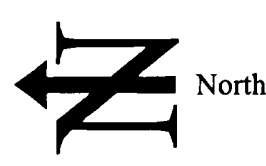

Load Cell

$\Delta$ String Pot

Strain Gage

Figure 4.8 - Schematic representation of sensor locations 


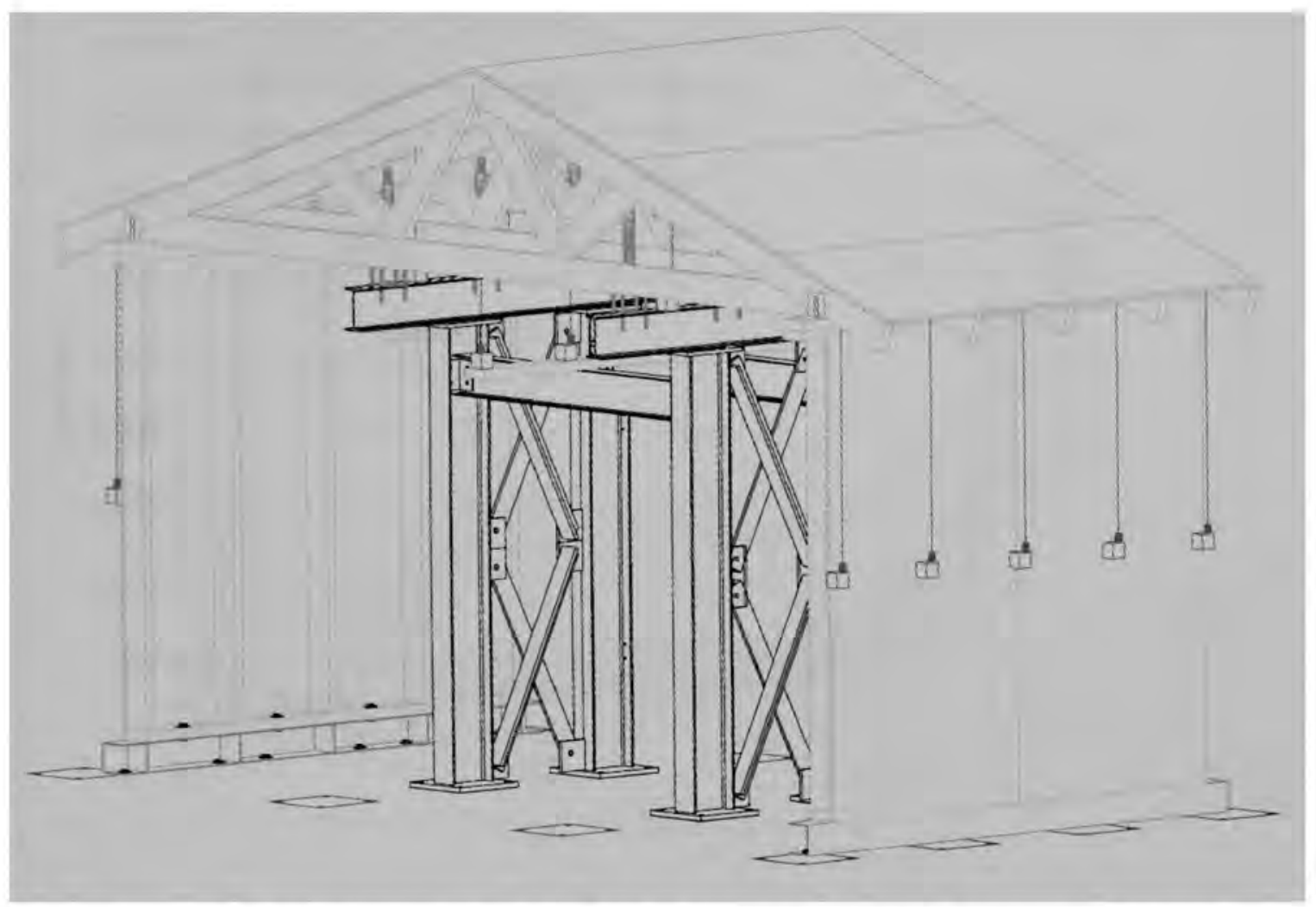

Figure 4.9- - Schematics of full-scale test specimen with sensors in place

\section{2 - Test Observations and Results}

The loading history for the test specimen is shown in Figures 4.10, 4.11 and 4.12. Figure 4.10 represents the load applied from each individual jack. Figure 4.11 shows the load applied on each quadrant of the roof. Figure 4.12 shows the total load applied on the specimen. Figure 4.13 compares the loads applied from each jack at the time of failure. As seen from Figures 4.10 and 4.11 , the loads applied from each jack were not exactly the same. This may be attributed to the manifold locations, hose lengths, and bends that might change the ease of flow in the system. 


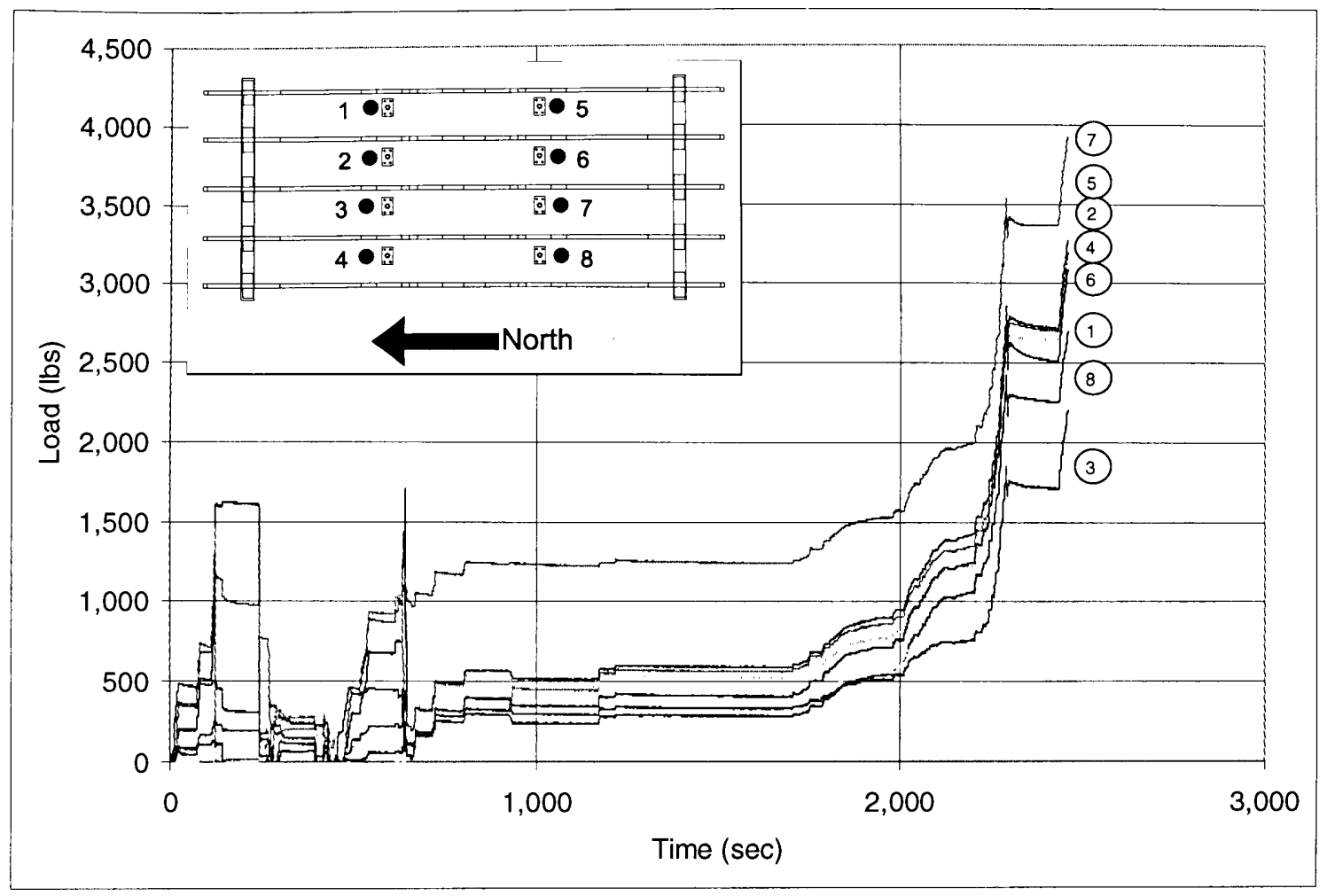

Figure 4.10 - Load applied from each jack

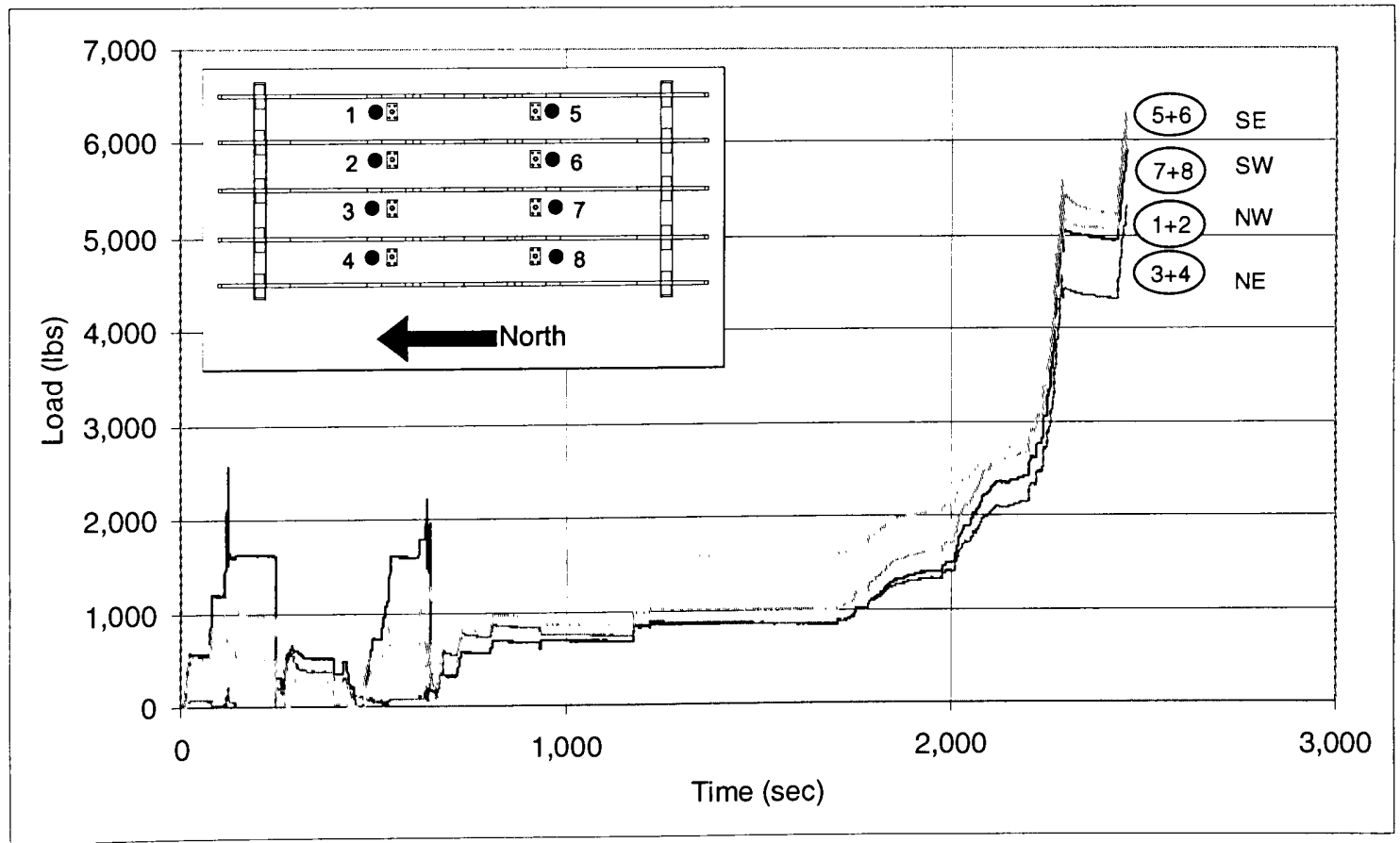

Figure 4.11 - Load applied to each quadrant of the roof 


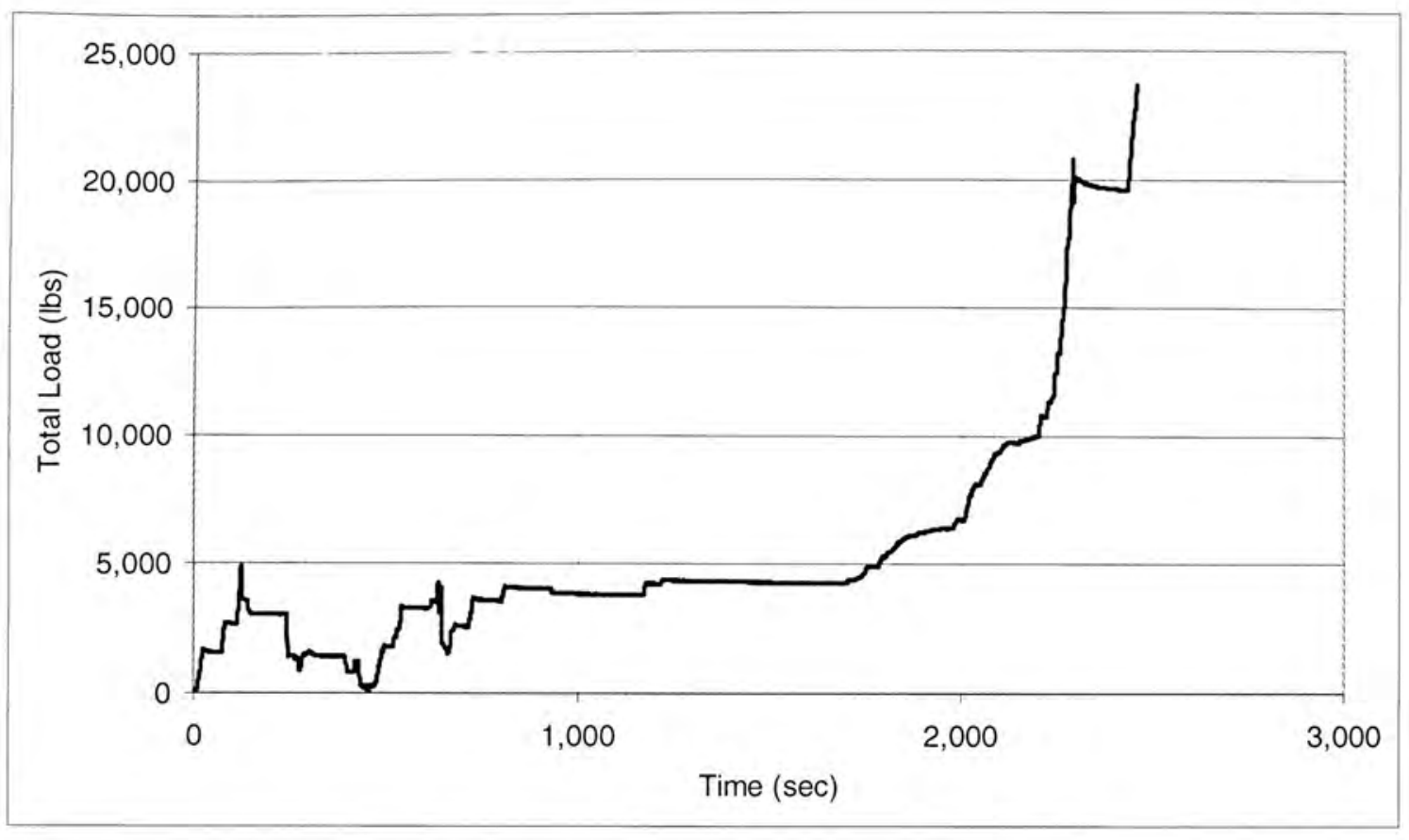

Figure 4.12 - Total load applied on the specimen

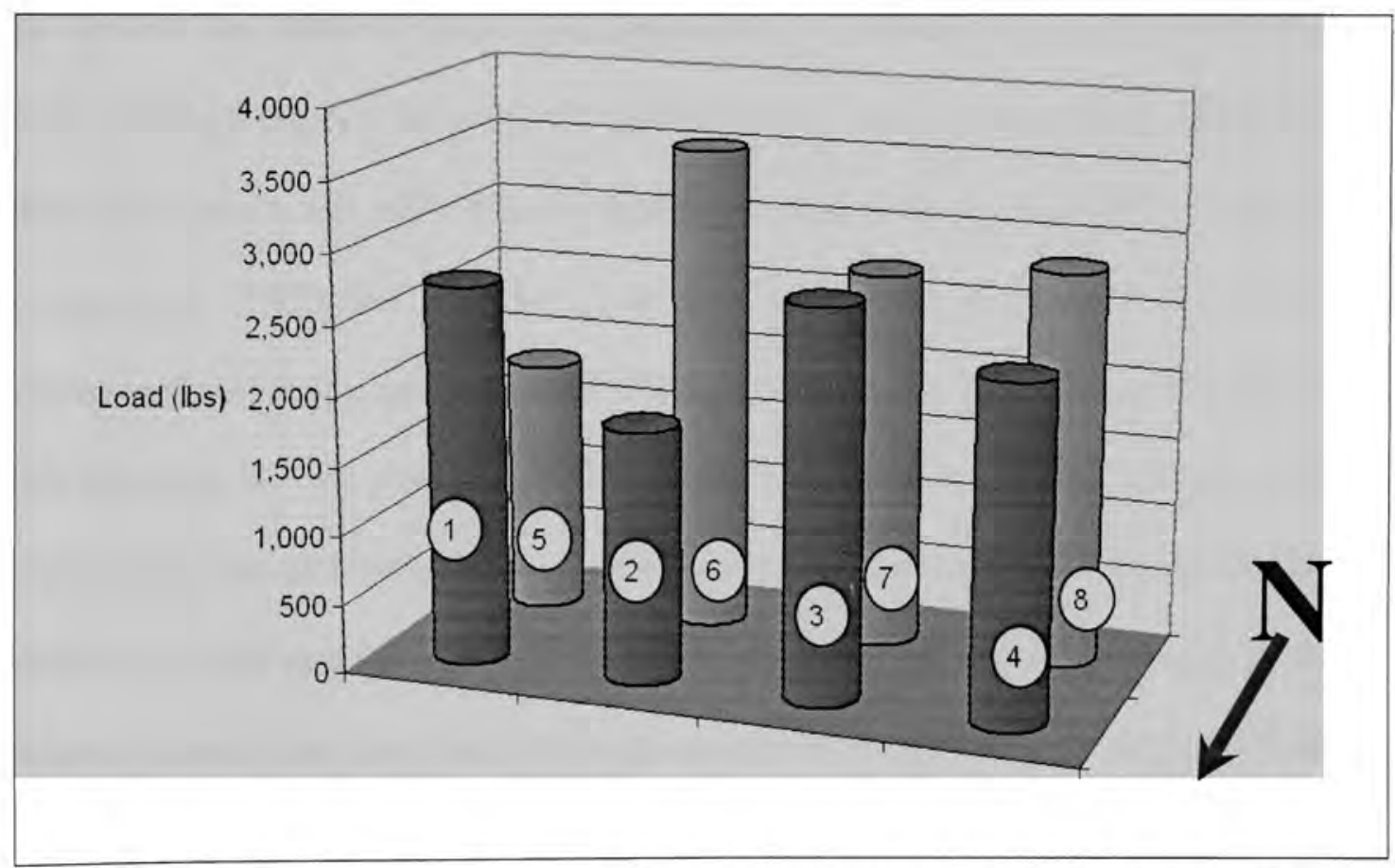

Figure 4.13 - The loads applied at each cylinder at initial failure load 
For explanatory purposes, the FRP ties are numbered as shown in Figure 4.14.

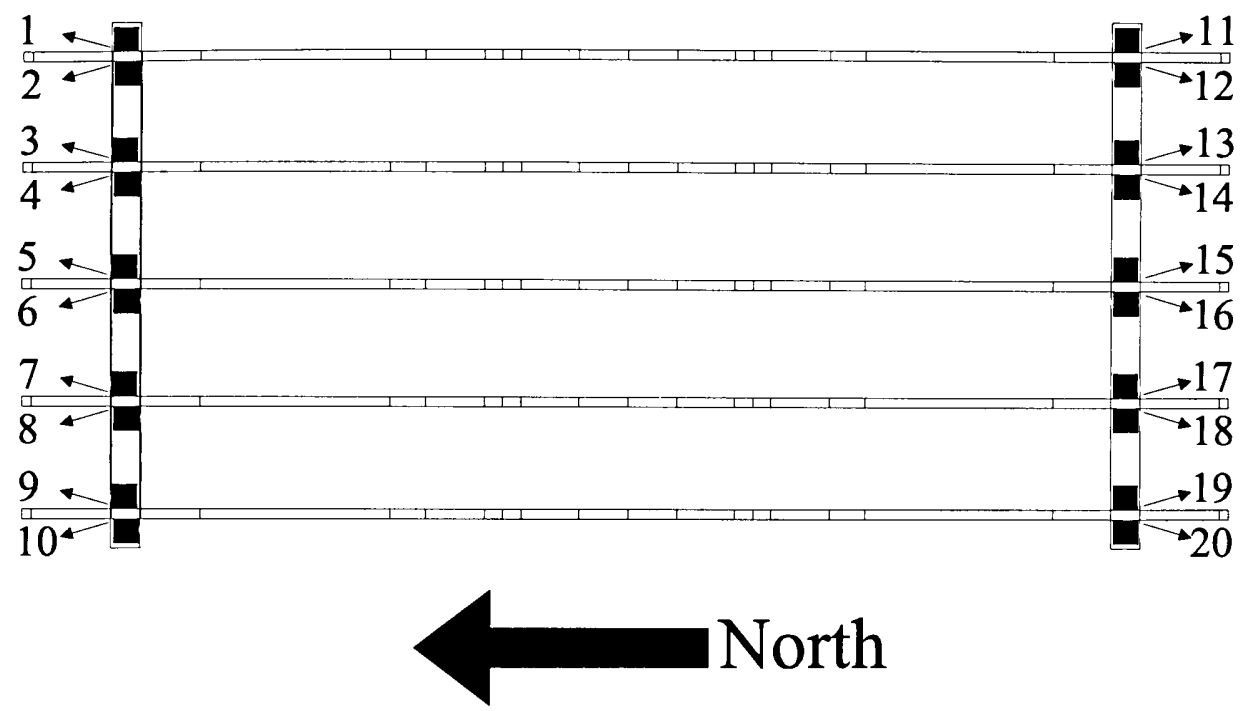

Figure 4.14 - The numbering of FRP ties

The initial failure of FRP ties was seen at connections 13 and 14 at a total load of 20,716 lbs. The failure of these two ties started as both began to peel off from the top plate. Although most of the portion of the FRP ties 13 and 14 were detached from the top plate, the system was still able to sustain the applied load. As the load was further increased to $23,659 \mathrm{lbs}$, FRP ties $7,8,11,12,19$ and 20 failed at the same time, following the complete detachment of FRP ties 13 and 14 in a domino pattern. FRP tie 13 detached from the top plate completely, in the same manner observed in the component level tests, while FRP tie 14 remained on the top plate and its failure was at the interface between the FRP and the truss. The two different modes of failures observed on the two different sides of the same truss may suggest that the FRP-wood bond strength in Mode I and Mode II are very close to each other, as also noted in the component level tests. The initiation of failure of FRP ties 13 and 14 at $20,716 \mathrm{lbs}$ is shown in Figure 4.15. The complete failure of these two FRP ties at $23,659 \mathrm{lbs}$ is shown in Figure 4.16. Failure of 
FRP ties 11 and 12 was very similar to that of FRP ties 13 and 14 . Although most of the FRP tie on the top plate was detached, FRP tie 11 remained attached to top plate and its failure took place at the interface between the FRP and the truss. FRP tie 12 remained attached to the truss, and peeled off from the top plate completely (Figure 4.17). FRP ties 19 and 20 failed as the FRP peeled off from the top plate. At the failure load, some parts of these ties were still attached to the top plate as seen on Figure 4.18. Figure 4.19 shows the FRP ties 7 and 8 at the ultimate load. A complete failure was not observed but considerable peel off of FRP from the top plate along with wood fibers was noted. As seen in the photographs, significant amount of wood fibers remain attached to FRP in the failed ties. Especially, in FRP ties 7 and 8, the failure was observed within the wood rather than at the FRP-wood interface.

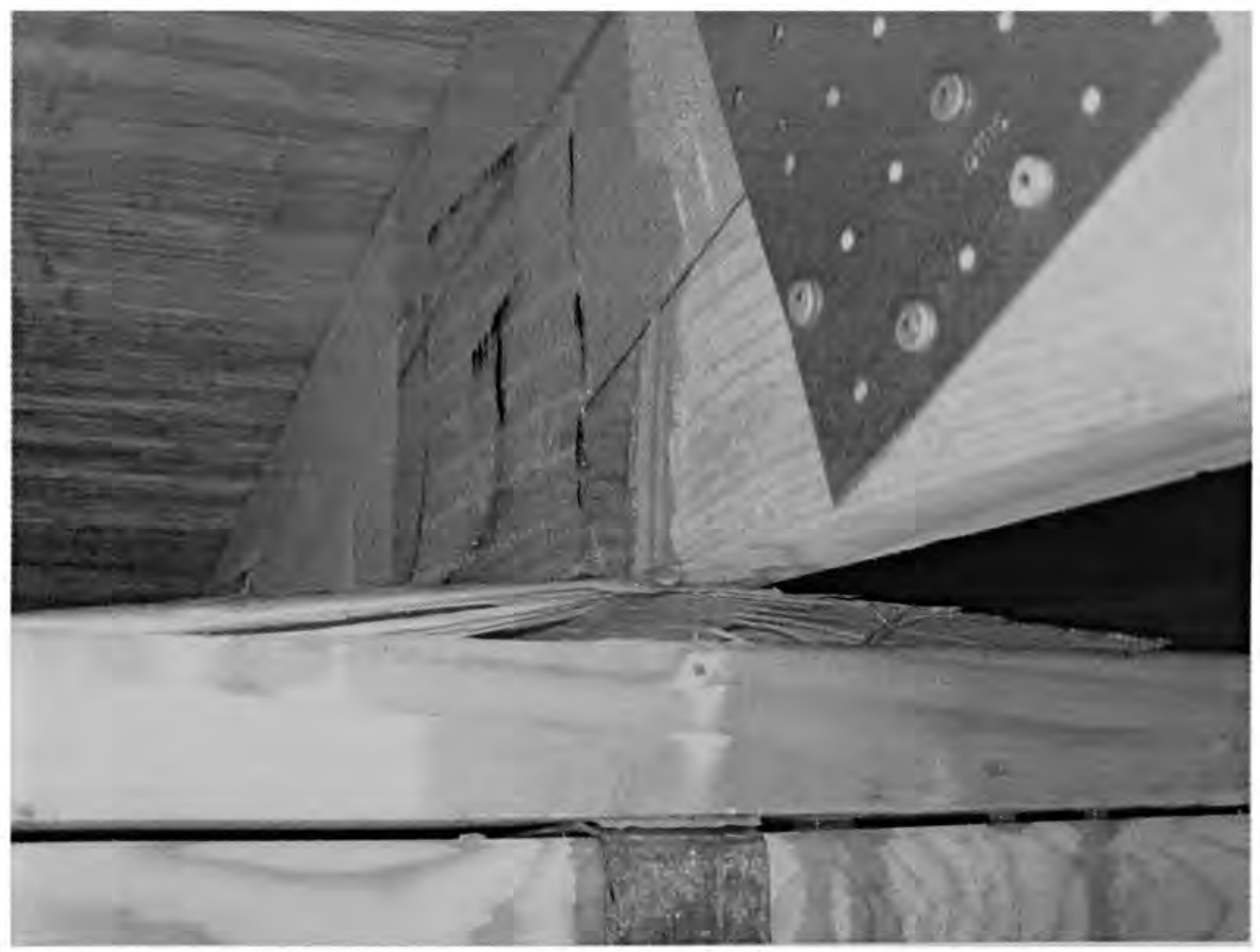

Figure 4.15 - Initiation of failure in FRP ties 13 and 14 at 20,716 lbs 


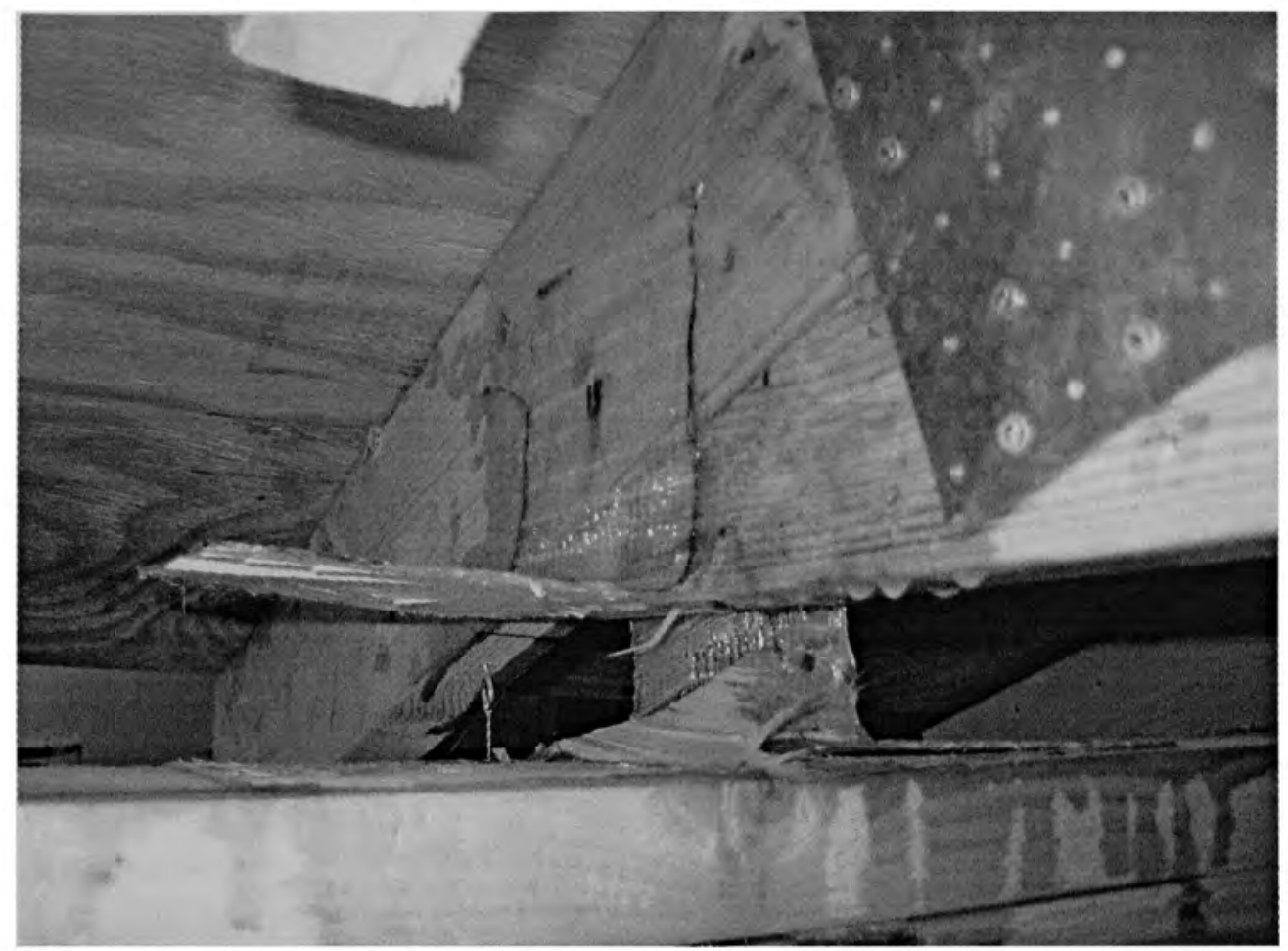

Figure 4.16 - Complete failure of FRP ties 13 and 14 at 23,659 lbs

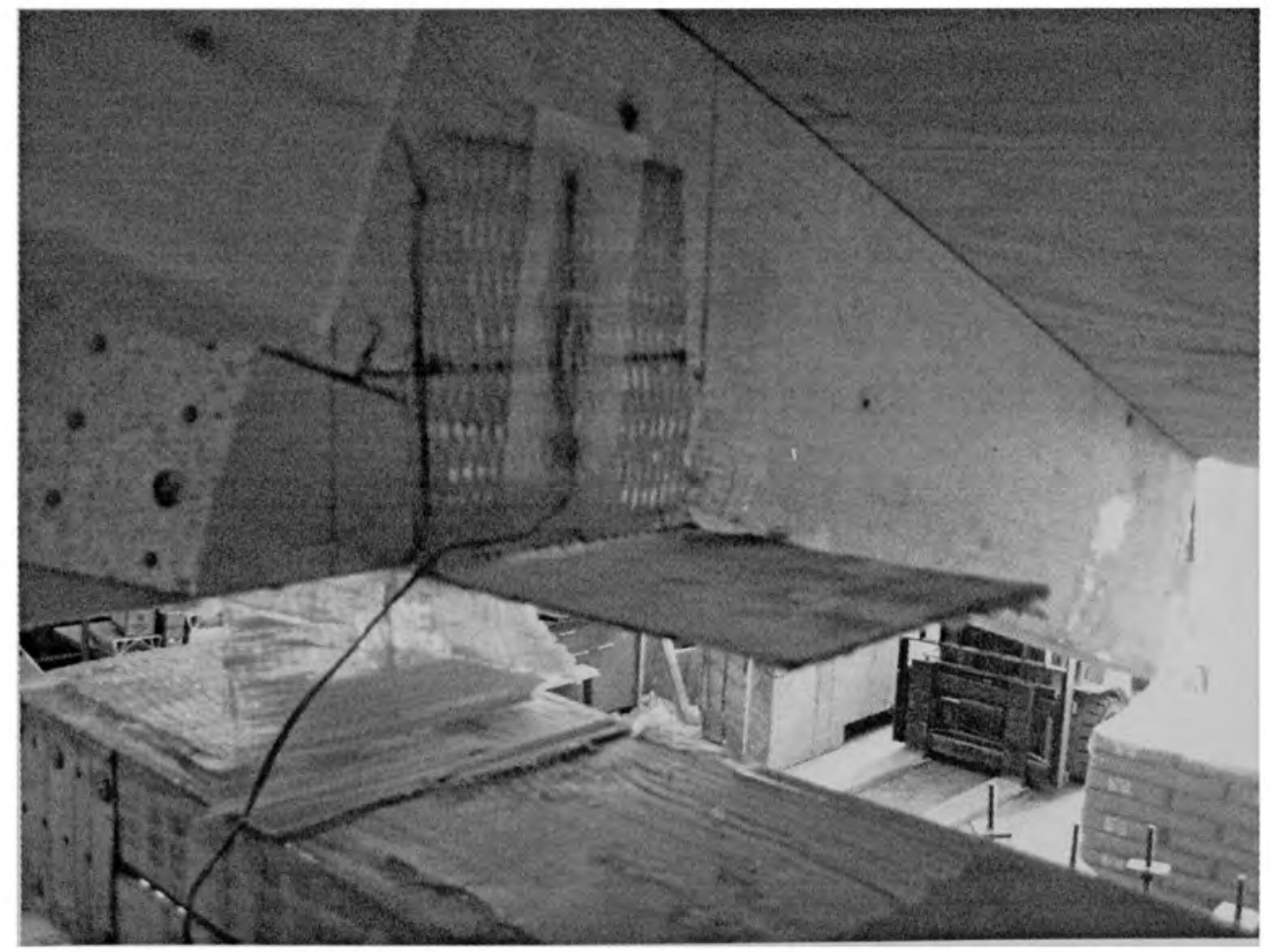

Figure 4.17 - Failure of FRP ties 11 and 12 


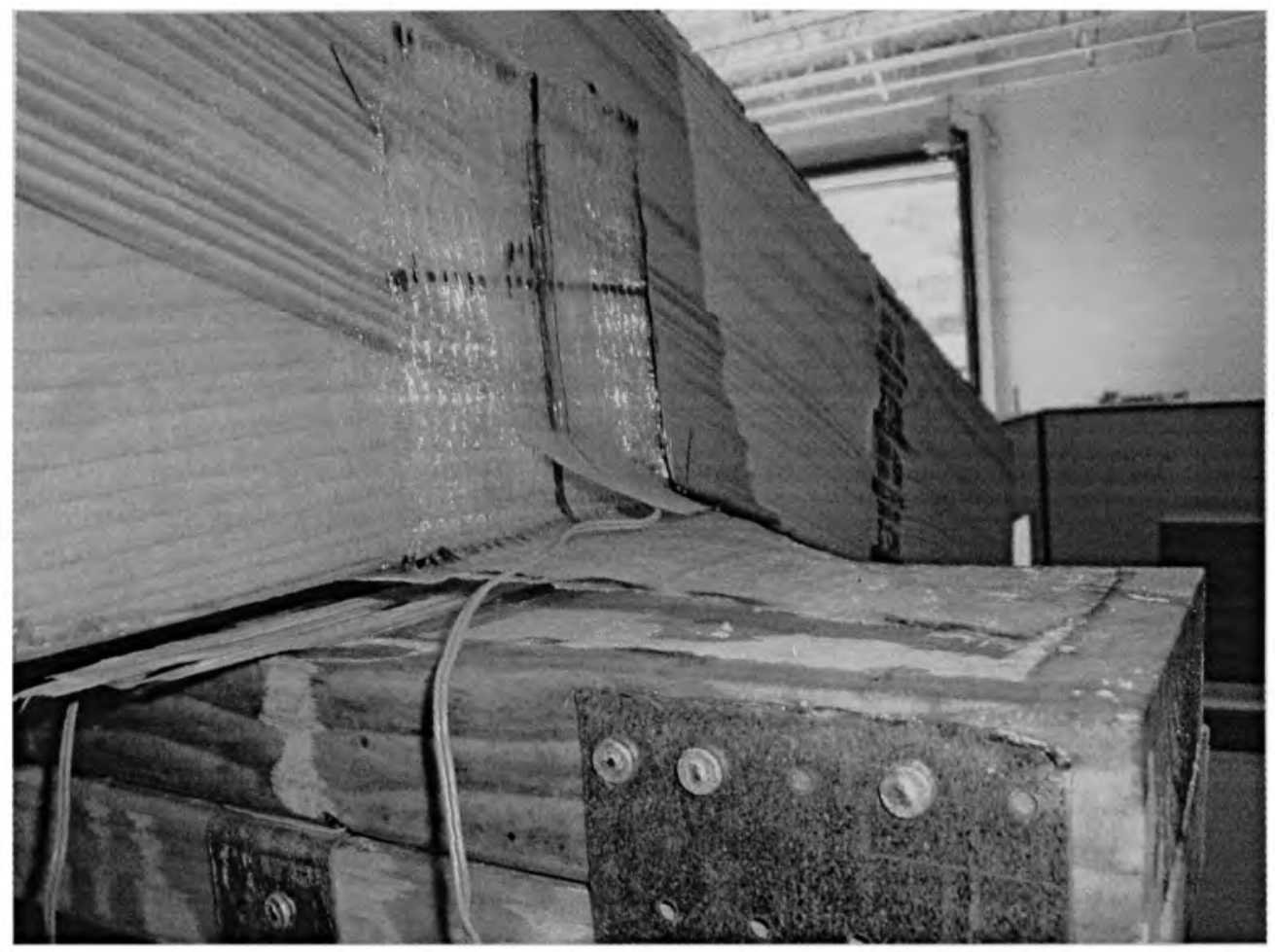

Figure 4.18 - Failure of FRP ties 19 and 20

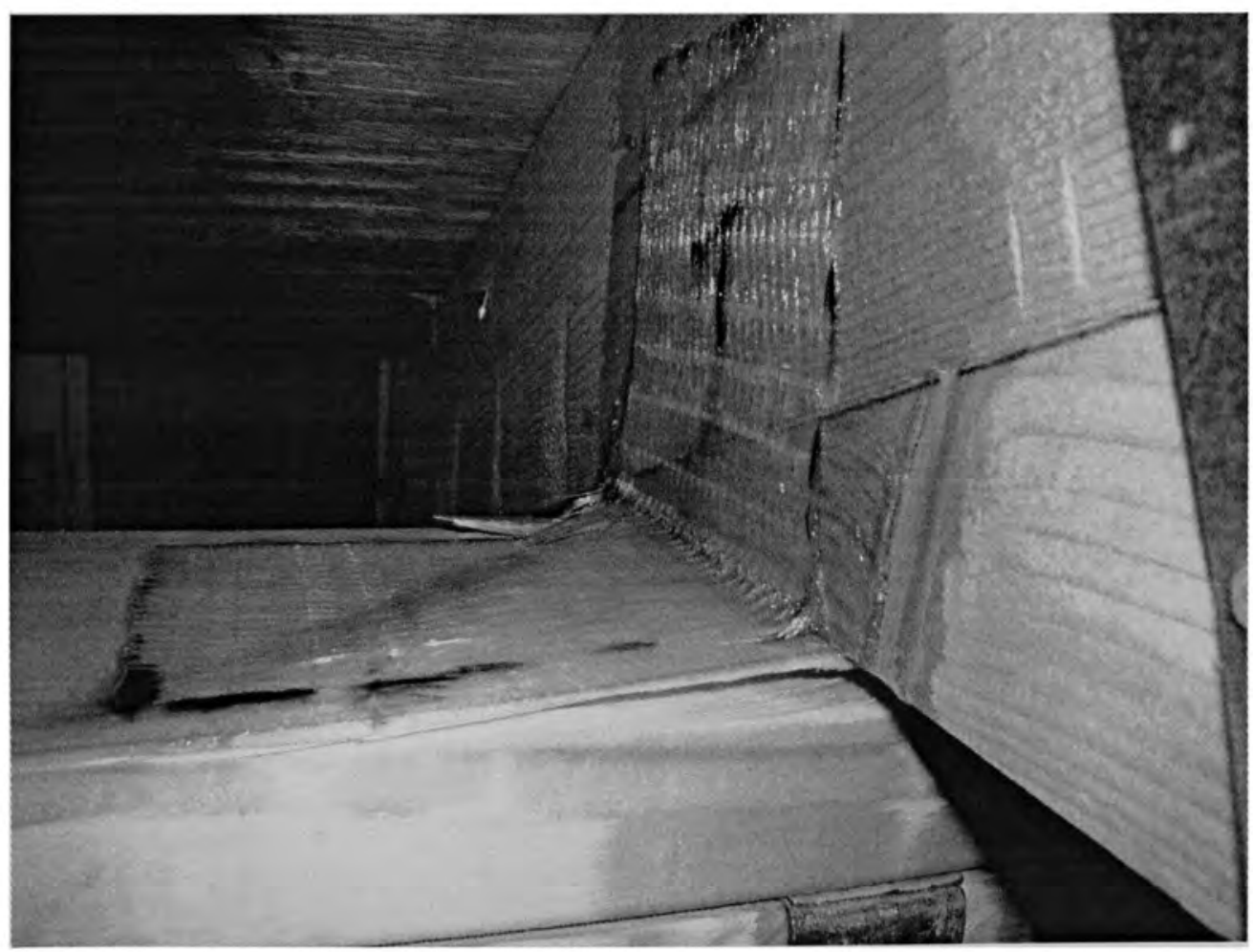

Figure 4.19 - Failure of FRP ties 7 and 8 and separation of wood fibers 
If it is assumed that loads applied from each jack is transferred to the closest connections, loads at pairs of FRP ties are as shown in Figure 4.20. Based on this assumption, the load versus displacement values of string pots located at the outer walls are presented in Figures 4.21-30.

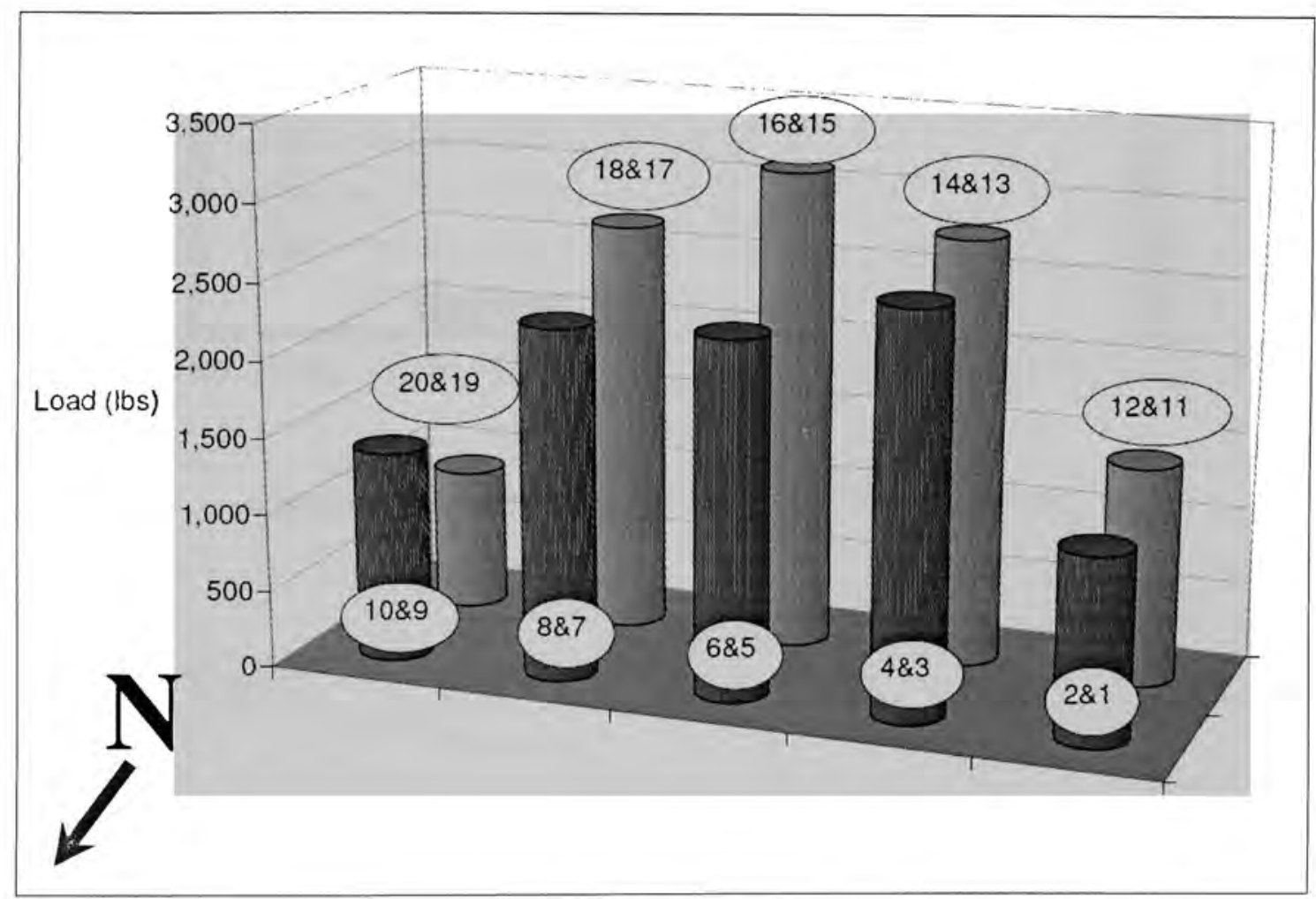

Figure 4.20 - The loads at pairs of FRP ties at initiation of failure 


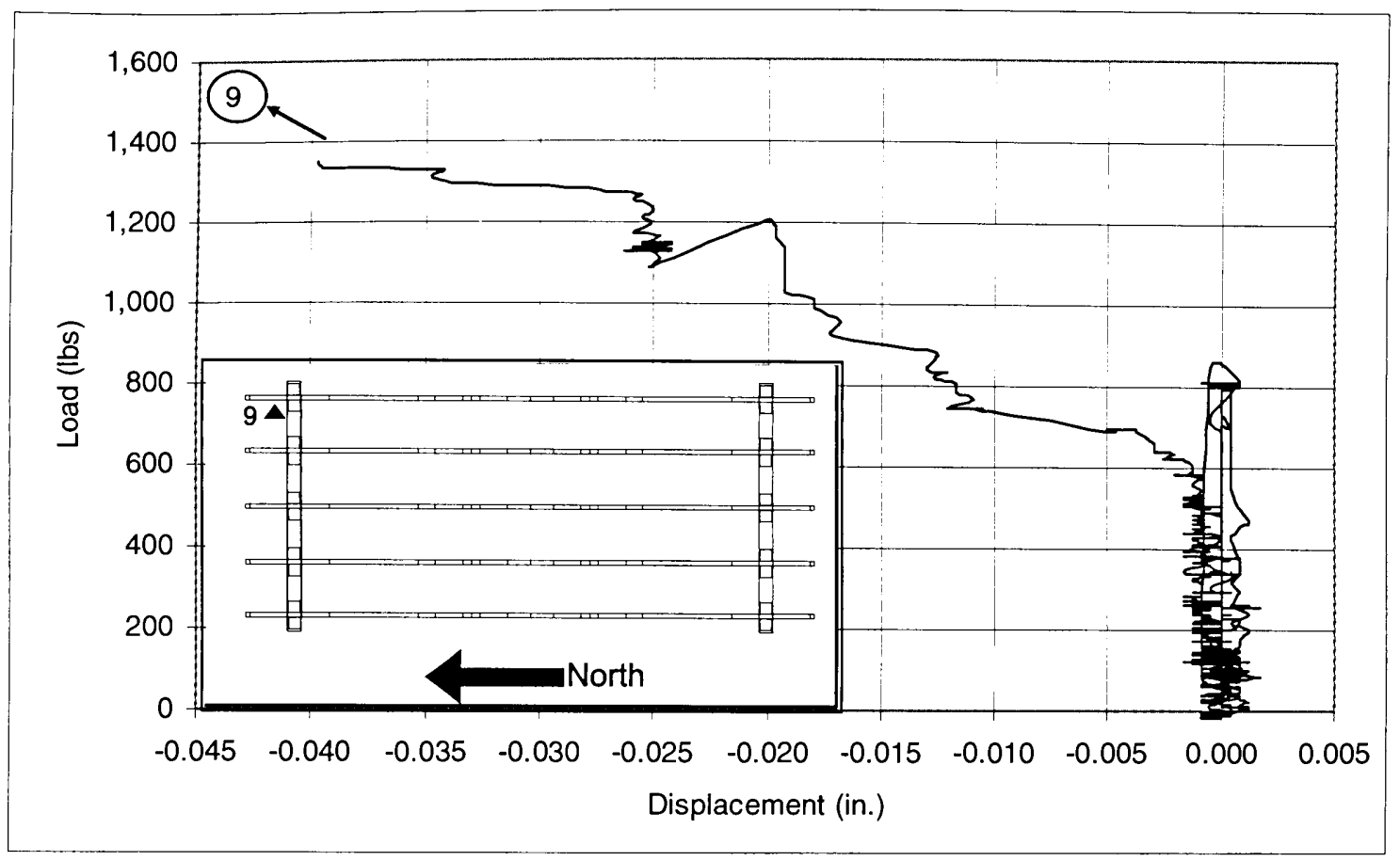

Figure 4.21 - Load-displacement for FRP ties 1 and 2

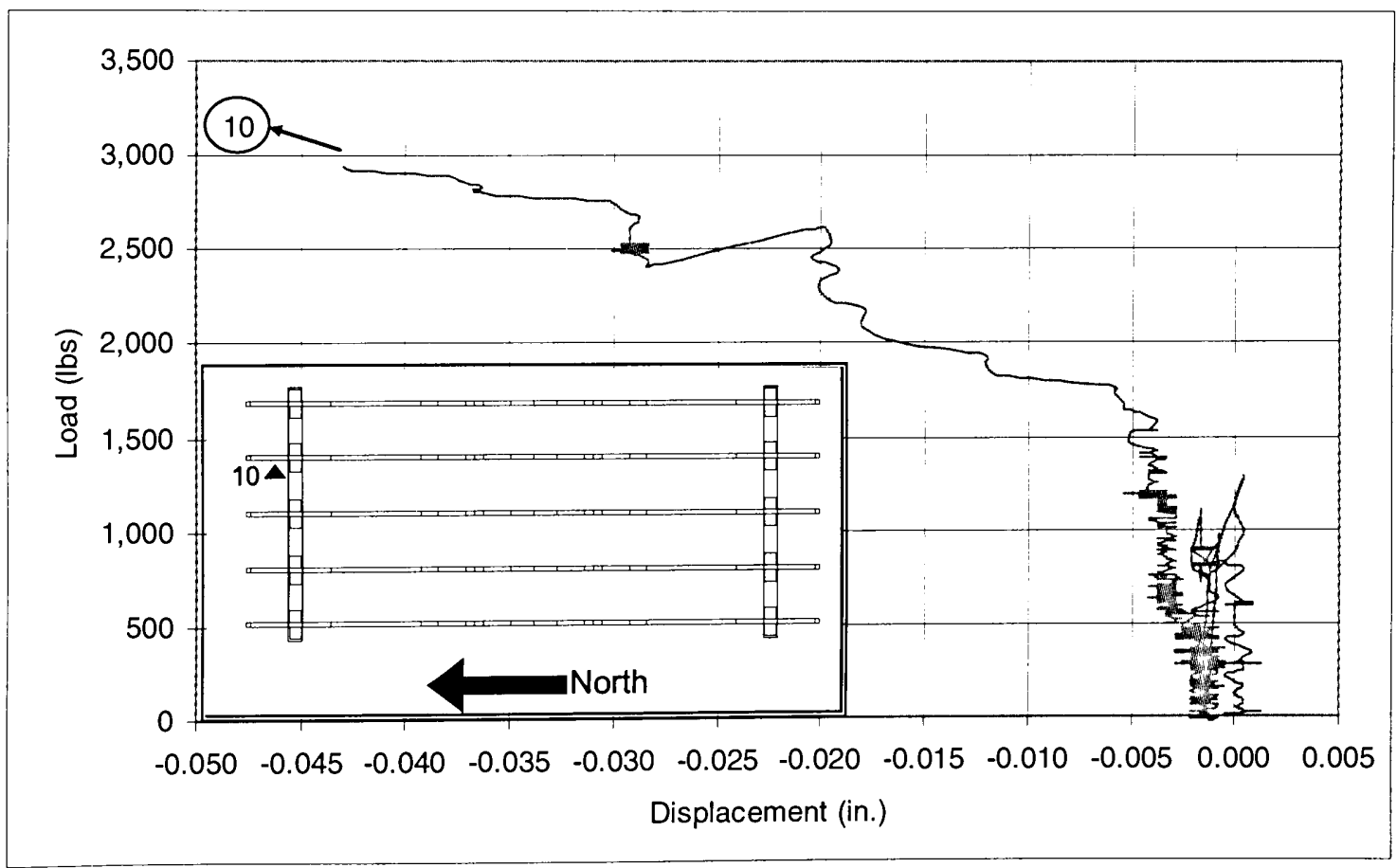

Figure 4.22 - Load-displacement for FRP ties 3 and 4 


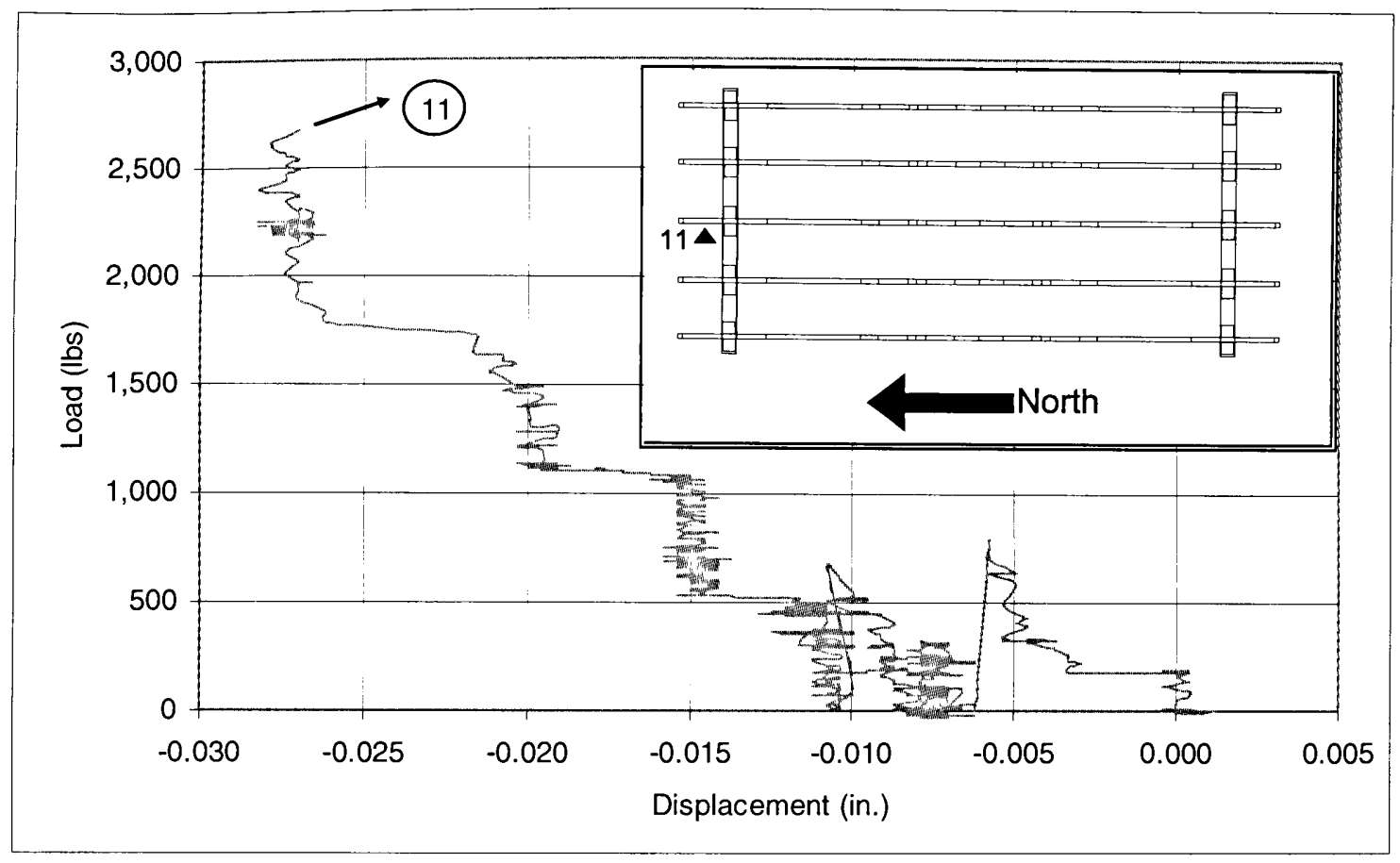

Figure 4.23 - Load-displacement for FRP ties 5 and 6

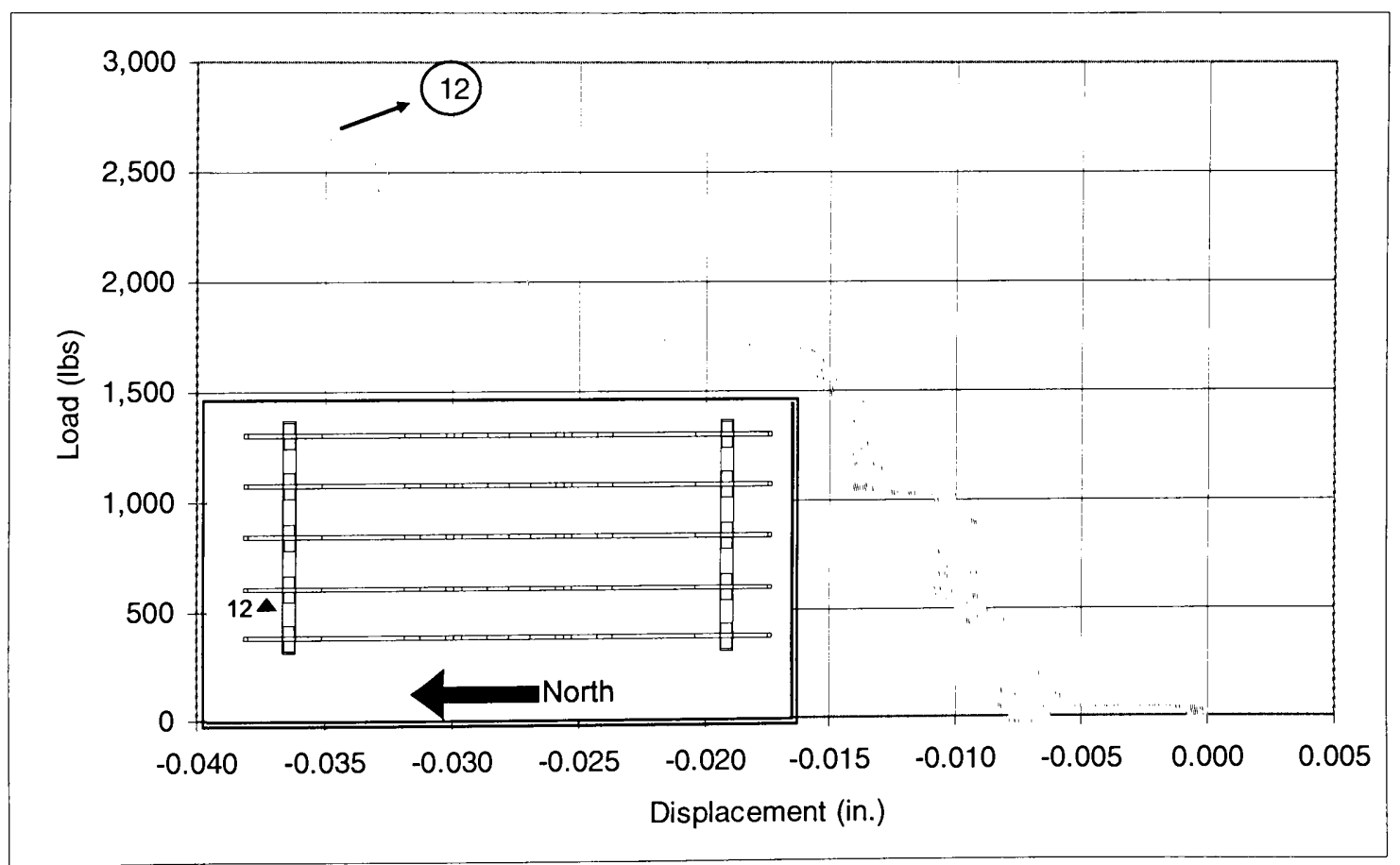

Figure 4.24 - Load-displacement for FRP ties 7 and 8 


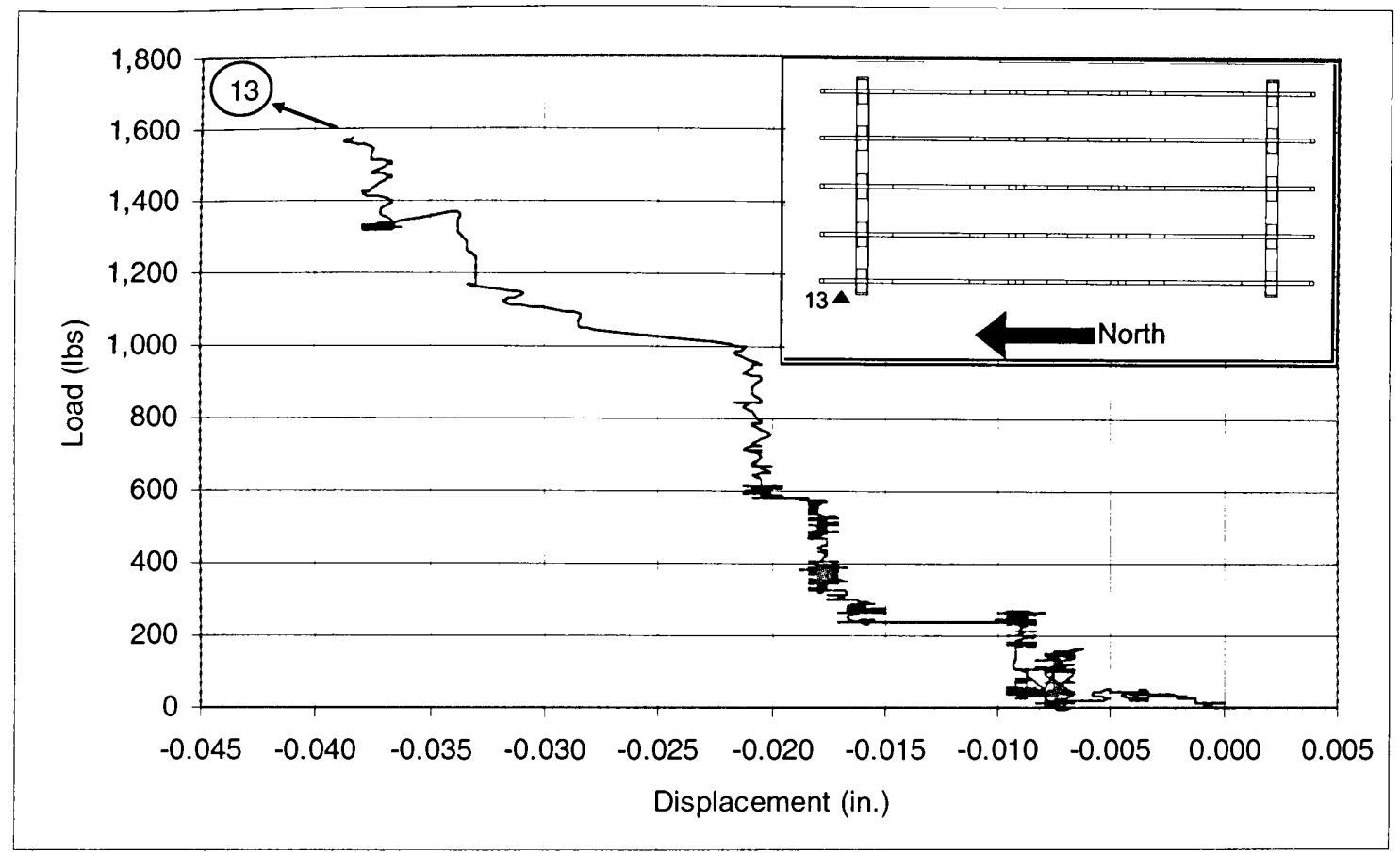

Figure 4.25 - Load-displacement for FRP ties 9 and 10

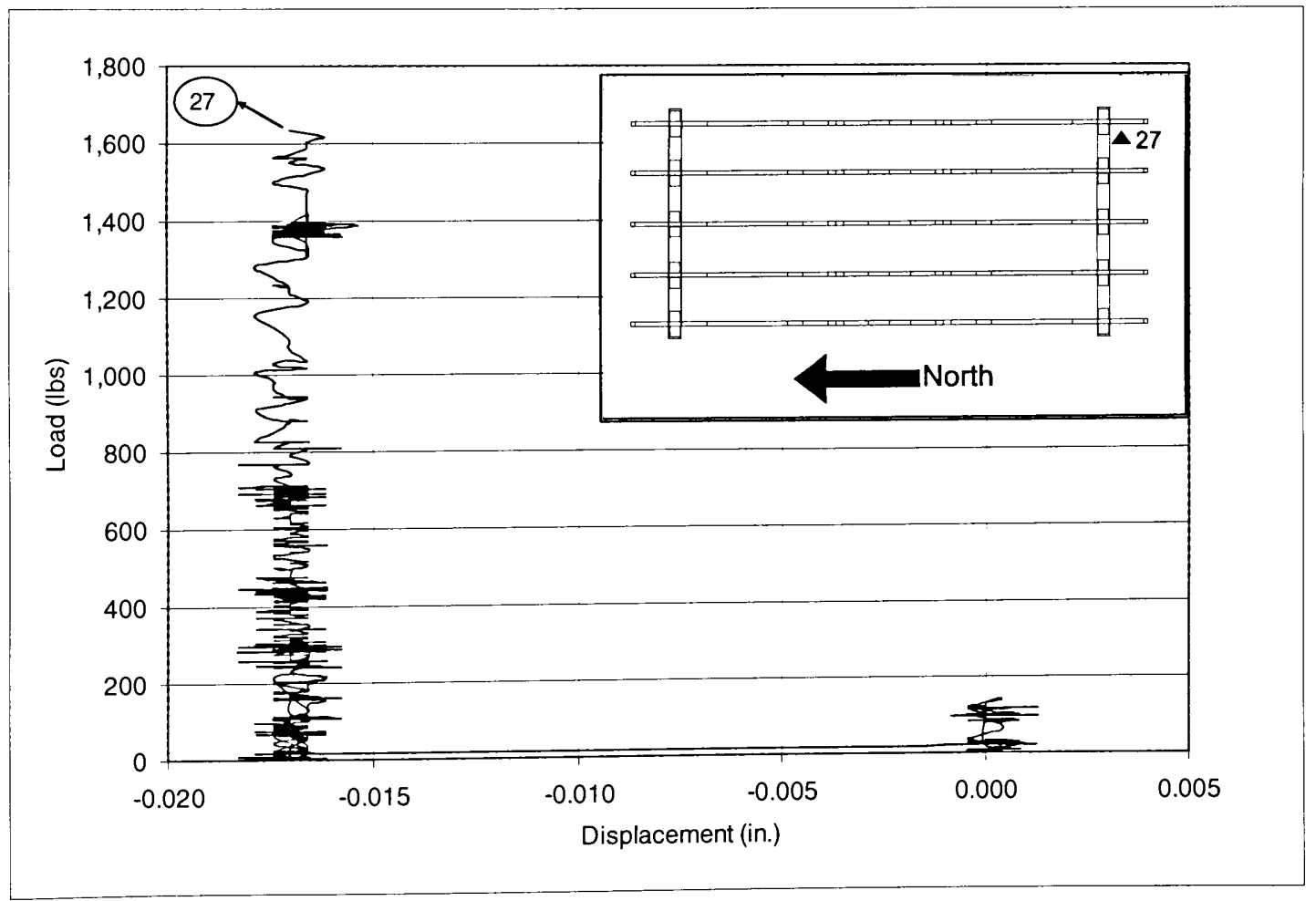

Figure 4.26 - Load-displacement for FRP ties 11 and 12 


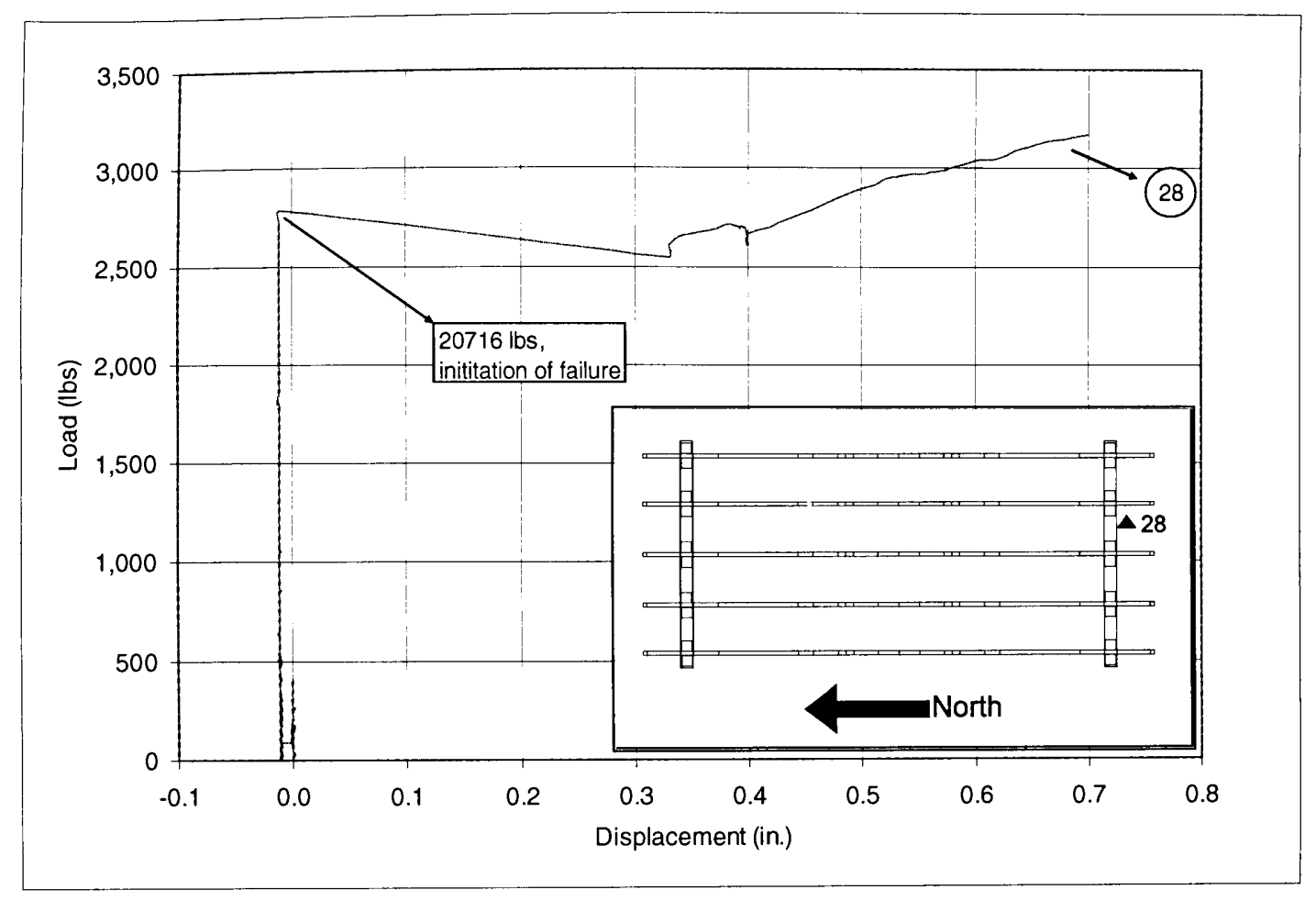

Figure 4.27 - Load-displacement for FRP ties 13 and 14

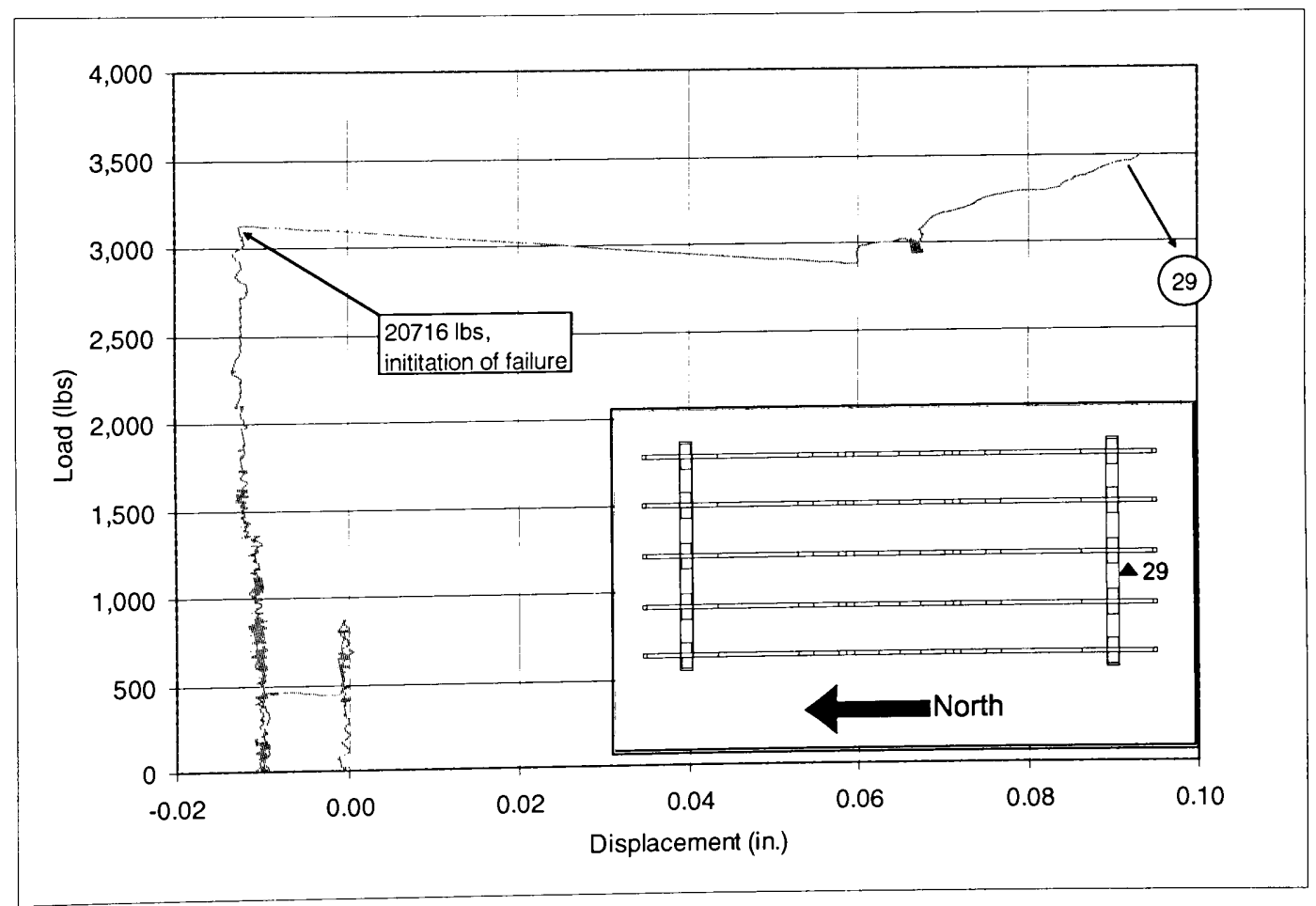

Figure 4.28 - Load-displacement for FRP ties 15 and 16 


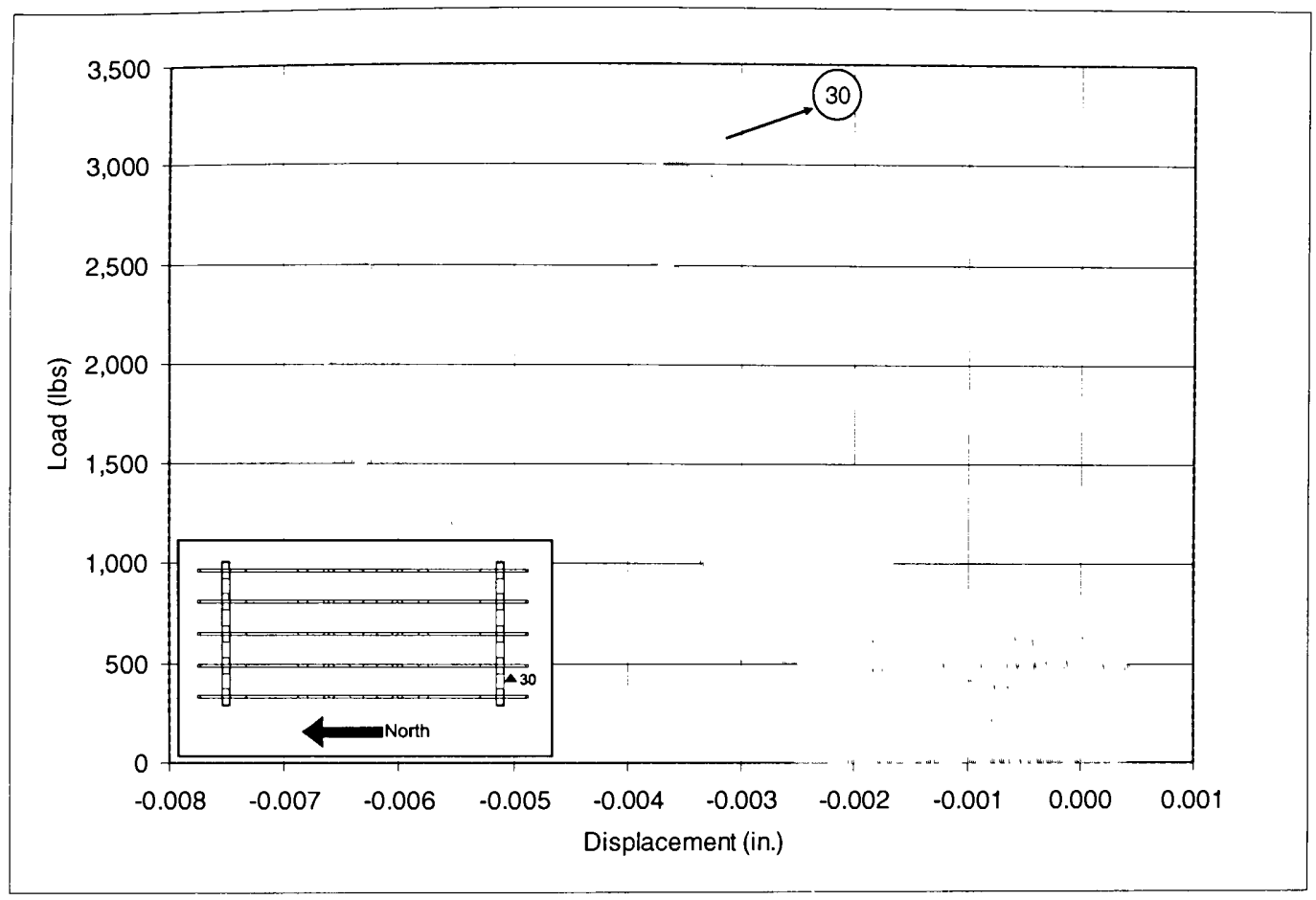

Figure 4.29 - Load-displacement for FRP ties 17 and 18

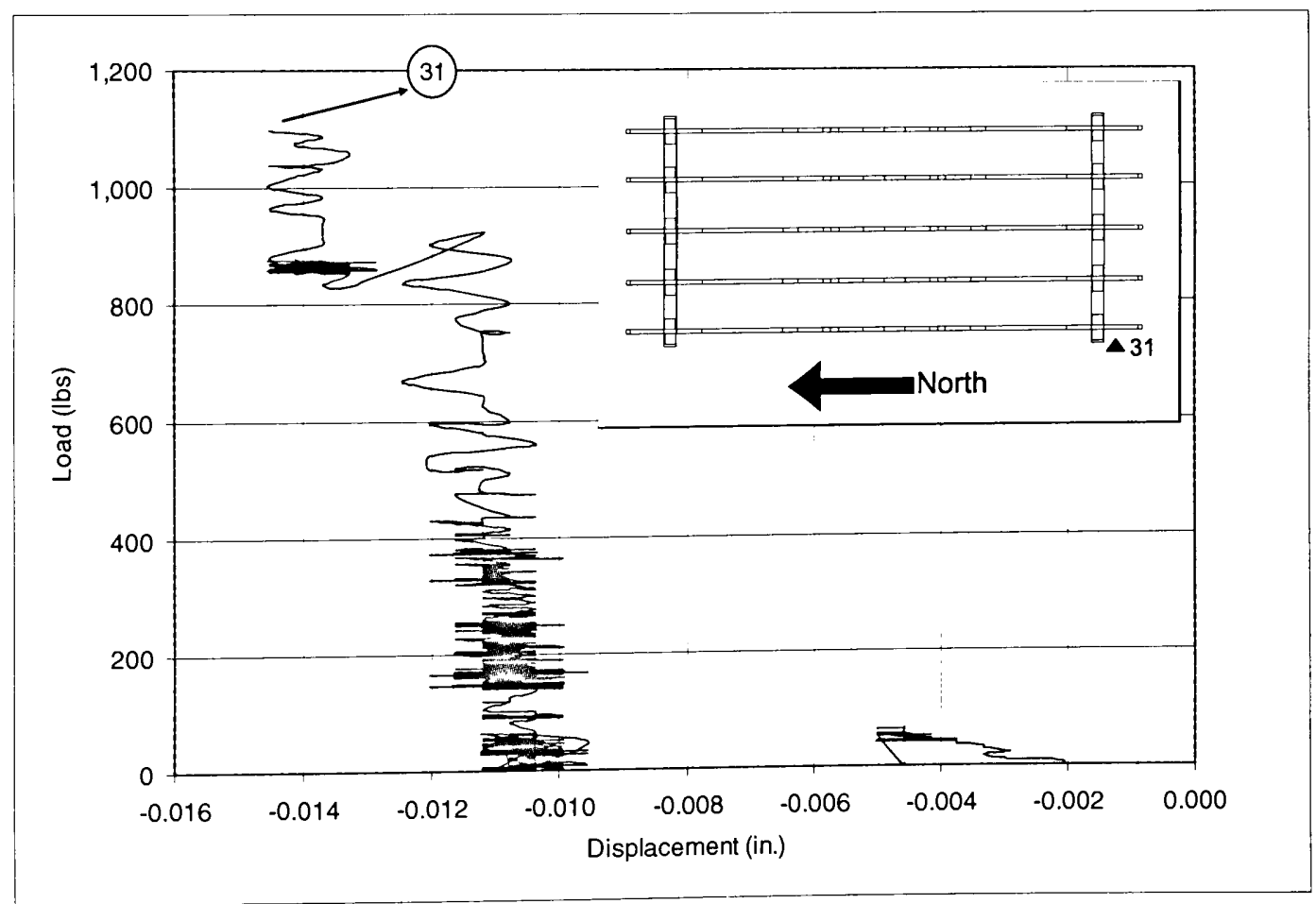

Figure 4.30 - Load-displacement for FRP ties 19 and 20 
The displacement readings obtained from string pots 9 through 13 on the north side of the trusses are shown in Figure 4.31. Figure 4.32 illustrates the displacement readings obtained from string pots 27 to 31 on the south side of the trusses. The data obtained from string pots 18 to 22 , which were displacements at the center of the bottom chord of the trusses are shown in Figure 4.33. The displacements in these figures are plotted against the total load applied. Upward displacements are considered positive. The three figures collectively suggest that the FRP tie connections provide very rigid and stiff load transfer mechanism from roof to the wall. It can be seen that the displacements are very small at each connection, and that the $1 / 8$ in. deflection limit is never reached. This is in full agreement with the component level tests described in Chapter 3.

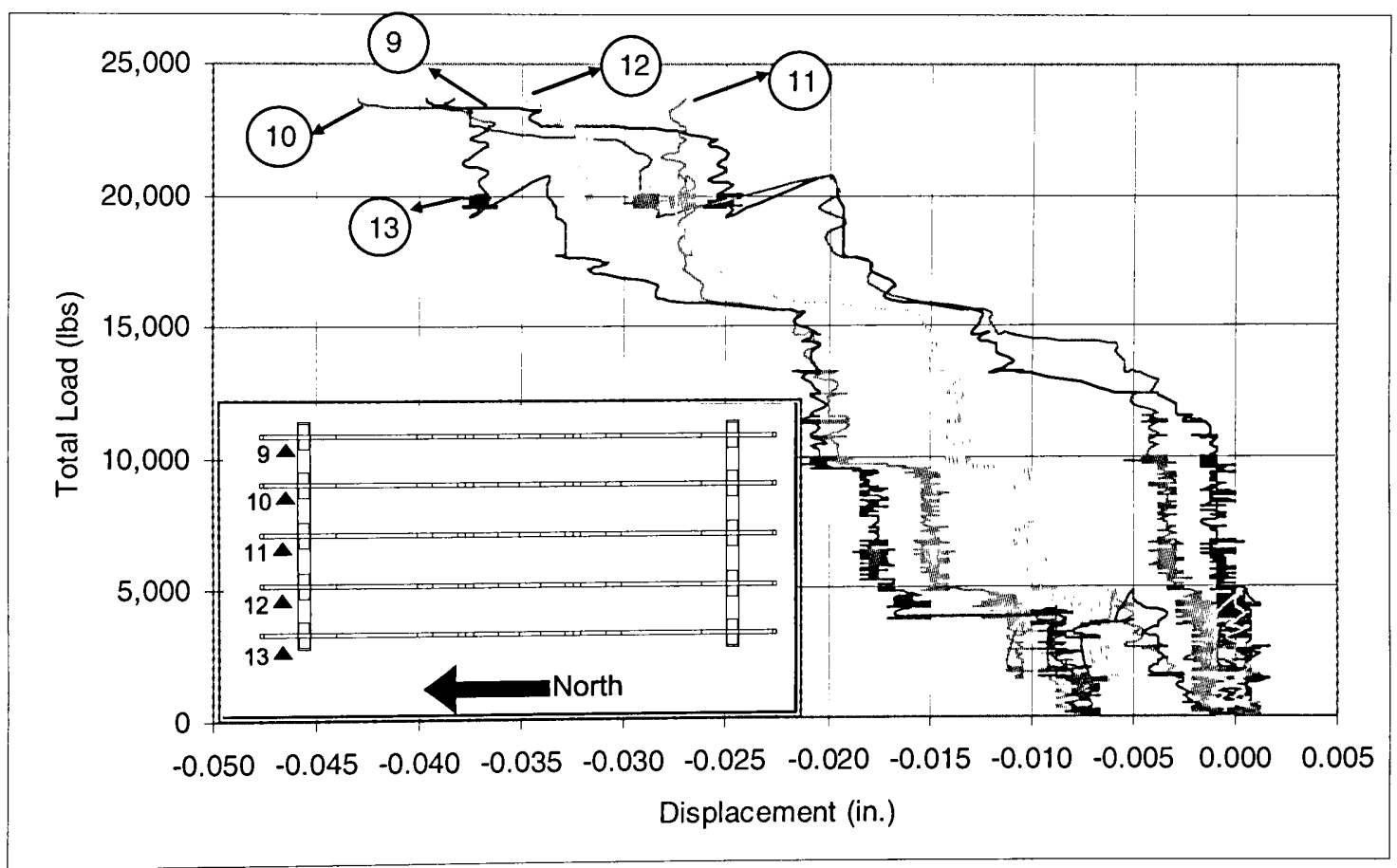

Figure 4.31 - Total load-displacements on the north side of the truss versus total load 


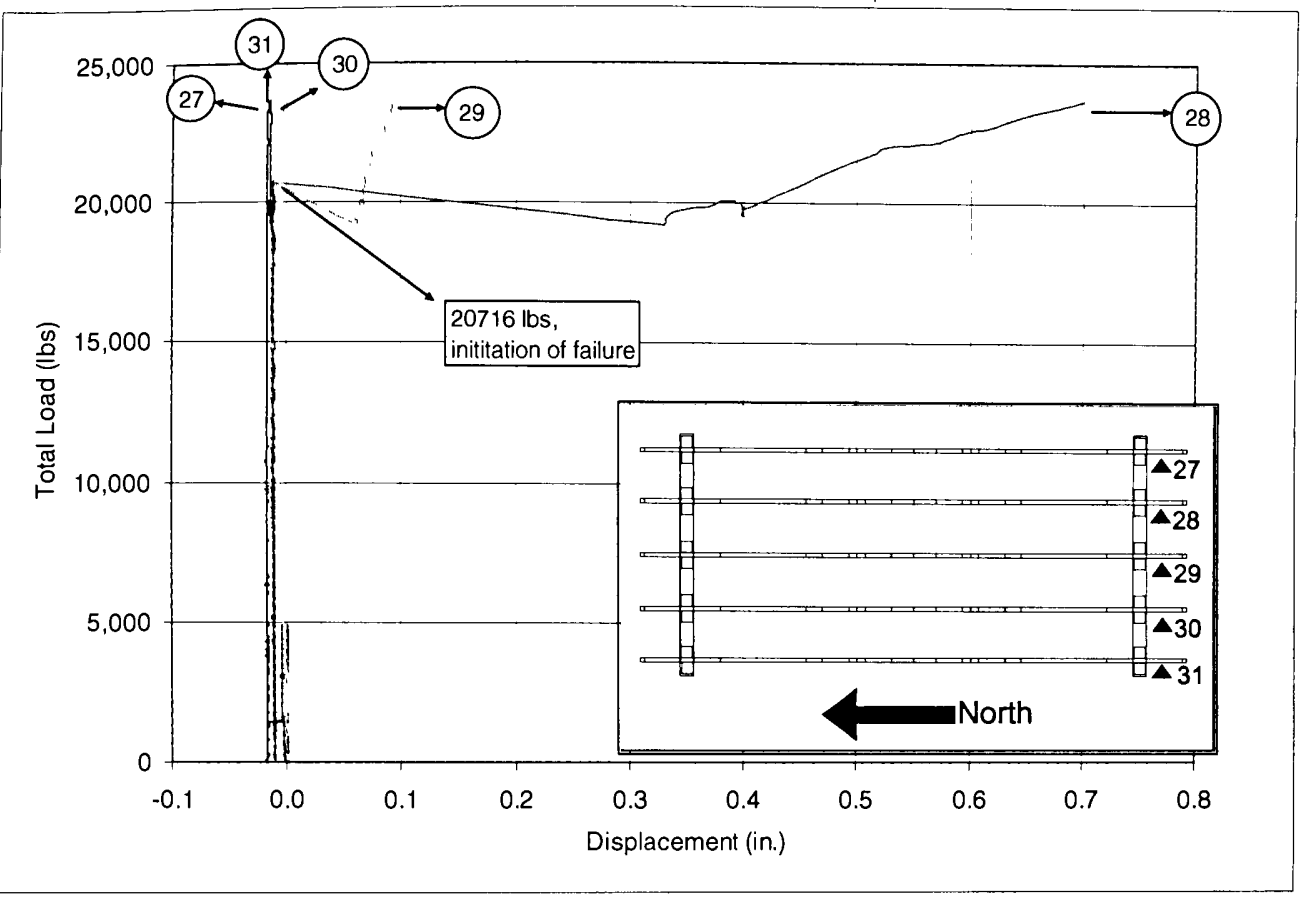

Figure 4.32 - Total load-displacements on the south side of the truss versus total load

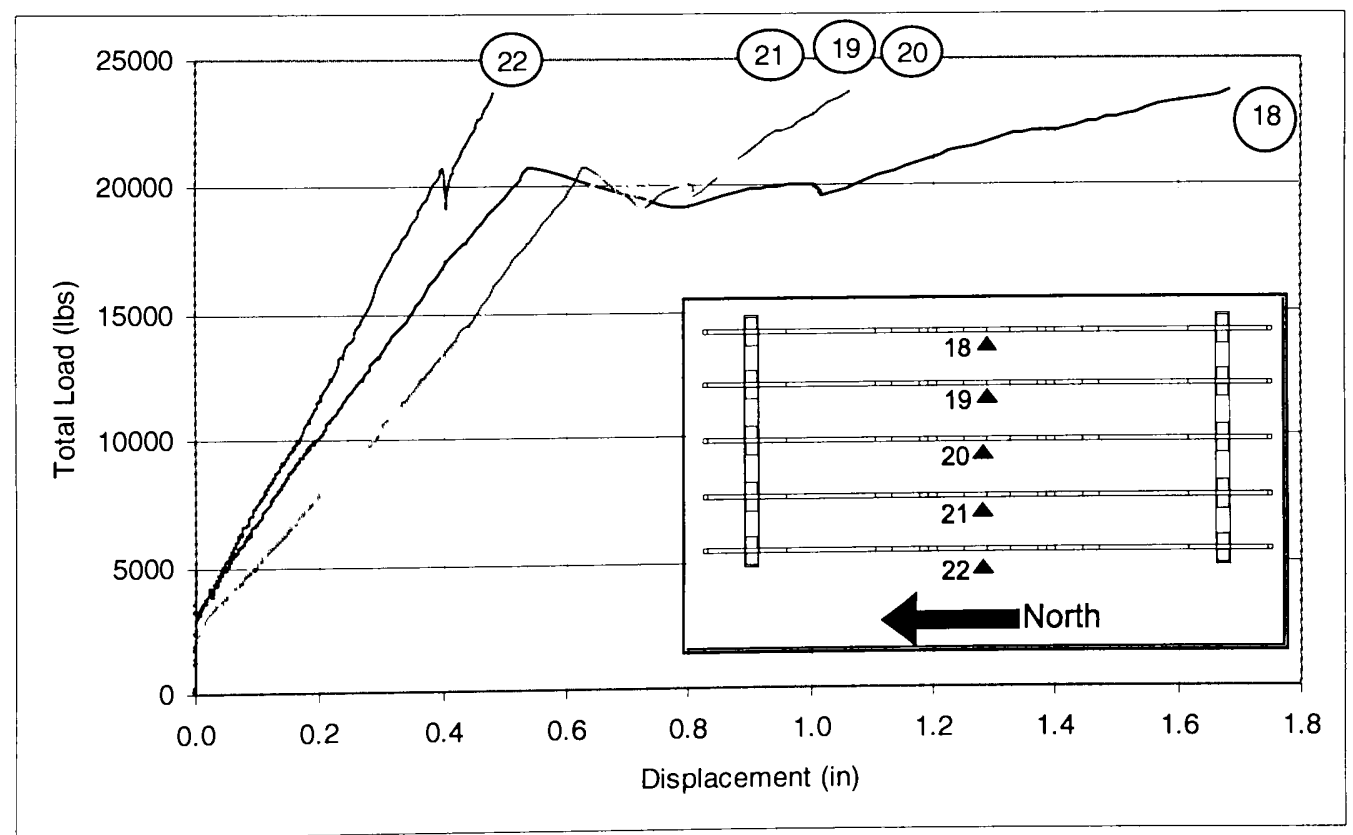

Figure 4.33 - Total load-displacements at the center of the bottom chord of the truss 
In Figures 4.34 through 4.37, strains at pairs of FRP ties at the corners are plotted versus the stress in vertical leg of FRP ties. Here it was assumed that the loads applied from each jack are equally shared between nearest pairs of FRP ties. The figures show that the ultimate stress values in failed ties are very close to bond strengths calculated in component level tests. The strains obtained from the strain gages placed on FRP ties at the corners are plotted versus time and versus total load in Figures 4.38 and 4.39 respectively. A maximum strain of 0.000581 was observed at one of the failed connections. According to the manufacturer's specifications, the GFRP used has an elastic modulus of $3,790 \mathrm{ksi}$, a tensile strength of $87 \mathrm{ksi}$ and a maximum elongation of $0.023 \mathrm{in./in}$. Therefore, the average stress in the vertical leg of the FRP tie on the joist is about $2.2 \mathrm{ksi}$, which is much less than its rupture strength.

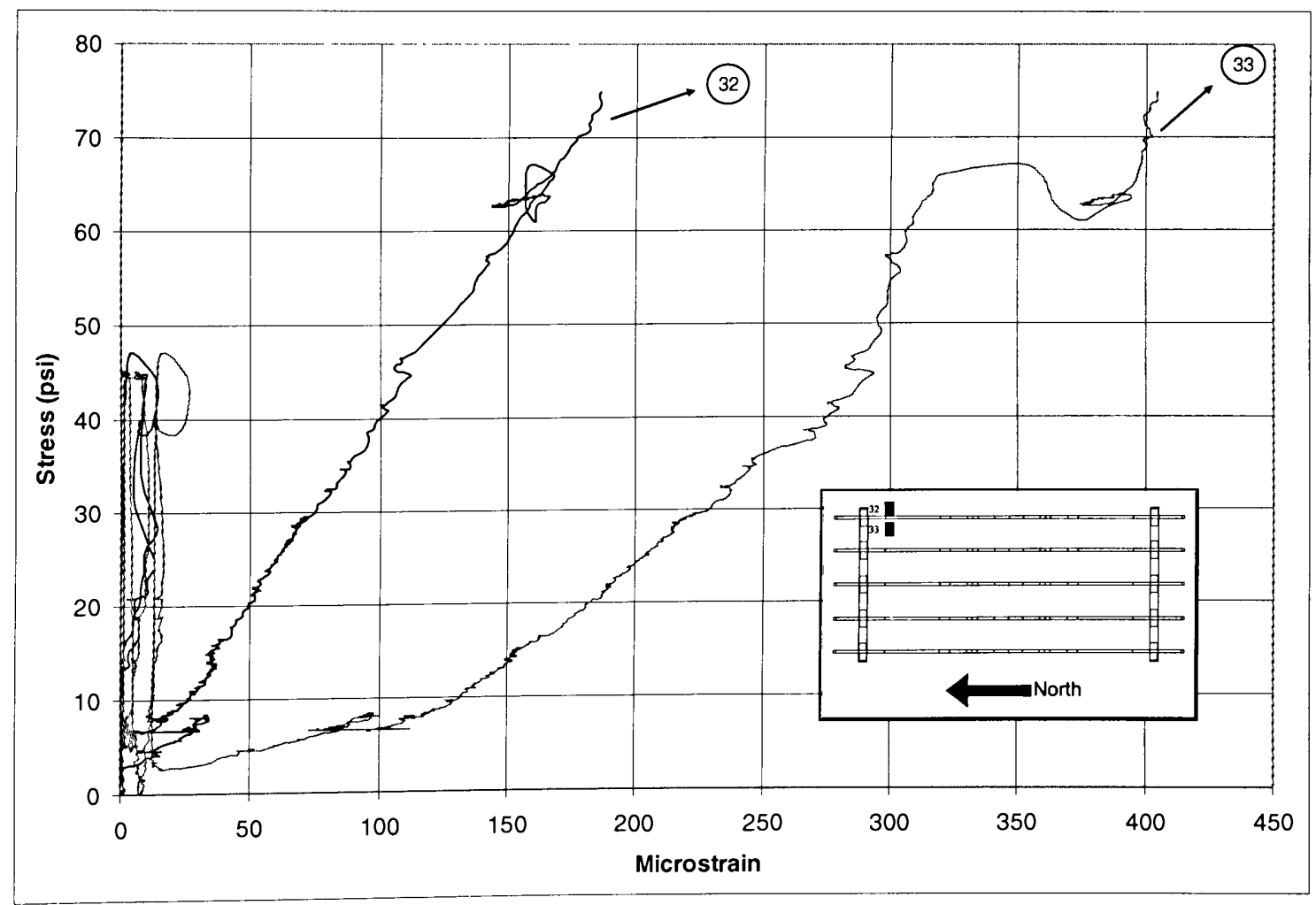

Figure 4.34 - Stress-strain for FRP ties 1 and 2 


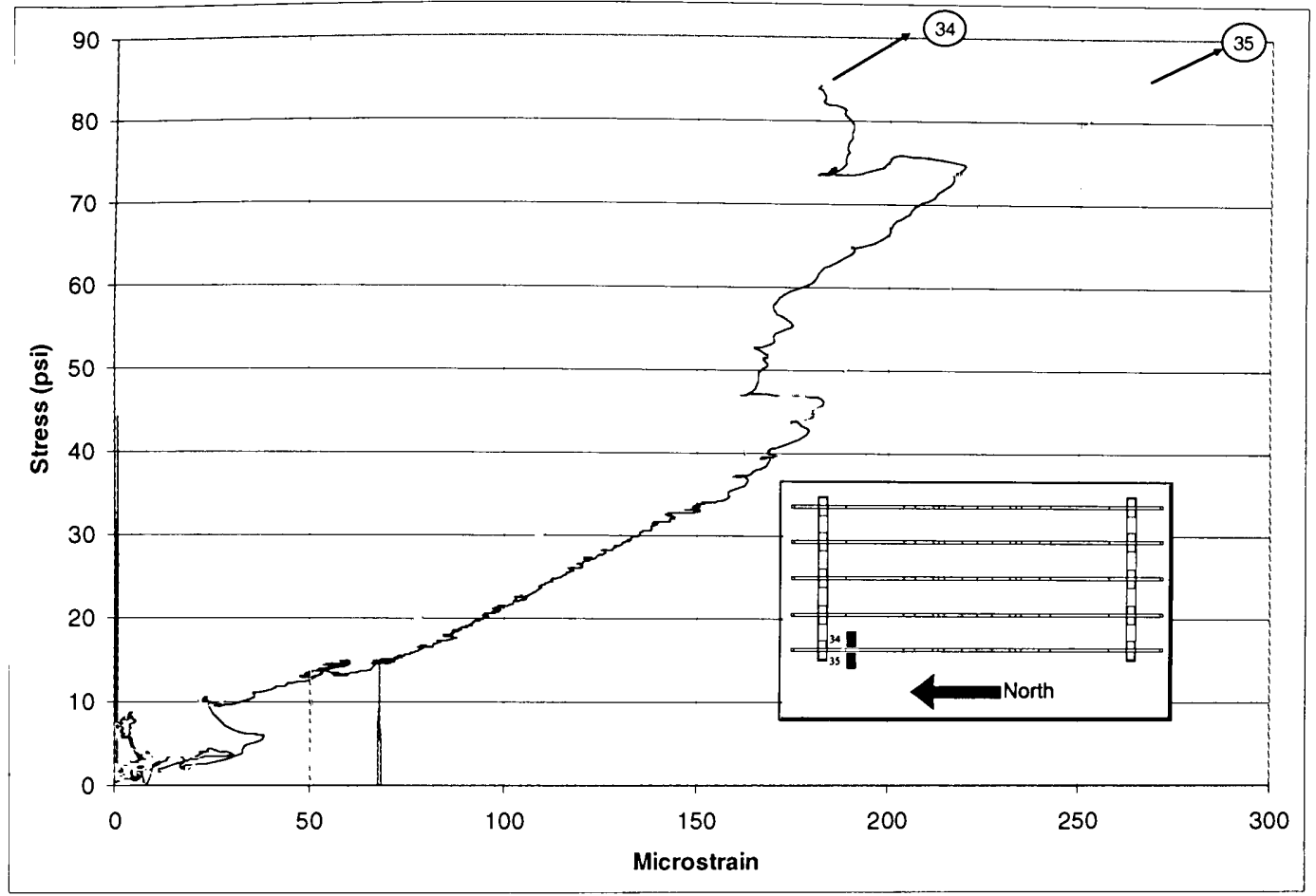

Figure 4.35 - Stress-strain for FRP ties 9 and 10

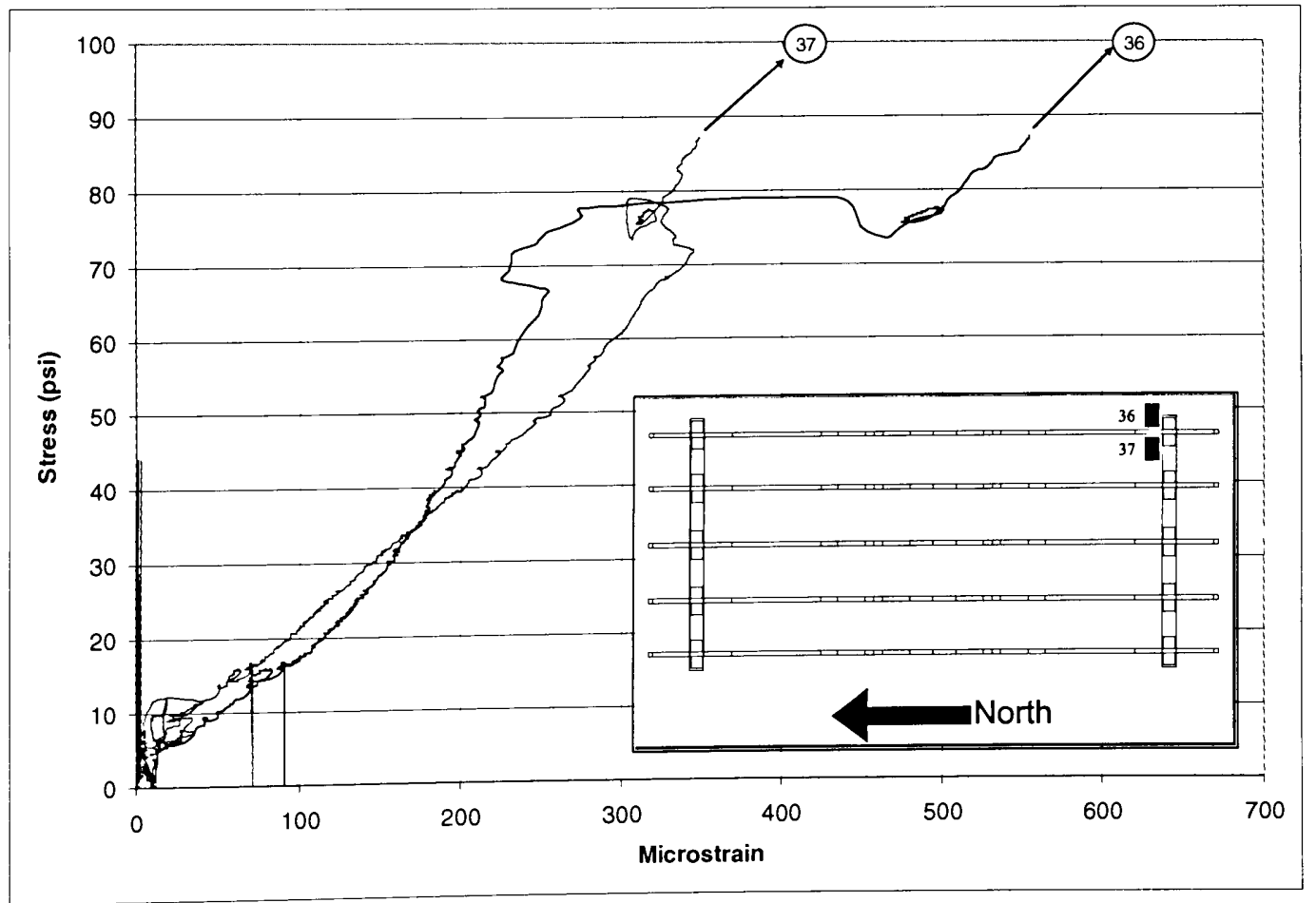

Figure 4.36 - Stress-strain for FRP ties 11 and 12 


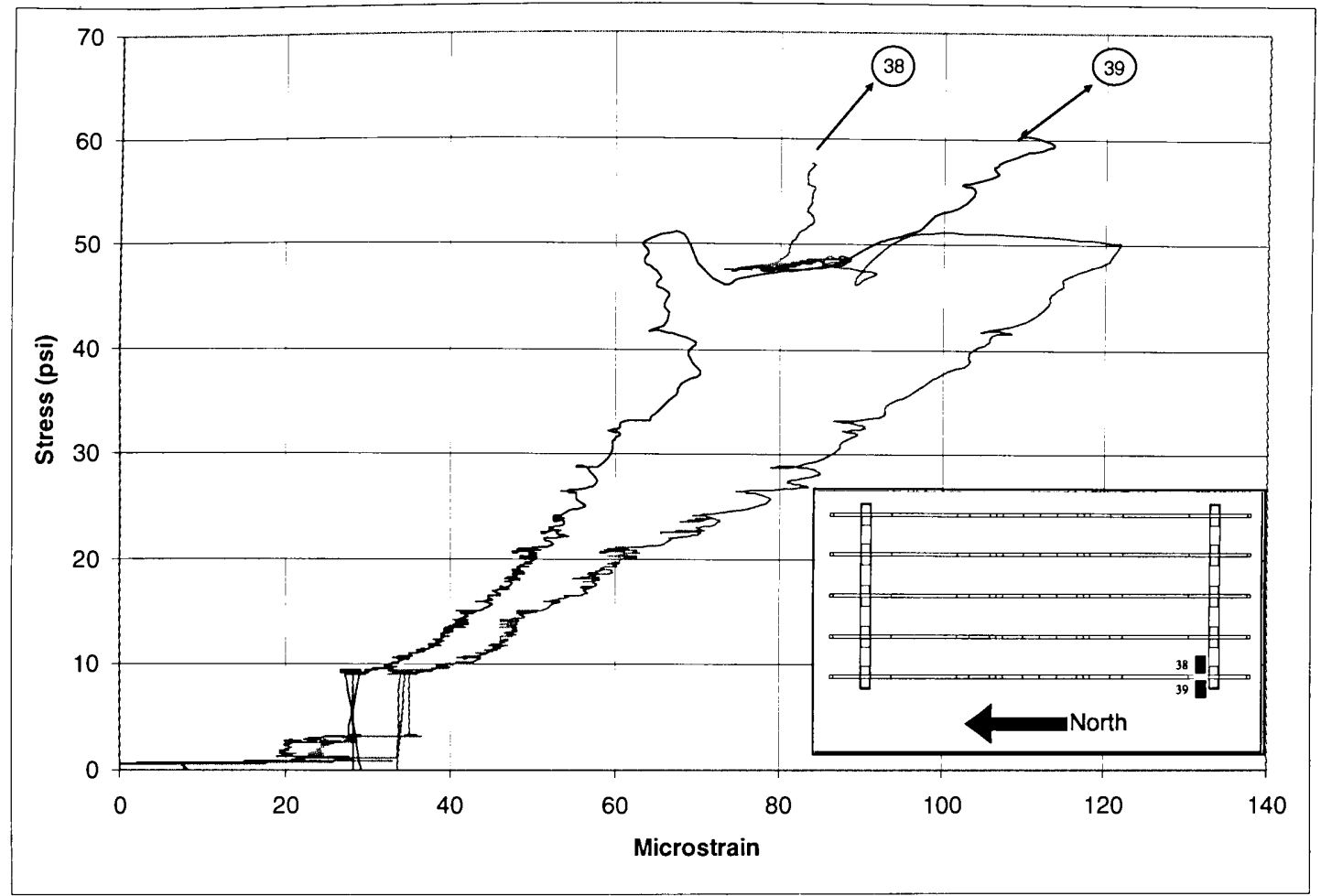

Figure 4.37 - Stress-strain for FRP ties 19 and 20

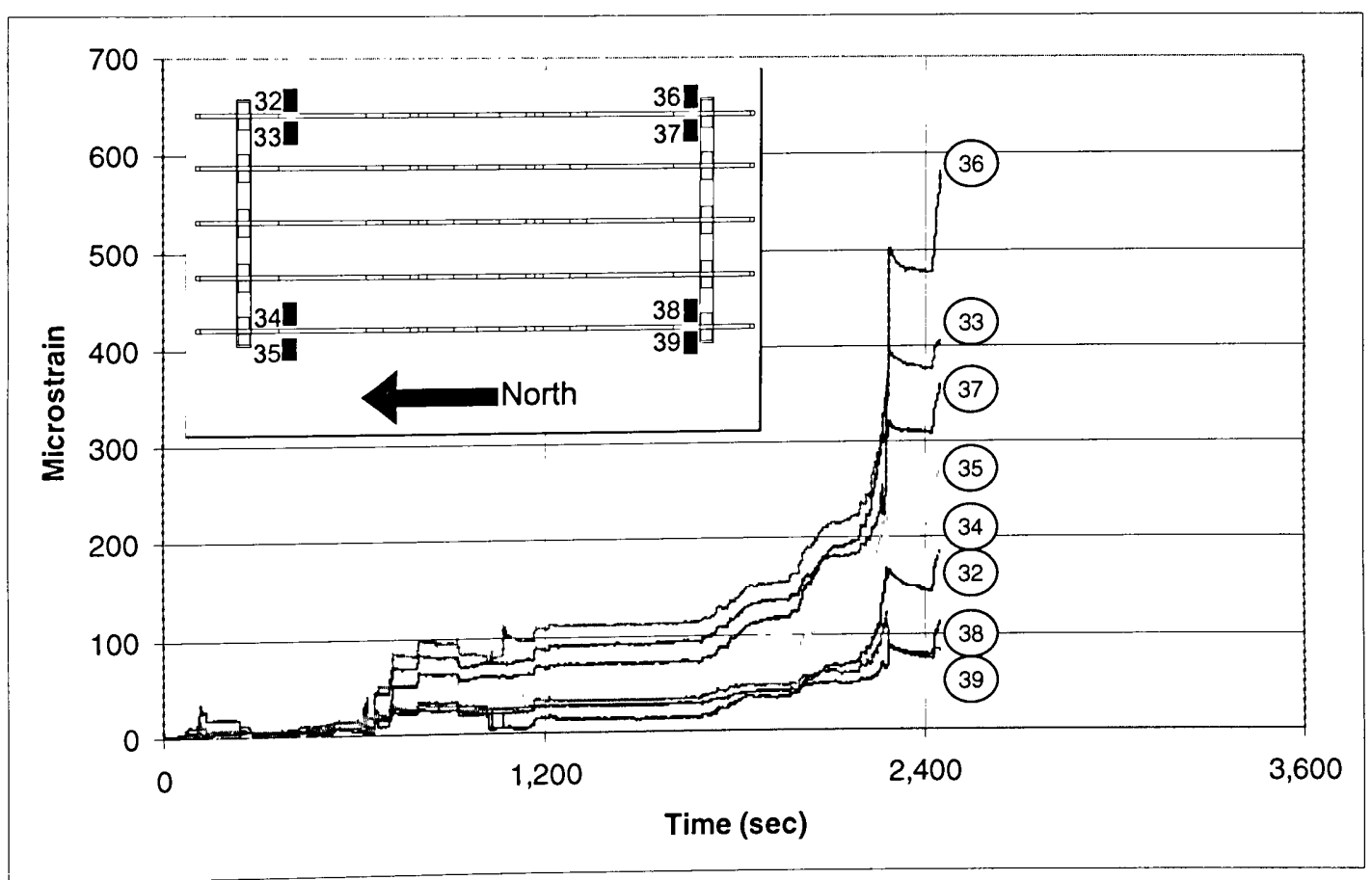

Figure 4.38 - Strain values of FRP ties located at the corners of the truss 


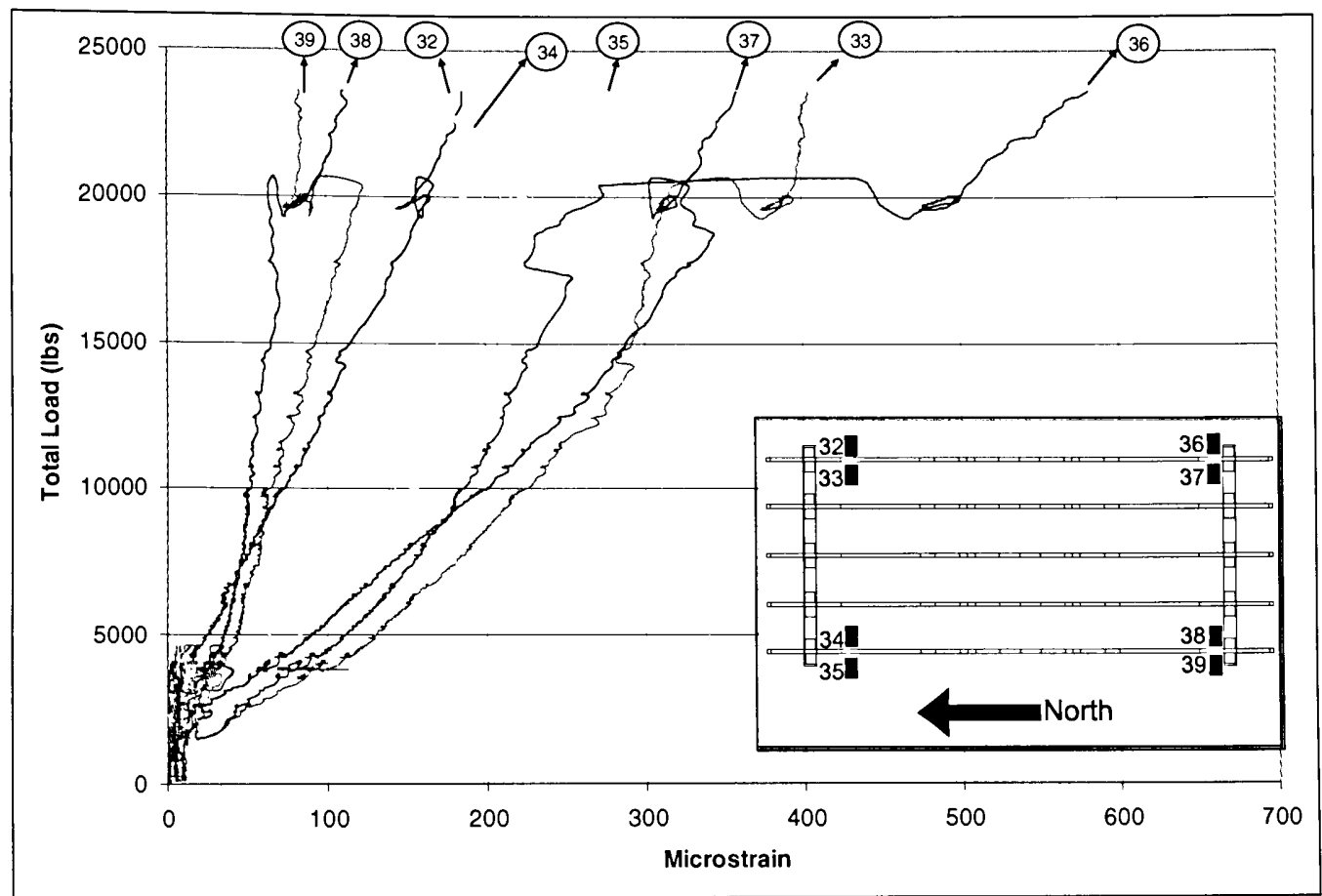

Figure 4.39 - Total load-strain for FRP ties located at the corners

The full-scale test has provided valuable information about the in-situ performance of the developed FRP tie. Since there are ten connection points in total, the ultimate load per connection can be estimated as 2,365 lbs. Considering that the application of load from jacks were not perfectly uniform and the system was able to take further load even after failure of one connection, it can be concluded that the capacity of one tie is greater than this value. This value exceeds the FBC requirement of $700 \mathrm{lbs}$ for High Velocity Hurricane Zones with a factor of safety of 3 as used by most of the hurricane clip manufacturers. Also, by looking at the displacement values at connection points, it can be seen that the FRP tie does not allow the roof system to displace significantly relative to the top plate. Hence, water and wind intrusion into the structure from the connections will be minimized. Overall, the developed FRP tie system can 
provide a cost-effective, efficient and easily applied roof-to-wall connection for both new and existing structures. 


\section{5 - Summary and Conclusions}

\section{1 - Summary}

Hurricanes are the costliest of natural disasters, causing billions of dollars of damage to the US economy. A significant portion of these losses relate to the singlefamily residential structures, most of which are constructed from dimensional lumber as non-engineered dwellings. The major cause of failure in these cases is the discontinuity in the vertical load path from the roof to the foundation, and particularly the weakness in the roof-to-wall connection. The metal connectors have been in place since Hurricane Andrew. However, they have several disadvantages as they weaken the wood due to closely spaced nails; they may deteriorate in harsh environmental conditions; and they also make the structure susceptible to water intrusions through the holes created by wood penetrations. Therefore, a non-intrusive, cost-effective, efficient roof-to-wall connection is developed to overcome the problems inherent with metal connectors.

The new connection was developed using high-performance advanced fiber reinforced polymer (FRP) composites through a detailed progressive component level testing. Initially, a double lap direct shear test was performed to evaluate the strength of FRP-wood interface in shear. Subsequently, three stages of component level FRP tie development tests were conducted. Several FRP tie configurations were tested according to the ASTM D 1761 standard. Out of the many FRP ties, the most feasible one in terms of cost-effectiveness, applicability and efficiency was selected. The new FRP-tie was then implemented in a full-scale specimen to validate and evaluate the in-situ performance of the tie. The full-scale specimen consisted of two $8 \mathrm{ft} .-3 \mathrm{in}$. high, $8 \mathrm{ft}$. long 
shear walls at a spacing of $17 \mathrm{ft}$. The shear walls were supported by five $\mathrm{W}$-type trusses. In order to simulate the uplift forces due to high-winds, a loading system consisting of eight hydraulic jacks connected to a single electric pump was used. The results of the full-scale test were in very good agreement with the component level tests in terms of both capacity and stiffness of the new FRP tie.

\section{2 - Conclusions}

The component level tests showed that the FRP-wood bond strength is directly related to the size of the bonded area However, the relation is not constant, and beyond a threshold value, no more increase is observed in the FRP-wood Mode II bond strength. Also, the component level tests and the full-scale test both suggest that the bond strengths of FRP-wood in Mode I and II are very close to each other.

The new FRP tie is a feasible and cost-effective alternative to the metal roof-towall connectors that are currently in use. The advantages of the new FRP tie can be summarized as follows:

- Since the new FRP tie connection is, it does not damage or weaken any part of the wooden structure. In metal connectors, on the other hand, it is known that nails crush the wood fibers and create weak spots, especially when closely spaced. This phenomenon is more apparent in old construction.

- A preliminary cost analysis based on the manufacturer's data indicates that the new FRP tie is quite comparable to the commercially available metal connectors with similar load capacities. 
- The application of FRP tie to existing structures in need of retrofit is much easier than the installation of metal connectors.

- Metal connectors deform considerably before failure, creating openings that will lead to intrusion of high-wind and water into the building. This may result in serious losses to building contents. Since the FRP tie is very stiff, it can minimize such intrusions that could otherwise damage building contents.

- The lateral load capacity of the FRP tie is better than most of the commercially available metal connectors.

Considering these factors, the new FRP roof-to-wall connection may prove effective in reducing hurricane-related losses. Moreover, the results of this study may facilitate further development of mitigation techniques for extreme wind effects; leading to human safety, and reduction of property loss and insurance costs.

\section{3 - Recommendations for Future Research}

The roof-to-wall connections may be subject to cyclic loading resulting from high-wind events. In order to assess the performance of FRP ties under such loading, a fatigue study must be conducted. Also, since the FRP tie can be subject to harsh environmental conditions in real life, the performance of the connection in wet-dry cycles must be investigated. The response of the FRP tie to lateral loadings must also be studied in more detail to improve present connection for combined loading conditions. 


\section{REFERENCES}

ASTM, "Standard Test Methods for Mechanical Fasteners in Wood," 2006

Davalos, J. F., Qiao, P. Z., and Trimble, B.S., "Fiber-Reinforced Composite and Wood Bonded Interfaces: Part 1. Durability and Shear Strength," Journal of Composites Technology and Research, Vol. 22, No. 4, pp. 224-231, 2000.

Davalos, J. F., Qiao, P. Z., and Trimble, B.S., "Fiber-Reinforced Composite and Wood Bonded Interfaces: Part 2. Fracture," Journal of Composites Technology and Research, Vol. 22, No. 4, pp. 232-240, 2000.

Ellingwood, B. R., Rosowsky, D. V., Li, Y., and Kim J. H., "Fragility Assessment of Light-Frame Wood Construction Subjected to Wind and Earthquake Hazards," Journal of Structural Engineering, Vol. 130, No. 12, pp. 1921-1930, 2004.

FEMA, "Building Performance: Hurricane Andrew in Florida," 1992.

Jia, J., and Davalos, J.F., "Study of Load Ratio for Mode-I Fatigue Fracture of Wood-FRP-bonded Interfaces," Journal of Composite Materials, Vol. 38, No. 14, pp. 1211-1230, 2004.

Li, Y., and Ellingwood, B. R., "Hurricane Damage to Residential Construction in the US: Importance of Uncertainty Modeling in Risk Assessment," Engineering Structures, Vol. 28, pp. 1009-1018, 2006.

van de Lindt, J. W., Graettinger, A., Gupta, R., Skaggs T., Pryor, S., and Fridley, K. J., "Performance of Wood-Frame Structures during Hurricane Katrina," Journal of Performance of Constructed Facilities, Vol. 21, No. 2, pp. 108-116, 2007.

Lyons, J. S., and Ahmed, M. R., "Factors Affecting the Bond Between Polymer Composites and Wood," Journal of reinforced Plastics and Composites, Vol. 24, No. 4, pp. 405-412, 2005.

Manning, B. R., and Nichols, G. G., "Hugo lessons learned." Proceedings, Hurricane Hugo One Year Later, Benjamin A. Sill and Peter R. Sparks, eds., American Society of Civil Engineers, New York, 1991.

Pielke Jr., R.A., Gratz; J., Landsea C. W.; Collins, D., Saunders, M. A., and Musulin, R., "Normalized Hurricane Damage in the United States: 1990-2005," Natural Hazards Review, Vol. 9, No. 1, pp. 29-42, 2008.

Plevris, N., and Triantafillou, T. C., "Creep Behavior of FRP-Reinforced Wood Members," Journal of Structural Engineering, Vol. 121, No. 2, pp. 174-186, 1995. 
Reed, T. D., Rosowsky, D. W., and Schiff, S. D., "Uplift Capacity of Light-Frame Rafter to Top Plate Connections," Journal of Architectural Engineering, Vol. 23, No. 4, pp. 156-163, 1997.

Riley, M. A., and Sadek, F., "Experimental Testing of Roof-to-Wall Connections in Wood Frame Houses," NISTIR 6938, Building and Fire Research Laboratory, National Institute of Standards and Testing (NIST), Gaithersburg, MD, 2003.

Sparks, P. R., Schiff, S. D., and Reinhold, T. A., "Wind damage to envelops of houses and consequent insurance losses", Journal of Wind Engineering and Industrial Aerodynamics, Vol. 53, pp. 145-155, 1994.

Stubbs, N., and Perry, D. C. "A damage simulation model for buildings and contents in a hurricane environment." Building an International Community of Structural Engineers, Proc., Structures Congress, S. K. Ghosh and J. Mohammadi, eds., ASCE, New York, Vol. II, pp. 989-996, 1996.

Tascioglu, C., Goodell, B., and Lopez-Anido, R., "Bond Durability Characterization of Preservative Treated Wood and E-glass/phenolic Composite Interfaces," Composites Science and Technology, Vol. 63, pp. 978-991, 2003.

Triantafillou, T. C., "Shear Reinforcement of Wood Using FRP Materials," Journal of Materials in Civil Engineering, Vol. 9, No. 2, pp 65-69, 1997

Yancey, C. W., Cheok, G. S., Sadek, F., and Mohraz, B., "A Summary of the Structural Performance of Single Family, Wood-Frame Housing," NISTIR 6224, Building and Fire Research Laboratory, National Institute of Standards and Testing Gaithersburg, MD, 1998. 